Portland State University

PDXScholar

Spring 5-19-2015

\title{
Effects of Selective Logging and Roads on Instream Fine Sediments and Macroinvertebrate Assemblages in the Clackamas Basin, Oregon
}

Paula Elizabeth Hood

Portland State University

Follow this and additional works at: https://pdxscholar.library.pdx.edu/open_access_etds

Part of the Environmental Sciences Commons, and the Forest Management Commons Let us know how access to this document benefits you.

Recommended Citation

Hood, Paula Elizabeth, "Effects of Selective Logging and Roads on Instream Fine Sediments and Macroinvertebrate Assemblages in the Clackamas Basin, Oregon" (2015). Dissertations and Theses.

Paper 2407.

https://doi.org/10.15760/etd.2404

This Thesis is brought to you for free and open access. It has been accepted for inclusion in Dissertations and Theses by an authorized administrator of PDXScholar. For more information, please contact pdxscholar@pdx.edu. 
Effects of Selective Logging and Roads on Instream Fine Sediments and Macroinvertebrate Assemblages in the Clackamas Basin, Oregon

by

Paula Elizabeth Hood

A thesis submitted in partial fulfillment of the requirements for the degree of

\author{
Master of Science \\ in \\ Environmental Science and Management
}

Thesis Committee:

Yangdong Pan, Chair

Eugene Foster

Joseph Maser

Portland State University

2015 


\section{Abstract}

Logging and associated skid trails, haul routes, and roads can have significant impacts on the magnitude and timing of sediments in streams in forested watersheds. Loss of vegetation, soil compaction, use of heavy logging equipment, and alteration of natural hydrologic patterns within the watershed can increase landslide rates, create erosion, and generate fine sediments. Selective logging, also called thinning, is a logging practice that leaves some trees within sale units unharvested. The ecological impacts of thinning on stream ecosystems are not fully understood and need further study. My hypothesis was that macroinvertebrate assemblages would be different in streams in nonreference areas that contain recent selective logging compared to streams in reference areas, and in downstream vs. upstream of selective logging units. I also hypothesized that selective logging and high road densities would be associated with increased instream fine sediments. I sampled water quality parameters and macroinvertebrates in three managed and three reference streams in the Clackamas River Basin during the field season of 2013. Turbidity, temperature, dissolved oxygen, conductivity, total dissolved solids (TDS), suspended sediment concentrations (SSC), and flow were sampled at each stream on four occasions during spring through early fall. Macroinvertebrates were sampled once in late summer or early fall. EPA rapid habitat assessments, canopy cover, pebble counts, embeddedness, and slope were also determined. Water quality parameters and macroinvertebrate indices in reference and non-reference sites were compared using t-tests, Welch's tests, or rank based equivalents. Macroinvertebrate assemblage patterns 
and associated environmental variables were characterized using non-metric multidimensional scaling (NMDS) ordination plots and envfit overlays. Macroinvertebrates had higher abundance and taxa richness in non-reference streams, and indices suggested poorer water quality in non-reference streams. Non-reference streams had a lower percentage of shredders and a higher portion of gatherer-collectors. Associations between land use, fine sediments, and changes in macroinvertebrate metrics and community assemblages were apparent at the reference vs. non-reference scale. It is likely that macroinvertebrates are responding, at least in part, to past logging and high road densities in non-reference streams. Fewer indications were found that recent logging may be affecting water quality and macroinvertebrates. Pearson's correlation coefficients show that the percent of recent logging upstream of study sites was correlated with several measures of fine sediments, suggesting that recent land use may be affecting sediment levels at the subwatershed scale. Stream temperatures increased from upstream to downstream in non-reference sites. Though no continual stream temperature data were collected in this study, the history of continuing temperature standard exceedances in the area suggest that further investigation of how selective logging may be affecting stream temperature and other water quality parameters in the Clackamas Basin is warranted. No other differences in water quality parameters were found from upstream to downstream, possibly because water quality was sufficiently protected, or because signals from land use impacts may be obscured by a several factors, including upstream confounding factors such as roads and past logging, and natural variability. 


\section{Dedication}

This thesis research is dedicated to my daughter, Wren Velasco-Overson, who is my truest inspiration to do the best that I possibly can in all things. Wren has been continually good humored about sharing her childhood with my endless academic work. In addition, she kept complaints to a minimum when getting stuck carrying other peoples' gear many miles in the woods on more than one occasion. 


\section{Acknowledgements}

I would like to extend my sincere and lasting gratitude to my graduate advisor, Dr. Yangdong Pan, who has always been generous with his insights, wisdom, and patience. I benefited greatly from his scientific expertise and thoughtful approach to teaching, and from his faith in the learning process. I would also like to thank my committee members, Dr. Eugene Foster and Dr. Joseph Maser, for their help and support. I am lucky to have had such talented and gracious guides help me through my graduate school journey.

My family provided unending patience and help of all kinds throughout my graduate studies. I could not have done this work without the support of my mother, Carolina Hood, and my sweetheart, David Kennedy.

Many people volunteered their time and support to help with my thesis research. I am humbled by the selflessness of the many people who dedicated countless hours to this project. Special thanks to Amy Balint, David Kennedy, Michael Krochta, and Monica Mogileswky, who all went far above the call of volunteer duty and spent days and even weeks doing field work in often cold and wet conditions. I owe a special debt of gratitude to Monica for having more motivation at times than I did for hiking many miles day after day in the pouring rain, and for maintaining a more positive attitude than any of us. You are perhaps the toughest trooper of all. Erin Poor and Naomi Lowinger did a lion's share of laboratory work, and provided many hours of great conversation during endless debris sorting. Other wonderful volunteers that I wish to thank include: Autumn Rainha, 
Brendan Phoenix, Danielle Fagan, David Roth, Jess Dalesky, Jim Destabler, Jonathan Hartigan, Gambit McKay, Karen Coulter, Kecia Jones, Lola Goldberg, Maksim Zemtsov, Matthew Przyborski, Maysa Miller, Michael DuCharme, Michael Miller, Michael Newman, Nathan Weick, Rick Park, Stephanie Moe, and Thomas DeAlameda. I apologize if I have inadvertently left anyone off of this list. It was my sincere honor to spend many hours investigating forested streams and the macroinvertebrates that live there with all of you. 


\section{Table of Contents}

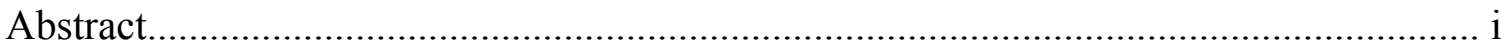

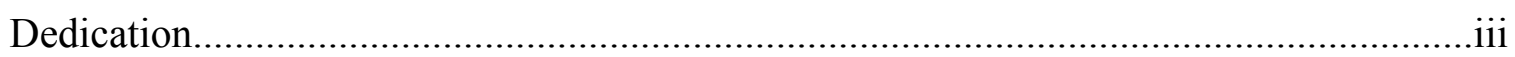

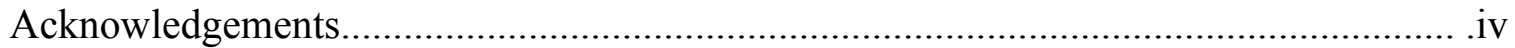

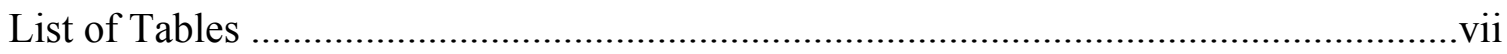

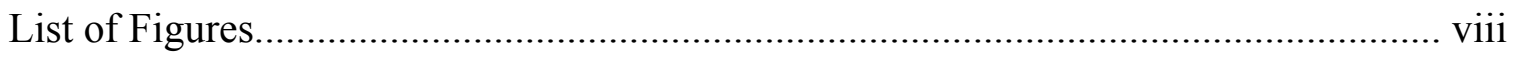

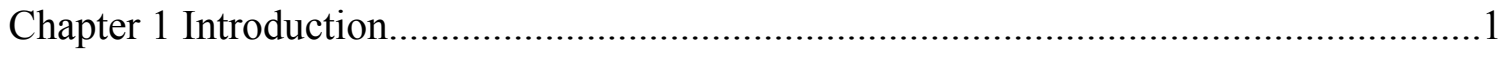

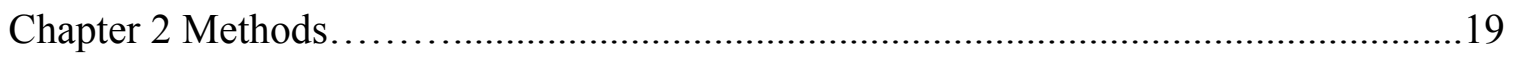

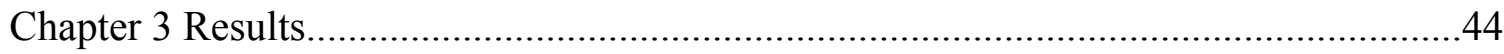

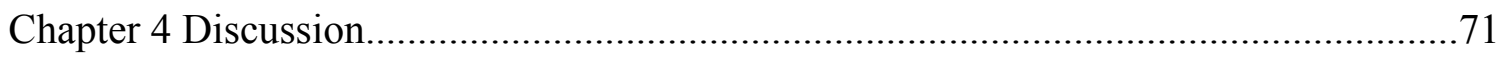

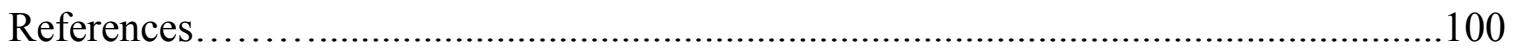


List of Tables

Table 1: Family Biotic Index score water quality ranking...........................41

Table 2: Summary of significance tests for water quality and environmental variables...45

Table 3: Summary of all water quality and environmental parameters.................48

Table 4: Mean, median, and range of values for selected variables...................51

Table 5: Selected macroinvertebrate metrics in non-reference and reference streams.....56

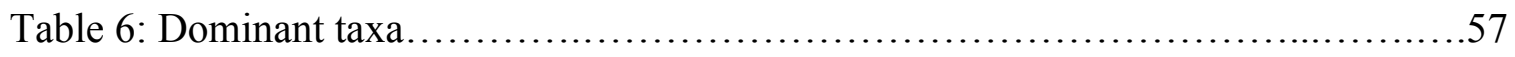

Table 7: NMDS 1 and NMDS 2 scores for significant macroinvertebrates..............62

Table 8: NMDS 1 and NMDS 2 scores for significant environmental variables.........69 


\section{List of Figures}

Figure 1: Conceptual model of sediment generation and transport....................4

Figure 2: General area, land use, and ownership of the Clackamas Basin, Oregon.......20

Figure 3: General location of sample sites .......................................

Figure 4: Generalized depiction of upstream/downstream study design .................33

Figure 5: Boxplots of average turbidity in all streams........................... 45

Figure 6: Boxplots of turbidity, total dissolved solids, temperature $\ldots \ldots \ldots \ldots \ldots \ldots \ldots . \ldots 46$

Figure 7: Boxplots of embeddedness, pebble counts, canopy cover, and EPA scores.....47

Figure 8: Boxplots of selected macroinvertebrate metrics........................55

Figure 9: Boxplots of macroinvertebrate functional feeding groups..................59

Figure 10: Dominant taxa on the NMDS ordination plot..........................61

Figure 11: Bubble plots of dominant taxa....................................63

Figure 12: Bubble plots showing abundance and richness........................64

Figure 13: Bubble plots showing gatherer-collectors and shredders.................64

Figure 14: Envfit of significant environmental variables on the NMDS plot..............66

Figure 15: Envfit of all environmental variables on the NMDS plot...................67

Figure 16: Pearson's correlation coefficients for selected variables..................70

Figure 17: Roads and past logging in the Fish Creek Divide circa1994.................91 


\section{Chapter 1: Introduction}

\section{Logging, roads, and fine sediment delivery:}

Timber harvest and associated skid trails, haul routes, and roads can have significant impacts on the magnitude and timing of sediment loading into streams in forested watersheds (Croke and Hairsine 2006, Lewis et al. 2001, Wood and Armitage 1997). Loss of vegetation, soil compaction, and alteration of natural hydrologic patterns within the watershed can create erosion, increase landslide rates, and generate fine sediments, some of which may ultimately be delivered into stream channels (Guthrie 2001, Harr and Coffin 1992, Hicks et al. 1991, Jones 2000, Jones and Grant 1996, Lewis et al. 2001, Montgomery et al. 2000, Wemple et al. 2000). For example, Montgomery et al. (2000) found that shallow landslide rates (i.e., landslides within the weathered bedrock portion of surface) increased in logged areas in the Oregon Coast Range by three to nine times that of background conditions. In the Fish Creek Watershed located in the Clackamas basin, Oregon, the Forest Service's Watershed Analysis found that landslide rates associated with roads and/or harvest areas were three times more common in survey areas over a 43 year study period compared to background levels (USFS 1994). Wemple et al. (2000) found that road-related erosion and landslide features generated 13,000 cubic meters of sediment in two small forested watersheds in the western Oregon Cascades along 230 kilometers of road during one 100-year storm event. Lewis et al. (2001) found that sediment loads increased over $100 \%$ in small tributaries after logging. Alteration of natural sediment regimes leading to sediment related imbalances are a major cause of 
stream impairment listings, affecting approximately $40 \%$ of US river miles (Nietch et al. 2005, USEPA 2006).

The regulation of instream sediment pollution continues to be controversial. For example, in 2010, the $9^{\text {th }}$ Circuit Court of Appeals ruled that sediment inputs from roads could be considered a point source of pollution (Northwest Environmental Defense Center v. Brown, 2010). This ruling was overturned in 2013 (Decker v. Northwest Environmental Defense Center, 568 U.S., 2013), and sediment inputs from roads and timber practices were again considered to be non-point pollution. Stream sediment pollution in relation to forestry practices is controlled through best management practices, a set of mitigation guidelines designed to support compliance with the Clean Water Act through lessening erosion, soil compaction, and other potential sediment sources related to logging and roads (USFS 2012). Environmental laws such as the Clean Water Act and the Endangered Species Act mandate management of water bodies in order to protect beneficial uses, water quality standards, and critical habitats. However, due to the natural variation of instream sediment loading, as well as the complexities and expense associated with estimating or quantifying stream sediments, clear guidelines for determining reference or recommended sediment levels have not been established (USEPA 2006). In addition, without sufficient baseline data, determining guidelines and criteria for sediment levels, or performing effective and meaningful monitoring in relation to current land management activities, is difficult at best. Currently, there is a lack of unified sediment criteria across states, with many states having vague, qualitative, or non-existent guidelines for sediment loading. Unfortunately, there is little scientific or 
agency consensus on what constitutes background sediment levels or what guidelines are needed to protect biota in differing aquatic environments (USEPA 2006).

While it is difficult to quantify natural background sediment levels in streams, studies suggest that logging and associated roads alter watershed hydrology and sediment levels in comparison to non-disturbance conditions or controls. For example, changes in historic watershed hydrologic regimes and processes due to logging and associated roads can alter the timing and magnitude of stormwater runoff into streams, which in turn may affect sediment delivery regimes (Croke and Hairsine 2006, Wemple et al. 2000). Excess fine sediments generated by road related erosion or harvest related soil compaction may be carried farther across the landscape because of decreases in water infiltration or runoff rates over damaged soils, which in turn can cause an increase in the distance of overland flow transporting the sediments (Figure 1). Thus, the sediments generated by management activity may be more likely to reach streams (Croke and Hairsine 2006, Nietch et al. 2005, Wemple et al. 2000). Areas of greatest soil compaction are skid trails and $\log$ haul routes, which are often responsible for the largest increases in overland flows and peak flows (Nietch et al. 2005, Jones and Grant 1996). In addition, improper road drainage can cause gullies, landslides, and other erosional features, which in turn lead to sediment generation, increased runoff, and more direct and rapid transport of runoff and sediment to streams (Croke and Hairsine 2006, Wemple et al. 2000). Furthermore, the distance of travel required for sediments to enter streams may be shortened by the artificial extension of stream networks by roads and culverts (Croke and Hairsine 2006, Wemple et al. 1996). Increases in the efficiency of delivery of water and 
sediment to streams due to road networks and changes to soil infiltration and groundwater inputs can affect the timing, magnitude, duration, and frequency of sediment inputs.

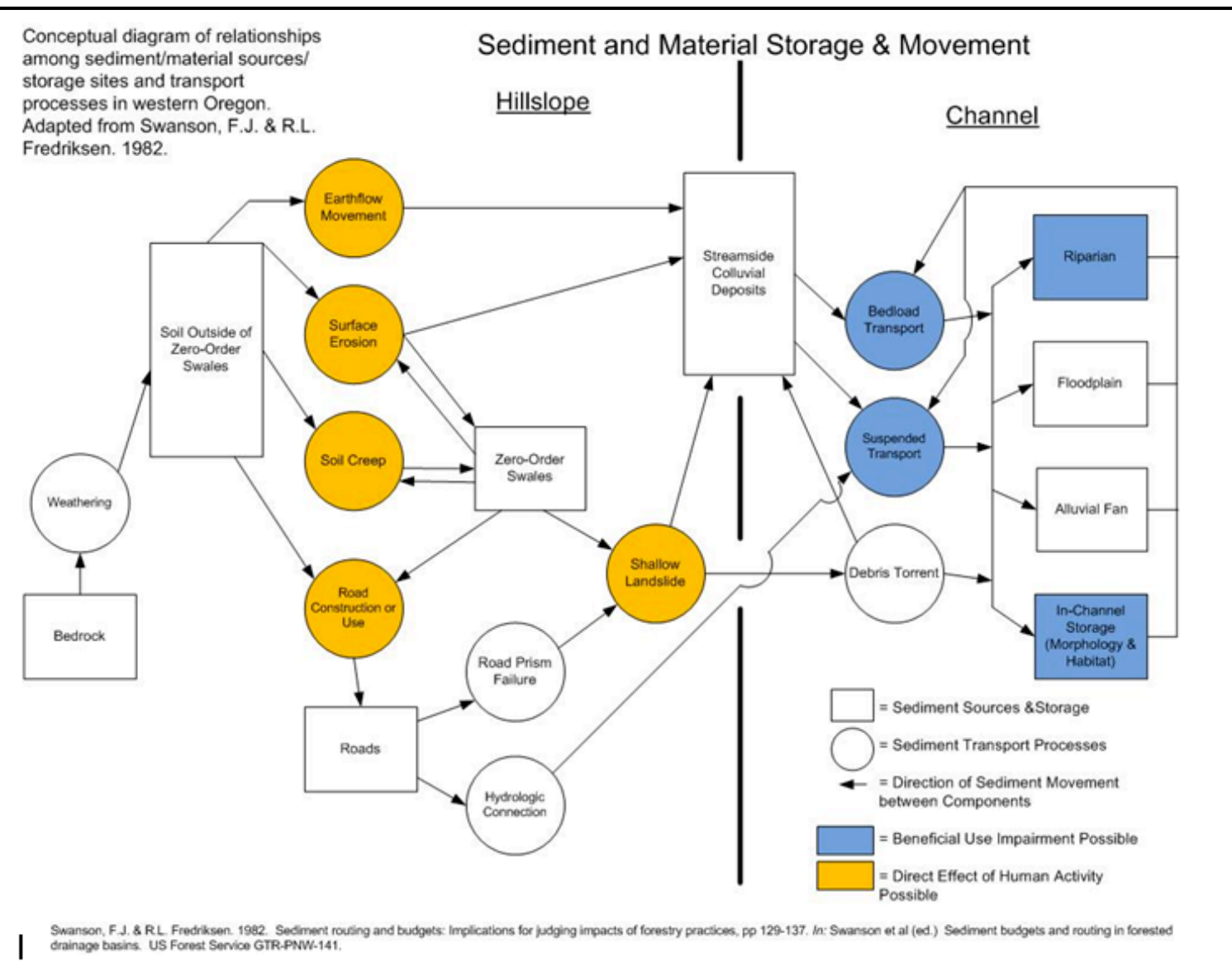

Figure 1: Conceptual model of sediment generation and transport, adapted from Fredrisksen (1982).

In addition to altering overland flow and sediment creation and transport processes, harvest management activities can alter base and peak flows regimes and hydrograph shape (Harr and Coffin 1992, Jones and Grant 1996, Jones 2000, Lewis et al. 2001, Wemple et al. 1996). Altered flow regimes can potentially affect instream sediment 
dynamics by causing sediments to scour out or embed stream substrates (Croke and Hairsine 2006, Lewis et al. 2001, Moore and Wondzell 2005, USEPA 2006). Harr and Coffin (1992) found that both clear-cutting and thinning increased the amount of snow pack, rates of snowmelt, leading to increases in both magnitude and timing of peak flows. Lewis et al. (2001) found that clearcutting increased storm runoff by approximately $58 \%$, and partial cutting of 30 to $50 \%$ increased runoff by approximately $23 \%$ in the Caspar Creek Experimental Forest in the northern California coastal range. In addition, roads increase peak flows by intercepting surface and subsurface flow, and diverting it into culverts and ditches that drain into streams (Wemple et al. 1996). Instream sediment dynamics such as timing and placement of fine sediment deposition, embeddedness, and scour are affected by stream power and flow regimes (Moore and Wondzell 2005, Wood and Armitage 1997). Sediment imbalances can include sediment starvation, streambed scour, and embeddedness. Embeddedness refers to the degree to which coarser stream substrates are covered or surrounded by fine sediments (USEPA 2006). Changes in watershed hydrology after logging were found to be significant causes of increased stream sediment loading (Troendle and Olsen 1993, Lewis et al. 2001). Alteration of peak flows may increase flooding and also cause damage to culverts and bridges (Moore \& Wondzell 2005), further increasing erosion and fine sediment inputs.

\section{Logging and instream habitats and fauna:}

Fish, amphibians, and macroinvertebrate communities may be negatively impacted by excess fine sediment inputs resulting from logging and roads (Bryce et al. 2010, Nietch et al. 2005). Increases in fine sediment loading can cause simplification of 
complex habitats and channel structure either through settling on or scouring out the streambed (Cover et al. 2008, Nietch et al. 2005). As a result, habitats such as pools, riffles, and side channels required by stream organisms for egg laying, resting, hiding, and rearing of young may be degraded or eliminated (Bryce et al. 2010, USEPA 2006). In addition, excess fine sediment loading, particularly in combination with the alteration of flow regimes and hydrologic processes, may negatively impact stream channel stability, limit hyporheic exchange, and alter groundwater inputs, potentially degrading conditions for stream organisms by further increasing sediment loading, decreasing necessary physical habitat, and altering stream water volume which can affect temperature and dissolved oxygen, and limit resources (Croke and Hairsine 2006, Moore and Wondzell 2005, Nietch et al. 2005, USEPA 2006). Fine sediment inputs exceeding natural background levels may bury and smother fish and amphibian eggs or young, decrease dissolved oxygen (DO) levels, interfere with behaviors such as mating, feeding and predator avoidance, cause shifts in macroinvertebrate community structures, and increase macroinvertebrate drift rates (Bryce et al. 2010, Nietch et al. 2005, USEPA 2006). For example, Coho salmon egg survival and fry emergence were negatively correlated with embedded fines of greater than $10 \%$. In addition, when fines exceeded $20 \%$, average survival decreases dramatically (Cederholm 1980). Macroinvertebrate drift rates increased significantly when exposed to suspended sediment concentrations of $8 \mathrm{mg} / \mathrm{L}$ for 5 hours, though ephemeroptera and plecoptera drift more rapidly upon exposure to sediments compared to those not exposed to sediments. Some ephemeroptera species, when exposed to concentrations of suspended sediments greater than $29 \mathrm{mg} / \mathrm{L}$ for 30 days, 
will disappear entirely. Longer exposure durations and smaller particle sizes caused increased rates of drift (IDEQ 2003).

\section{Quantifying sediment loading in small watersheds: methods and limitations}

Long term sediment loading and hydrograph information for small forested watersheds are often lacking, creating difficulties in determining historic, as well as current, sediment levels (USEPA 2006, USGS accessed 2012). In addition, gaps remain in our understanding of the sediment delivery processes from disturbed sites to streams. Consequently, the effects associated with timber harvest on stream sediment loading are difficult to quantify or predict (Croke and Hairsine 2006). Few lower order streams are gaged or monitored in the long term, resulting in a scarcity of statistically meaningful streamflow, hydrograph, or biological data for small watersheds (Tague and Grant 2004, USEPA 2007). Detailed or continuous measurement of streamflow and sediment loading without established gages is difficult and costly, limiting the ability of scientists to perform detailed long term studies on these parameters in relation to land management impacts. Furthermore, methods used to measure instream sediments have a variety of shortcomings or associated challenges such as expense, physical impracticality, and subjectiveness.

Methods used to measure bedded sediments, such as percent of fines by volume and/or area can be impractical to measure in wadeable mountain streams where obtaining stream substrate cores may be difficult and expensive due to large cobbles and boulders and rapid streamflow. Methods such as Wolman pebble counts, substrate stability, residual pool volumes, pool frequency and depth, professional judgment, and pictures can 
be difficult to quantify precisely, may not accurately reflect the amount of bedded sediments, may be subjective, or may not be appropriate for looking at recent impacts (Bauer and Ralph 2001, Olsen et al. 2005, Whitman et al. 2003). Other methods include basket, tray, and pit samplers. These are considered fairly accurate by the USGS, though they can be time consuming and costly for smaller agencies or individual scientists. The USGS is in the process of developing other methods to measure bedded sediments, such as radar and sonar based technologies, but these methods have yet to be finalized and vetted, and are not yet widespread (Gray et al. 2010).

Due to the expense and time associated with gathering bedded sediment data, methods for measuring suspended sediments, such as turbidity and/or total suspended solids (TSS), are more frequently used by scientists and agencies (Gray et al. 2010). Most US states base sediment criteria on measures of turbidity and/or total suspended solids (USEPA 2006). Turbidity is most commonly used as a surrogate for sediment loading, due to ease of measurement, generation of precise and quantifiable data, and relative low cost. However, examining multiple metrics is recommended (USEPA 2006). Turbidity is the measure of the cloudiness of the water, as estimated by how effectively a beam of light passes through water, and is generally measured in units of Nephelometric Turbidity Units (NTUs) or, less frequently, Formazin Turbidity Units (FTUs) (Henley et al. 2000, USEPA 2006, Rasmussen et al. 2011). Suspended sediment particles interfere with light transmittance and cause an increase in cloudiness, and so turbidity is correlated with suspended sediment in the water column (USEPA 2006, Rasmussen et al. 2011). Measurements are made through discretely captured field samples, by streamgage 
sensors, or by instream turbidity sensors that can feed into data logger software.

However, a key drawback of using turbidity as a surrogate for sediment loading is that the majority of sediments are transported in the stream water column during storm events, and patterns of transport during storm events are erratic (Edwards and Glysson 1999). For example, peak sediment transports may be present directly before or after peak flows, and do not exhibit reliable temporal patterns (Ellison et al. 2010). In other words, measuring turbidity at a particular moment or season may not accurately represent the actual sediment load of the stream, and may fail to detect high sediment pulses or deviation from natural timing or frequency. Discrete field sampling or even instream turbidity sensors may miss major sediment movement events in the stream (Ulrich 2002). In addition, the degree to which turbidity and suspended sediments are correlated is controversial. The size, shape, and mineral content of the particles, as well as the water color and temperature, can affect turbidity readings. Also, the instrumentation for measuring turbidity is not standardized, and can further contribute to variability in readings (Packman et al. 2000). For example, different models of turbidity meters may have 2 to 4 receptors for light sensing, and therefore have different levels or patterns of accuracy (Anderson 2005). Henley et al. (2000) claims that using turbidity as a surrogate for sediment is dubious, and recommends that turbidity at least be calibrated to suspended sediment concentrations for greater accuracy (Henley et al. 2000). The USGS recommends using turbidity data which has been calibrated to suspended sediment concentrations to create a suspended sediment load curve to increase accuracy and prediction (Rasmussen et al. 2011). On the other hand, Packman et al. (2000) found a 
very high correlation ( $\mathrm{R}^{2}$ of 0.96$)$ between turbidity and TSS when examining 9 streams in both urban and forested watersheds. They suggest that turbidity is an adequate and probably viable measure of TSS (Packman et al. 2000), and so strengthens the case for using turbidity as a surrogate for sediment loading. Rasmussen et al. (2011) report that TSS measurements tend to be biased low and that SSC is a preferable method of estimating suspended sediments. They also found that SSC has a strong linear correlation to turbidity, and that when the correlation is proportional, turbidity can be used to estimate SSC values (Rasmussen et al. 2011), though data may need to be log transformed in order to display a linear relationship (Ellison et al. 2005, Galloway et al. 2005). The USGS recommends using SSC over TSS, as TSS measurements tend to be biased low 25 to 34 percent, and SSC methodology is more standardized and accurate (USGS 2000). Increasingly, the USFS and the USGS use continuous instream turbidity sensors which, when a specified turbidity is exceeded, trigger a pump sampler to obtain a limited number of water samples to be analyzed later for suspended sediment concentrations (Gray et al. 2000, Lewis 2003).

Macroinvertebrates, fish, periphyton, and mussels are used by scientist and agencies as bioindicators of stream health, and one or more is generally measured in conjunction with direct estimates of suspended and/or bedded sediments (USEPA 2006). Natural variability of sediment loading across watersheds is high (Tague and Grant 2004, USEPA 2006), and ecological responses to sediment levels may be complex (Herlithy et al. 2005, Reid et al. 2010, Smith et al. 2009). These factors, combined with the challenges of directly measuring fine sediments, necessitate quantifying of one or more biological 
indicators in order to obtain a more robust picture of overall ecosystem health. While sediment pulses, even those that are frequent, may not reliably coincide with the timing of turbidity samples, they nevertheless may affect stream organisms. Measures of biological indices have been shown to be effective in detecting ecosystem impacts in logged watersheds in relation to sediment stress as well as other variables. In their study comparing logged and reference watersheds in the Ouachita Mountains of Arkansas, Hlass et al. (1998) found that in logged watersheds, turbidity and TSS showed inverse correlations with scores from a Modified version of the index for biotic integrity (IBI), an index which takes into account multiple biological metrics. In Georgia, low IBI scores based on fish were correlated with TSS values greater than $8 \mathrm{mg} / \mathrm{L}$ in low flow stream conditions. Streams with TSS values of less than $6 \mathrm{mg} / \mathrm{L}$ had high IBI scores (IDEQ 2003).

Macroinvertebrates are often selected as bio-indicators because they are ubiquitous in all stream orders (including those outside of the range of fish and mussels), easy to collect, and relatively simple to identify to necessary taxonomic category. In addition, some macroinvertebrate feeding groups, families, and/or genera are more sensitive to excesses of fine sediments then others, and so have relatively predictable shifts in community structure or composition when sediment stress is present (Miserendino and Masi 2010). For example, Miserendino and Masi (2010) found that higher abundance of the collector-gatherers correlated with fine sediments in areas where riparian logging had disturbed stream channels. Kreutzweiser et al. (2005) also found significant increases in gatherer taxa which seemed to be correlated to a significant 
increase in fine sediments in some logged areas. Reid et al. (2010) found that logged areas showed increases in Diptera, mollusks, worms, and a decrease in Ephemeroptera, and concurrently showed increased fine sediments, temperature, and algal mass. Wood and Armitage (1997) also found that sediment rich environments favored oligochaetes and chrinomids. In addition, they found that particular species of ephemeroptera were better adapted to high sediment and low oxygen environments than others. They also found that filter feeders may be negatively affected, as their feeding apparatuses may become clogged by fine sediments, and that increases in turbidity may limit the amount of light reaching the stream substrate, thus limiting algae production and affecting the entire food web (Wood and Armitage 1997). However, biological responses to disturbances such as logging can be complex and variable. Studies have shown seemingly conflicting responses in the macroinvertebrate community following logging. For example, macroinvertebrate densities, abundance, diversity, and species richness have been found to decrease, increase, or remain the same following logging in different studies. This may be due, at least in part, to heterogeneity in geomorphology, size of and response to riparian buffers, utilization of different indices with differing levels of sensitivity, upstream watershed characteristics, stage of forest and macroinvertebrate recovery, seasonal variability, and scale (Herlithy et al. 2005, Reid et al. 2010, Smith et al. 2009). Increasingly, current studies are elucidating the nuances associated with macroinvertebrate responses to disturbance, and a greater understanding of these responses will continue to increase the accuracy and strength of their use as a bioindicator of stream health in relation to logging and associated sediment inputs. 
A variety of indices for macroinvertebrate analysis include: taxa richness, ratio or relative abundance of scrappers to filterer and/or collector functional feeding groups, ratio or relative abundance of shredder functional feeding group to total number, percent contribution of dominant taxa, Shannon and Simpson diversity indices, Hilsenhoff Biotic Index (HBI), Family Biotic Index, community similarity index, community loss index, index of similarity between two samples, and the Pinkham and Pearson community similarity index (Klemm et al. 1990, Barbour et al. 1999). Smith et al. (2009) looked at total invertebrate abundance, taxon richness, rare taxon, and looked at whether functional feeding groups were statistically similar between reference and disturbed sites (Smith et al. 2009). The New Zealand Macroinvertebrate Working Group looked at abundance and rare taxa (Stark et al. 2001). The fine sediment bioassessment index (FSBI) developed by Relyea et al. (2000) identifies multiple benthic macroinvertebrates by species or taxa that can be used as indicators of fine sediment levels based on their sediment tolerance. They found EPT and Simpsons were not sensitive to varying sediment levels (Relyea et al. 2000). The FSBI was further investigated by Relyea et al. 2012 and was found to be successful in indicating sediment impairment (Relyea et al. 2012).

Natural variability of fine sediment loading is influenced by numerous factors including topography, channel morphology, gradient (USEPA 2006), land cover (Allan et al. 2004), general rock type (Johnson et al. 2003), soil erodibility (USEPA 2006), road density (Cederholm et al. 1980), stream order (Johnson et al. 2003), and catchment size (Bolstad and Swank 2007). For example, the geology of an area plays a key role in affecting fine sediment loading in streams (USEPA 2006), and is one of the main drivers 
of streamflow regimes (Tague and Grant 2004). Soft sedimentary rocks, considered erosive, are more likely to generate sediment in relation to land management disturbances than hard volcanic rocks, which are considered resistant (USEPA 2006). Similarly, Dyrness (1967) reported that the pyroclastic rocks in the western Cascades such as tuffs and breccias are more prone to soil mass movements than areas containing underlying bedrock of basalt or andesite (Dyrness 1967). Swanson and Swanston (1977) also reported that pyroclastic rock that has been extensively weathered is the most susceptible to earthflow and creep, and that these features generate a large portion of instream sediments. Complex patterns of creep and earthflows are formed over larger areas of slow mass movement, and rates of movement may vary considerably among discrete creep or movement areas. Movement is most likely to take place or become accelerated in times of higher soil moisture conditions when precipitation or snowmelt is occurring (Swanson and Swanston 1977).

Geology, soil porosity, and underlying bedrock permeability have pronounced effects on water infiltration and runoff rates (Moore and Wondzell 2005). Tague and Grant (2004) found that the different geologic rock formations of the western Cascades vs. the high Cascades had such a pronounced effect on groundwater, subsurface flow, and consequently streamflow, that they could be used as a reliable predictor of peak and base flow responses (Tague and Grant 2004), which in turn can influence sediment dynamics (Croke and Hairsine 2006, Moore and Wondzell 2005). The western Cascades are characterized by shallow soils with high clay content, which can limit groundwater storage capacity and cause rapid subsurface flows, making peak flows flashier and base 
flows lower (Tague and Grant 2004). The high Cascades, on the other hand, have blocky lava rock formations with many crevices and fractures, allowing for deep and slower subsurface flow and large aquifer storage capacity. As a consequence, high cascades base flows are comparatively larger and colder, and peak flows less flashy. The authors also pointed out that groundwater inputs may play an equally important role in base and peak flows as snowmelt (Tague and Grant 2004). In the Western Cascades, rain-on-snow events are the primary drivers of peak flows, and streamflows are usually highest in the months from November to April (Harr and Coffin 1992).

\section{Need for study}

While numerous studies have investigated the effects of clearcut logging on erosion, landslide rates, and fine sediment generation (Croke and Hairsine 2006, Guthrie 2001, Hicks et al. 1991, Jones 2000, Jones and Grant 1996, Lewis et al. 2001, Montgomery et al. 2000, Troendle and Olsen 1993), fewer studies have examined how selective harvest practices affect sediment dynamics and instream sediment loading (Kreutzweiser and Capel 2001, Reid et al. 2010). Additional field studies are needed in order to help determine both background instream sediment levels, and levels in response to selective harvest practices in small forested watersheds. Additional field data would also facilitate more accurate modeling of the effects of land management practices on sediment loading, hydrograph shape, and other hydrologic processes (Croke and Hairsine 2006, USEPA 2006), as well as possible impacts on biota. In particular, more information regarding instream sediment levels is needed in areas where multiple uses and/or legal 
mandates may cause conflicts between ecological resources such as endangered salmon and current logging practices.

While selective logging is likely to be less environmentally destructive than clearcut logging in most situations, the extent of its impacts on forest health and stream water quality is not clear. Little research has been done on water quality in relation to selective logging, and the research that exists has often yielded contradictory or ambiguous results. Some studies found selective logging may be associated with increases of instream fine sediments (Kreutzweiser et al. 2005, Miserendino and Masi 2010), changes in macroinvertebrate community structure or metrics (Flaspohler et al. 2002, Kreutzweiser et al. 2005), alterations in nutrient cycling and leaf litter decomposition rates (Lecerf and Richardson 2010), and increases in stream temperatures (Guenther et al. 2012). However, others have found little or no change in stream fine sediment levels (Kreutzweiser and Capell 2001) or macroinvertebrate community structures (Gravelle et al. 2009). Kreutzweiser et al. (2005) found only limited changes to macroinvertebrate community structure that tend to accompany specific riparian disturbances, such as roads or skid trails disturbing soils near streams. However, Flaspohler et al. (2002) noted that changes to biota associated with selective logging were found decades after logging. Given that selective logging is taking place on many thousands of acres of public and private lands, a more clear and detailed understanding of the possible effects associated with selective logging is necessary in order to protect riparian and aquatic resources. Investigation of possible impacts at multiple scales in diverse environmental and geologic conditions, cumulative impacts, and chronic, sub- 
lethal effects on biota may be necessary in order to develop a sufficient understanding of how biotic and abiotic resources may be affected. Possible thresholds, complex temporal responses, long-term effects, and integrated ecosystem interactions should be considered.

\section{Purpose and hypotheses}

The objective of this study is to determine the effects of selective logging practices and associated roads on the magnitude of instream sediment loading in small forested watersheds in the Clackamas Basin in Oregon. To this end, I focused on stream turbidity as a surrogate for sediment loading (USEPA 2006) in first, second, and third order streams in managed and unmanaged watersheds in the Clackamas. In addition, I sampled macroinvertebrates, and measured stream conductivity, total dissolved solids, suspended sediment concentrations, and substrate embeddedness and pebble counts. I hypothesized that macroinvertebrate assemblages would be different in reference vs. streams with adjacent selective logging units with recent logging (non-reference streams), and in reaches downstream of selective logging units vs. upstream reaches. I also hypothesized that selective logging and high road densities would be associated with increased instream fine sediments. I expected macroinvertebrate taxa associated with fine sediments in other studies to increase, while those found to be sensitive to fine sediments are expected to decrease (Angradi 1999, Reylea et al. 2012).

Macroinvertebrate responses to disturbances can be variable and complex. As a result, the expectations concerning possible macroinvertebrate patterns in relation to logged and unlogged areas in this study encompass a number of possible outcomes. Reylea et al. (2012) identified the sediment tolerance levels of approximately 100 
macroinvertebrate taxa. This suggests that perhaps taxa considered to be sediment intolerant in other studies may show patterns of presence or absence in this study (Reylea et al. 2012). Macroinvertebrate responses may also include non-sediment specific responses to logging such as greater abundance of emergent insects in impacted areas (Banks et al. 2007, Progar and Moldenke 2009). I expected macroinvertebrate community structures and assemblages to show distinct patterns in relation to harvest and to increasing road densities, though responses may vary according to degree, size, and age of logging units. In reference areas and upstream of logging units, I expected shredders and taxonomic groups that are intolerant of sediment to comprise a higher percentage of overall macroinvertebrate samples (Herlithy et al. 2005, Reid et al. 2010, Smith et al. 2009). I expected to find a higher abundance of collector-gatherers in reference streams, and downstream of logged areas (Miserendino and Masi 2010). I also expected that the percent of dipterans and certain families of Ephemeroptera will increase (such as the Baetidae) (Waters 1995), while Plecoptera and other Ephemeroptera taxonomic groups will decrease (IDEQ 2003, Wood and Armitage 1997). Additionally, in watersheds with a relatively small percent of logged area, I expected there to be an increase in overall diversity and abundance of macroinvertebrates due to the combination of the opening of the canopy from riparian selective logging and increased nutrient input combined with overall good water quality from upstream inputs. Finally, I expected that macroinvertebrate community composition will show patterns of dissimilarity between reference and non-reference sites when plotted on ordination plots. 


\section{Chapter 2: Methods}

\section{Clackamas River Basin Site Description}

The Clackamas River Basin is located approximately 48 kilometers southeast of Portland, Oregon (Figure 2). The Clackamas River is a tributary of the Willamette River. It drains approximately 2,435 square kilometers, and ranges in elevation from near sea level to just over 2,134 meters (Salminen 2005). From the headwaters at the Ollalie Lakes area in Mt. Hood National Forest, to just above the North Fork reservoir, the Clackamas River drains a watershed of approximately 1,725 square kilometers- this area encompasses much of the portion managed by the Forest Service. The majority of the lower Clackamas Basin is privately owned, while the upper Basin (which is more than half of the entire basin) is publicly owned, most of which is managed by the Forest Service. The major tributaries of the Clackamas River are the South Fork of the Clackamas, Fish Creek, the Roaring River, the Oak Grove Fork of the Clackamas, and the Collawash River. In 1988, a 76 kilometer stretch of the Clackamas was designated Wild and Scenic by Congress. This 76 kilometer stretch begins in the Ollalie Lakes area and ends at Big Cliff, just upstream of the North Fork Reservoir (USFS 1993). 


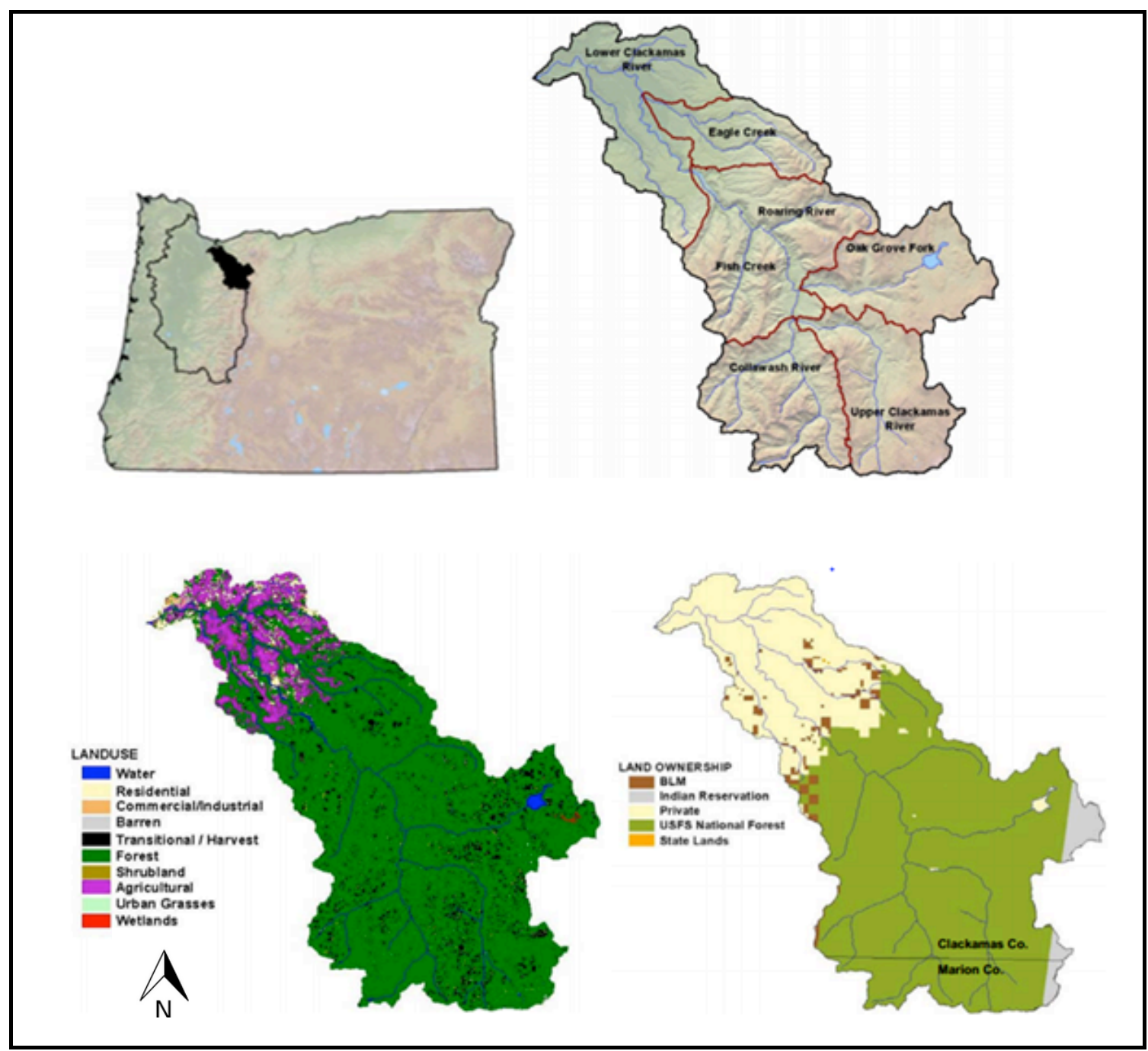

Figure 2: General area, land use, and ownership of the Clackamas Basin, Oregon (ODEQ 2005).

More than 1,674 kilometers of fish-bearing streams and rivers feed into the Clackamas River (USFS 1993). The entirety of the Clackamas Basin within USFS jurisdiction is designated core cold water habitat, and various portions of the mainstem and its tributaries are managed for salmonid spawning and rearing designations during seasonal and biologically relevant portions of the year (ODEQ, OAR 340-041). 
Spawning and core cold water designations are used in reference to temperature standards for regulatory purposes (ODEQ, OAR 340-041; ODEQ, accessed 2015), and these beneficial uses may be negatively affected by excess fine sediments (Bryce et al. 2010, USEPA 2006).The Clackamas River Basin carries what is believed to be the last significant and self-sustaining run of wild, late-winter Coho (Oncorhynchus kisutch) in the lower Columbia River basin. Declines for this run have been documented by the USFS, and the run is considered to be at "moderate risk of extinction" (USFS 1994). Coho are candidates for federal listing, and considered threatened by the state. The Clackamas also supports an important population of winter steelhead (Oncorhynchus mykiss), and runs of steelhead in the Clackamas are listed as threatened federally and are a state species of concern, and the winter run is considered a core population (meaning that it is considered important to species recovery due to historic abundance). The Clackamas spring Chinook are considered threatened, and are a core and genetic legacy population ("genetic legacy" populations poses the most pure/intact genetically wild stock). Cutthroat Trout (Oncorhynchus clarki) are listed as critical by the state. Bull Trout (Salvelinus confluent) were extirpated from the Clackamas Basin, however the US Fish and Wildlife Service reintroduced them into the Basin in 2012 (Salminen 2005, USFWS 2013). Pacific lamprey also use the river, and their numbers appear to be declining. The Clackamas Basin is considered one of the most important anadromous and trout fisheries on national forest land in the northwest. All of the anadromous species that it hosts use the river and/or its tributaries for spawning, rearing, and migration (USFS 1993), and require clear, cold water for critical habitat (USFS 1993, Salminen 2005). 
Providing critical habitat and recovery plans for federally listed species is required under the Endangered Species Act (ODFW 2010).

Existing water quality problems in the Clackamas Basin include elevated stream temperatures and excess nutrient and sediment inputs in some areas (Salminen 2005, ODEQ 2006). Within publicly managed areas, the Clackamas River mainstem, Fish Creek, Eagle Creek, and portions of the Collawash, and Nohorn Creek are list for violations of temperature pollution (ODEQ, accessed 2013). In the upper basin areas managed by the Forest Service, high temperatures and elevated nitrogen were hypothesized to be the related to logging and logging related activities (which can include prescribed burns and applying fertilizers). Elevated phosphorus levels in the upper basin could be a result of natural geology, though it is also hypothesized that logging activities might be at least partly responsible for providing a mechanism for excess phosphorus to enter streams. Most of the problems with high sediment levels have been reported in the lower Clackamas. However, elevated instream sediment loading exists in the upper Clackamas as well. For example, the Fish Creek subwatershed has recurring problems with sediment related stress due to logging and roads. The Clackamas Basin Watershed Summary Overview reported that while the technology exists to monitor instream sediments, most organizations have not conducted this kind of monitoring in the Clackamas Basin. Furthermore, it is impractical to measure sediment loading extensively across the entire basin (Salminen 2005).

The Clackamas Basin is predominantly composed of volcanic deposits including pyroclastic flows, tephras (such as pumice and ash), lahars, and related deposits 
(Salminen 2005), as well as lava flows (USGS accessed 2012, USFS 1993) and alluvial deposits. The deposits generally range from 10,000 to 45 million years old, and originated in the quaternary and tertiary periods. Since deposition, faulting and folding has modified the structure of the deposits. Glaciation, mass wasting, and alluvial interactions have shaped the geomorphology of the landscape (Salminen 2005). Volcaniclastic formations that have been altered by these processes tend to be the most prone to earthflows and other instabilities, and these altered landforms tend to be the most unstable in the western Cascades. Additionally, soils developed on volcaniclastic materials tend to be particularly prone to creep and earthflow, particularly in gently sloped areas, and are usually poorly drained, finely textured, and deep (Salminen 2005, Swanson and Swantson 1977). More highly altered volcaniclastic material may have high expandable clay content, and be especially prone to instabilities. Conversely, soils associated with lava flows such as basalt and andesite formations are generally more stable, and tend to be more coarse and better drained (Swanson and Swanston 1977). The Clackamas Basin and the area around Mt. Hood are considered to be the most at risk for landslides on Mt. Hood National Forest. The Clackamas contains large earthflow complexes, both dormant and active, some of which cover several square miles (USFS 2010).

The Clackamas Basin has been divided and then further subdivided into several ecoregions by the USEPA, and these ecoregions are determined in part by the geologic formations within the areas. The Clackamas Basin falls within the Western Cascades and High Cascades ecoregions, with most of the productive timber areas that are on public 
land fall into the further subdivided ecoregions of the Western Cascades including: the Western Cascades Lowlands and Valleys (characterized by low ridges, valleys, buttes, and moderate gradients), and the Western Cascades Montane Highlands (characterized by steep slopes, highly dissected ridges and buttes, and rock basins with lakes from past glaciations). The Western Cascades are underlain by Columbia River Basalts, and the underlying basalts have been exposed in many areas by uplift, river incision, and other processes. Runoff processes and landform instability patterns of the Columbia River Basalts tend to be more similar to those of the High Cascades (which is less than 2 million years old). For example, slope failures in the High Cascades tend to include rock falls and large slump blocks rather than debris or earth flows, and soils are generally less erosive than those of the Western Cascades. However, soils in the Western Cascades can vary, and may include shallow soils with high clay content or a range of deep clay loams and cobble loams (Salminen 2005, Tague and Grant 2004). The elevation range of the Western Cascades is generally 91 to 1,067 meters (Salminen 2005).

Forest stands in the Western Cascades lowland and valley ecoregion are predominately composed of Douglas-fir, western hemlock and western red cedar. Red alder, big leaf maple, and vine maples are also common. Forests in the Western Cascades Montane Highlands are predominately composed of pacific silver fir, Douglas-fir, western hemlock, mountain hemlock, and noble fir. Big leaf maple, vine maple, red alder, and pacific yew also occur. Mean precipitation for the entire basin is approximately 180 centimeters/year, and ranges from 109 to 277 centimeters/year with most of the precipitation falling during the winter, spring, and fall (Salminen 2005). 
Oregon's forests have very productive timber output, and National Forests across the state have historically been heavily logged. For example, from 1962 to 1989 between 4,000 and 5,000 million board feet were logged each year from Oregon forests (with the exception of 6 years, 2 of which were just under 4,000 million board feet). This number has significantly declined, with approximately 200 to 650 million board feet being logged each year between 1994 to 2010 (Daniels 2011). Almost 80 percent of the forests in Western Oregon are under 120 years old (USFS 2004). In Mt. Hood National Forest, an average of 27,158 thousand board feet has been logged each year from 1994 to 2010 . From 1999 to 2010, logging took place on approximately 17,780 acres in Mt. Hood. However, accurate figures are difficult to determine. For example, this acreage does not include many fuels reduction projects, even though fuels reduction projects include commercial harvest of green trees by private bidders, and may involve substantially more acres on a given year than other categories of logging which are categorized as "harvests". For example, in 2010, the Mt. Hood Monitoring Report for 2010 reported 1,800 acres of land as being treated for harvest, which did not include 3,791 acres that were classified as fuels treatment. Of the approximately 1 million acres that comprise Mt. Hood National Forest, approximately 183,000 acres are managed for timber emphasis (also called "matrix" designation), 155,625 acres contain grazing allotments (these may overlap with other land use designations, including wilderness), and 124,000 acres are designated wilderness. Significant portions of total logging activity take place on areas not designated for timber emphasis, such as late successional reserves (USFS 2010). 
The Clackamas Basin has a history of extensive logging, which has simultaneously declined with overall timber production in Oregon, but is still common. Logging began in the early 1800's, and volumes and dates of logging were generally not recorded. However, it is clear that many millions of board feet were logged before the 1950's, and that from the 1950 's to 1994 an additional $30 \%$ of the upper Clackamas watershed was logged. Between 1970 and 1994, approximately 21,000 acres were cut in the upper watershed. Clearcutting was the most prevalent harvest method, and logging on steep slopes and in riparian areas was common. As of 1994, the upper Clackamas Basin contained approximately 779 kilometers of permanent road (Taylor 1999). Since 2002, there have been approximately 15,000 acres of forest on Forest Service land in the Clackamas Basin that have either been logged, auctioned, proposed for auction, or are currently in the final stages of the National Environmental Policy Act (NEPA) processes. More than half of the recent management has a prescription involving thinning or selective harvesting (USFS documents accessed through Bark 2012, USFS 2012). Due to the economic recession and subsequent congressional extensions on logging deadlines, approximately 7,500 acres of forest were behind schedule for planned logging as of June 2012. Harvests could take place in many sales at the same time, potentially creating cumulative impacts beyond those initially analyzed or predicted by the Forest Service in their NEPA analysis.

Thousands of acres of logging, many of which are intended as restoration, are currently taking place in the Clackamas and within other basins on public forests. Part of the stated purpose and need of the selective logging project in this project- the 2007 
Plantation Thin- was to "accelerate the development of mature and late-successional stands conditions" in previously clearcut forests. In riparian areas, thinning was also implemented in order to help accelerate recruitment of woody debris for stream channels (USFS 2006). However, some studies cast doubt on the effectiveness of thinning as restoration. For example, based on a combination of field observations and modeling, Pollock et al. (2012) found that young forest stands left untreated were on track to develop structure in line with mature reference stands, while stands that were treated did not seem to follow a developmental path that would be in-line with mature forest reference structures. In a separate study, Pollock and Beechie (2014) examined how riparian thinning affected large diameter dead and live trees. They found that thinning negatively impacted large dead wood, and that "because far more vertebrate species utilize large deadwood rather than large live trees, allowing riparian forests to naturally develop may result in the most rapid and sustained development of structural features important to most terrestrial and aquatic vertebrates" (Pollock and Beechie 2014).

\section{Site Selection}

Watersheds were selected with respect to minimizing physical differences and natural variability other than land management usage. Watershed selection criteria included size (Bolstad and Swank 2007), stream order (Johnson et al. 2003), elevation (Scott et al. 2007), geology (Johnson et al. 2003), slope (Allan et al. 2004, Johnson et al. 2003), road density (Cederholm et al. 1980), and characterization of harvest units. Watersheds are between 0.26 and 7.59 square kilometers, contain $1^{\text {st }}$ through $3^{\text {rd }}$ order streams, and are between approximately 300 to 1,500 meters in elevation. Watershed 
geology were selected to be as similar as possible, with at least $80 \%$ resistant geology (andesite/basalt bedrock), and as gentle and similar of slopes as possible (mean basin slope is 11.3 to 19.7 degrees). Reference sites are old growth with trees over 180 years old and contain no roads within the sub-watersheds where sampling will occur. Existing road densities in harvested watersheds are greater than 1.24 kilometers/square kilometer (2 miles/square mile). Harvest areas vary in size and age, but areas which were selectively logged within five years and were directly adjacent to streams were selected. Site selection was performed using GIS analysis and data from the USFS data library and FOIA requests to the USFS (USFS accessed 2011, USFS accessed 2012). Geologic data from the Pacific Northwest Ecosystem Research Consortium (accessed 2013) and watershed characteristic data from USGS Streamstats (USGS accessed 2013) were also used.

Based on the site selection criteria, seven watersheds were selected in the Clackamas Basin in Mt. Hood National Forest, Oregon (Figure 3). Three watersheds were selected as reference sites, and minimal to no management activity. No records were found indicating reference areas have been logged, or have any roads within their catchment boundaries. The other four watersheds contain selective logging units adjacent to streams but with riparian buffers. However, one of these streams (Pot Creek) was excluded in analysis due to a missed sampling session in this stream, which resulted in the absence of comparable late summer/early fall data for macroinvertebrates and water quality parameters. Consequently, a total of three reference and three non-reference streams were analyzed in this study. In general, riparian buffers adjacent to study reaches 
were 15-meter wide. Within 15 meters of the stream protection buffers, "low impact harvesting equipment such as, but not limited to, mechanical harvesters or skyline systems, which have minimal ground disturbance would be allowed" (USFS 2006). The exact dates that logging took place in units adjacent to study reaches were not available from the Forest Service. Two of the non-reference streams selected were second order streams (Canine and Dog creeks), and one was third order (Pup Creek). Two of the reference sites were first order streams (Doris and Ora creeks), and one was second order (Alice Creek). Canine Creek is an unnamed creek just north of Pup Creek; it is referred to it as Canine Creek for convenience. Non-reference study reaches had an average elevation of 814 meters; average stream reach elevation ranged from 742 meters to 847 meters. Reference streams had an average elevation of 813 meters; average stream study reach elevation ranged from 776 meters to 846 meters. Average subwatershed slope in non-reference watersheds was 19 degrees and ranged from 18-20 degrees. Average subwatershed slope in reference watersheds was 18 degrees and ranged from 17 to 19 degrees. Within sample reaches, non-reference streams had an average slope of 10 degrees, and average stream study reach slope ranged from 10-12 degrees. Reference streams had an average slope of 14 degrees at sample reaches; average stream study reach slope ranged from 10-18 degrees. Non-reference subwatershed bedrock consisted of basalt bedrock; reference subwatersheds were basalt and andesite. In the Soil Resource Inventory conducted by the USFS (1979), the area encompassing my reference sites was categorized as potentially having more erosiveness soils compared to other areas in Mt. Hood due to shallow soils and steep slopes. Non-reference subwatersheds had an average 
road density of 5.23 kilometers/square kilometer, and ranged from 1.77 kilometers/square kilometer to 3.71 kilometers/square kilometer; reference watersheds had zero kilometers/square kilometers road density. In portions of the subwatershed upstream of study reaches, non-reference watersheds had 3.95 kilometers/square kilometer road density. According to Prism modeled annual precipitation estimates through the USGS streamstats website, non-reference sites receive approximately 203 centimeters/year, and reference sites receive approximately 226 centimeters/year. Douglas fir (Pseudotsuga menzii) was the dominant tree species in all subwatersheds, with Western hemlock (Tsuga heterophylla), Western red cedar (Thuja plicata), and Red alder (Alnus rubra) codominating in some portions of subwatersheds. Current tree density across the entire 2007 Thin logging project are generally described as having a relative density of greater than 70 . 


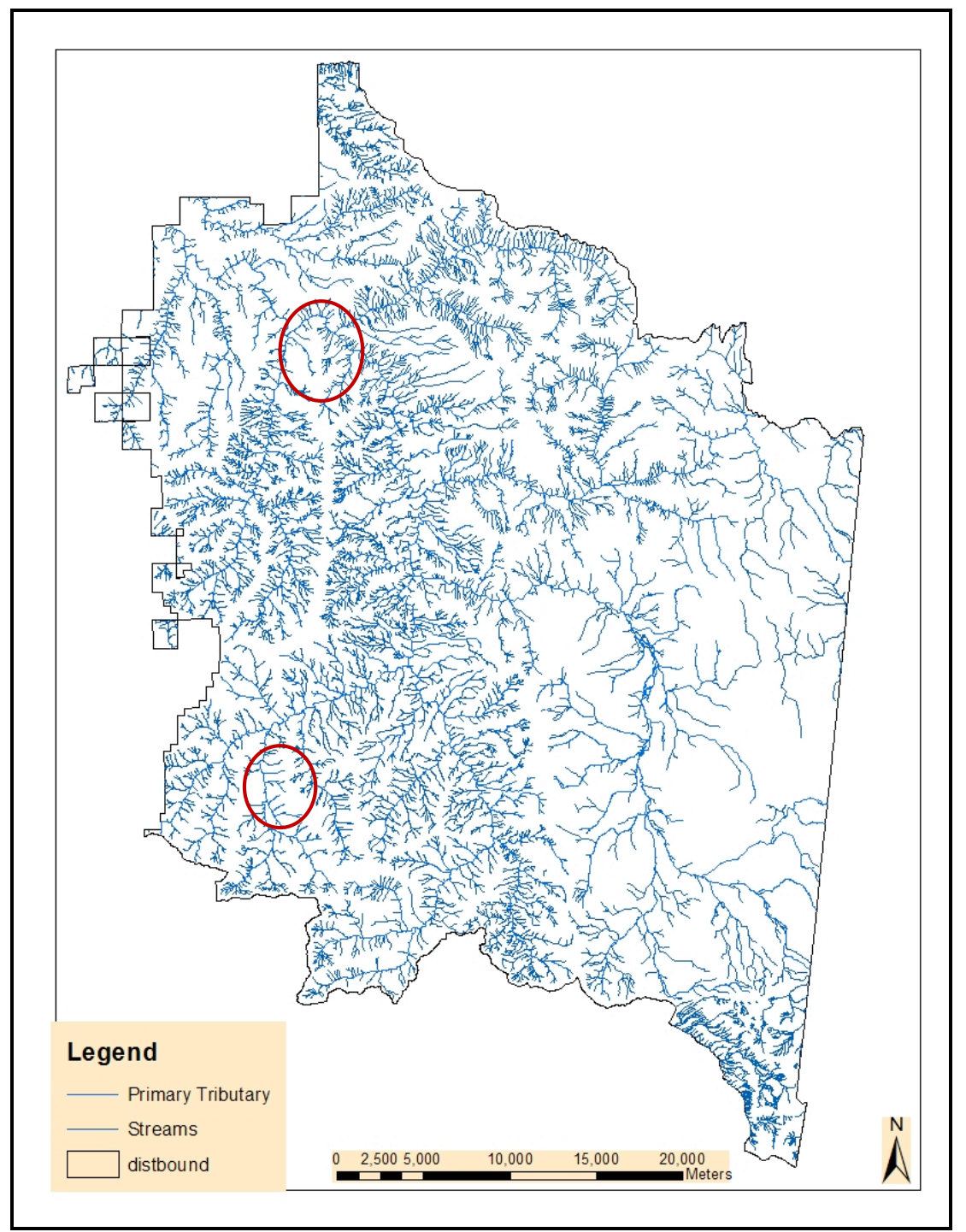

Figure 3: General location of sample sites within the Clackamas River Ranger District in Mt. Hood National Forest. Sample site areas are circled in red, and include a total of six streams.

\section{Stream Sampling}

Turbidity, suspended sediment concentration, stream discharge, embeddedness, temperature, and canopy cover were measured; macroinvertebrates were sampled and an EPA rapid bio-assessment was performed. In addition, stream temperature, conductivity, and dissolved oxygen were measured. Study reaches were 50 meters long, approximately 
equal to 20 times the average wetted width of the streams in this study. Streams were sampled upstream and downstream of logging units in non-reference sites (Figure 4). Study reaches were located as far as possible from culverts, and were placed in the most accessible portion of the stream above and below logging units. Above and below turbidity readings were represented as the difference of subtracting upstream from downstream turbidity, and treated as one data point. Percent embeddedness and suspended sediment concentrations were treated similarly, and analyzed as one data point. In the reference sites, the "above and below" sampling were replicated as similarly as possible to the impacted sites with respect to elevation changes, and samples were taken at up and downstream locations at similar elevations as those in the impacted sites. A total of 12 sample locations across all watersheds were sampled, producing a total $n=6$. Early fall samples were taken following rain events. Variability of rain-related sediment movement into streams was minimized by sampling each study reach on four occasions. Rain events were also examined to determine if more frequent rain events took place on average before sampling for any stream reaches. Rain events were based on Snotel precipitation data from Peavine Ridge. Downstream reaches were sampled first; upstream sampling took place approximately four hours later on the same day. 


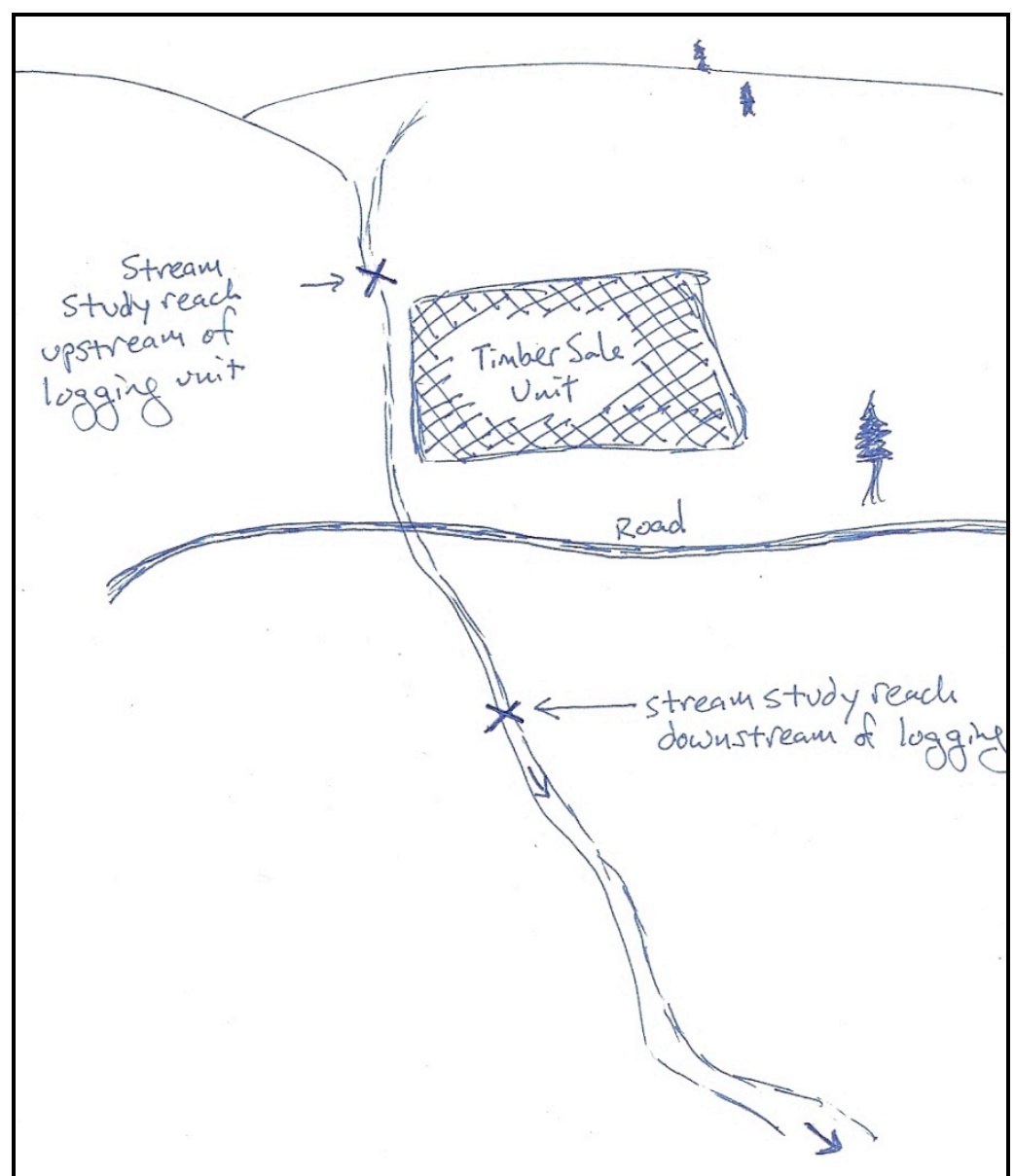

Figure 4: Generalized depiction of upstream/downstream study design: non-reference sample site is depicted, including above and below logging unit study design. Sample sites downstream of roads are located at least 100 meters away from culverts. Reference sites included upstream and downstream of reference forest stands.

Several studies have used similar criteria for study reach length. Bain and Stevenson (1999) recommend a sample reach of 20 times the wetted width of the stream when sampling for macroinvertebrates. Reid et al. (2010) based the length of the study reach on channel width. In smaller streams, Reid's study reaches were also approximately 20 times the width of the stream. Stream widths varied from 2.5 to 16 meters, and study reaches varied from 40 to 120 meters (Reid et al 2010). Generalized EPA biotic sampling 
guidelines suggest a stream sampling reach length of 40 times the wetted width of the stream for capturing fish species variability (USEPA 2002). While 40 times the wetted width of the stream is necessary in relation to surveying for fish species, macroinvertebrates exist at much higher densities in streams and stream study reaches do not need to encompass as much length in order to capture variability.

\section{Turbidity}

During each sampling event at each study reach, instream turbidity was grab-sampled once at each of the five transects. Grab samples were taken by alternating from right bank, middle, and left bank from downstream to upstream, and were taken at approximately $30 \%$ depth from the surface. These readings were averaged into a single turbidity reading for that date and location. Each stream was sampled for turbidity on four separate occasions. Sampling took place once in spring, twice in summer, and once in fall). Sampling efforts yielded 24 independent samples- four independent samples for each of the six streams (independent samples were derived from a total of 240 measurements). Areas of stagnant water were not sampled for turbidity. Samples were taken facing upstream, with the mouth of the sample bottle also facing upstream and at a 45 degree angle to the streambed.

In preliminary sampling done in the logged sites in the summer of 2012, five grab samples per reach was shown to capture the majority of the variability of turbidity readings. Preliminary turbidity sampling included 45 to 100 turbidity grab samples per study reach along 50 meter transects. Based on preliminary sampling, it was determined 
that approximately five grab samples per study reach (combined into one value per reach) was sufficient to capture variation in turbidity.

Streams are generally narrow and shallow in sample sites (on average less than two meters wide and $50 \mathrm{~cm}$ deep), and are considered well mixed (Lewis and Eads 2009). In preliminary sampling it was determined that depth integrated sediment samplers were too large for use in the streams, and submerging the samplers deeply enough to collect water resulted in scrapping the stream bottom and disturbing bottom sediments. The sample bottles for the turbidity grab samples were rinsed 3 times prior to each reading, and samples were collected approximately half way down from the surface of the stream to the stream bottom. Turbidity was measured in the field or immediately upon return from the field using a Hach 2100P turbidimeter, which uses a tungsten filament lamp and two light detectors, one of which is at a 90 degree angle. The turbidity meter fulfills the design criteria required by the USEPA, and was calibrated according to specifications (Hach Co. 1999).

\section{$\underline{\text { Suspended Sediment Concentration }}$}

Suspended sediments concentrations (SSC) were determined for study reaches. Water samples for SSC were collected in a 3L plastic Nalgene container. Samples were collected in or adjacent to the stream study reach in an area that is sufficiently deep to allow for collection without disturbing bottom substrates. SSC were measured once per stream during the sampling season, excluding Dog Creek (one of the non-reference streams), which was not sampled due to weather and field difficulties. Instead, Pup Creek (also non-reference) was sampled twice. The laboratory analysis of SSC was adapted 
from standard methods used by Guy (1969) as reported in Galloway et al. 2005 for the USGS. The samples were filtered through pre-dried and pre-weighed Whatman grade 934AH, 24 diameter, 1.2 micrometer pore size filters (Gray et al. 2000, Sigma-Aldrich Supply Co. 2012), and placed on a crucible where and any remaining visible water was evaporated. Samples will then be placed in a furnace for 1 hour at 110 degrees Celsius $(+$ or -2 degrees) (Galloway et al. 2005). The weight was divided by the volume of the original sample that was passed through the filter in order to determine suspended sediment concentration in milligrams/liter. Filters and crucibles were pre-dried for 1 hour at 110 degrees Celsius ( + or -2 degrees) and weighed after cooling to room temperature in a desiccators (Galloway et al. 2005). When applicable, quality assurance procedures recommended by the USGS were followed (USGS 1998).

\section{Embeddedness}

Embeddedness was determined following an adaptation of EPA procedure (Lazorchak et al. 1998). Embeddedness was measured every five meters (once at each transect as well as once between each transect) within the study reach, in flowing areas of the right, middle, and left of the stream. One particle was selected from each location by placing a meter stick at the midpoint, and selecting the particle at the middle of the stick's base. The embeddedness of a ten $\mathrm{cm}$ circle around the particle was estimated using a clearbottomed bucket, which was also used to view the substrate.

Cover et al. (2008) suggest that embeddedness should be examined in riffle/run dominated reaches, and pool substrate composition should be measured in pool/glide dominated reaches. Cover et al. (2008) also looked at percent fine sediments in pools, and 
embeddedness was measured using a point count within a grid in riffle habitats.

However, clearly defined pool and riffle structure are lacking in some watersheds in this study due to effects from historic management. For example, in the Fish Creek watershed, pool structure was at 11 percent of historic norms by 1985 due to effects from logging and roads (USFS 1994). Though restoration efforts have likely improved pool frequency, logging and management has continued in the area to the present time (USFS 2006), indicating that pool structures may still be lacking. Additionally, looking at embeddedness across multiple transects will more thoroughly characterize general reach condition. Therefore, sampling at each transects was selected in this study in order to include multiple habitats within the stream.

\section{Water Quality}

An YSI was used to measure stream temperature, conductivity, and DO in order to further characterize stream variables that could affect macroinvertebrate composition. Readings were taken twice per study reach (at the second and fourth transects) in the middle of the stream. Measurements were averaged to one value for that date and location. Sampling efforts yielded 24 independent samples- four independent samples for each of the six streams (independent samples were derived from a total of 96 measurements: four measurements at each of six streams on four separate occasions). Areas of stagnant water and white water were avoided.

Temperature data was collected during sampling events for all water quality parameters ( $n=24$; no continuous temperature collection probes were used). 
Stream discharge was determined using USEPA standard procedure for measuring cross sectional area and velocity (Lazorchak et al. 1998). The most channelized section of the stream study reach was selected to measure flow, and was selected to avoid large obstacles, eddies, stagnant areas, or excess velocity. Stream velocity was measured using a Flowmate 2000 portable flow meter. Wetted width was measured perpendicular to streamflow. Stream depth and velocity measurements were taken perpendicular to streamflow. Stream depth and velocity measurements were taken perpendicular to the streamflow, at approximately every $1 / 2$ meter, or in 3 to 5 evenly spaced sections of the stream. Velocity measurements were taken at $60 \%$ depth from water surface.

\section{Habitat Assessment}

A rapid habitat assessment was performed once during the study duration at each sample site along a 50 meter stretch in order to give a basic characterization of near and in stream conditions. The assessment utilized an adaptation of the EPA characterizations using survey forms that include rating physical characteristics of the streams and stream banks from 0 to 20 (representing poor to optimal conditions), and scores were then summed and averaged. Characteristics which are rated include instream cover, epifaunal substrate, embeddedness, velocity/depth, channel alteration, sediment deposition, channel flow, bank condition, vegetation protection on banks, and riparian disruption and buffering. Percents of streambed substrates classified as silt, clay, mud, muck, cobble, boulder, and bedrock were also estimated. Riffle frequency, pool substrate characterization, and pool cover were included and rated by dominant habitat type (Lazorchak et al. 1998). 
Canopy cover was measured with a densitometer, in a left bank, stream middle, and right bank alternating fashion from down to upstream. Pebble counts were conducted in a zigzag pattern starting from downstream to upstream, and included 100 measurements. Slope was measured at the stream reach using a clinometer. GPS coordinates were taken.

\section{Macroinvertebrates}

Macroinvertebrates were collected in October and mid-November of 2013 using a Surber sampler with a 0.5 mesh netting over a 0.3 meter squared area of stream substrate per location. Surber samplers are more quantitative than other sampling options, and were therefore used on all stream reaches. Collection occurred at two systematically selected riffles in each study reach. Macroinvertebrate sampling targeted to specific riffle habitat is similar to other studies and protocols, which are also focused on sampling particular instream habitats (Herlihy et al. 2005, Smith et al. 2009, Stark et al. 2001, USEPA 2002). For example, Smith et al. (2009) collected macroinvertebrates from 10 randomly selected mid-channel riffles per sample reach. The New Zealand Macroinvertebrate Working Group recommended sampling macroinvertebrates at "several" random locations within 50 meter stream reach stretches for semi-quantitative sampling, thus ensuring sampling of multiple instream habitats (Stark et al. 2001). In other studies, a transect approach was taken for macroinvertebrate collection For example, Reid et al. (2010) collected macroinvertebrates at 5 equally spaced run habitats along the stream reach (and the channel study reach varied from 40 to $120 \mathrm{~m}$ long, proportional to channel width). For this study, a targeted approach was selected to lessen variability for comparison purposes, 
and to target areas which are likely to be most affected by fine bedded sediments. While clearly developed pool and riffle structure may be lacking in some stream study reaches, the targeted sampling of specific habitats were followed as closely as possible.

Samples from riffles in each study reach were combined into one sample container, producing one sample per study reach and two samples per stream (Barbour et al. 1999, Lazorchak et al. 1998).

Further laboratory analysis of macroinvertebrate samples included sorting of macroinvertebrates from debris such as leaves, needles, sediment, and rocks collected during the sampling process. No subsampling was conducted; the entire sample was processed and individuals were identified to appropriate taxonomic level, usually family. The stonefly families Capniidae and Leuctridae were combined into the group "slenderflies" due to difficulties distinguishing the early instars of these families from each other. Representative organisms of each family were used to validate accurate identification of organisms.

\section{Statistical Analysis}

Water quality data were tested for significant differences using t-tests if assumptions of normality and equal distribution were met. Welch's t-test was used if data were normal but did not have equal variance. Wilcoxon Rank Sum test was used if data were not normally distributed and/or did not display equal variance.

Both turbidity and SSC may be heavily influenced by and correlated with precipitation amount and storm events. During summer sampling, precipitation was 
minimal, and the comparison across sample sites should represent similar baseline levels of sediment concentrations across all sites.

Pearson's correlation coefficient values were determined for sediment-related water quality parameters and percent of the watershed logged within five years upstream of study reaches. Pearson's correlation coefficients were determined using correlation matrix analyses in $\mathrm{R}$.

Macroinvertebrates were analyzed according to established indices, including abundance, taxa richness (to family), functional feeding group percentages, percent contribution of dominant taxa, Shannon and Simpson diversity indices, and EPT and Family Biotic indices (Barbour et al. 1999, Haggarty et al. 2003, Hilsenhoff 1988). Tolerance values for the Family Biotic Index were assigned according Barbour et al. (1996), Hilsenhoff (1988), Merritt and Cummins (2008), and Adams and Vaughan (2007) (Table 1); the FBI considered to be "modified" as not all sources included tolerance values for taxa present in this study and is referred to as MFBI.

Table 1: Family biotic index score and water quality ranking (Mandeville 2002).

\begin{tabular}{|c|c|c|}
\hline Family Biotic Index & Water Quality & Degree of Organic Pollution \\
\hline $0.00-3.75$ & Excellent & Organic pollution unlikely \\
\hline $3.76-4.25$ & Very good & Possible slight organic pollution \\
\hline $4.26-5.00$ & Good & Some organic pollution probable \\
\hline $5.01-5.75$ & Fair & Fairly substantial pollution likely \\
\hline $5.76-6.50$ & Fairly poor & Substantial pollution likely \\
\hline $6.51-7.25$ & Poor & Very substantial pollution likely \\
\hline $7.26-10.00$ & Very poor & Sever organic pollution likely \\
\hline
\end{tabular}


Non-Metric Multidimensional Scaling (NMDS) ordination plots were utilized for determination of patterns or groupings within macroinvertebrate communities or taxa in relation to sampled water quality parameters and habitat assessments. NMDS ordination plots are based on how similar or dissimilar macroinvertebrate community structures are to each other in different samples sites. Envfit was used to examine associations between environmental variables and macroinvertebrate community structure patterns on the NMDS ordination plot. Envfit is based on the strength of the association between environmental variables and macroinvertebrate assemblage structures on the NMDS ordination plot.

Data sources for envfit environmental variables include field data collected as part of this research, data from USGS streamstats (USGS accessed 2013), and data derived from GIS analysis which used USFS spatial data (USFS accessed 2012). USFS spatial data regarding roads and logging units were obtained through Freedom of Information Act (FOIA) requests (USFS accessed 2011). Data collected in the field for this research include: stream temperature, conductivity, TDS, DO, flow, turbidity, embeddedness, pebble counts, canopy cover, slope (at study sites) EPA rapid assessment scores, and semi-qualitative estimates from EPA rapid assessements including: LWD area per reach, and percent of instream components (bedrock/boulders, gravel/sand, silt/clay, and mud/muck). Data derived from streamstats (USGS accessed 2013) include: annual maximum and minimum air temperatures, annual precipitation (both precipitation and air temperature are modeled on streamstats using PRISM), average soil premeability, percent forest cover, watershed size upstream of study sites, elevation at site, and relief. Percent 
forest cover as available on streamstats was derived from the 1992 National Land Cover dataset, and so represents historic forest cover from approximately 22 years ago.

Road density and number of stream crossing were determined using streamstats and ESRI ArcMap 10.1. Streamstats was used to obtain subwatershed delineations and their area above study reaches; ESRI ArcMap 10.1 was used to clip road and stream crossing shapefiles to subwatershed delineations from streamstats. Road segment lengths were summed and then divided by delineated subwatershed area. Stream crossings were counted in delineated subwatersheds. Percent of logging within five years was determined by clipping shapefiles of recent harvest units (cut within five years prior to sample collections) to the subwatershed delineations, summing logging unit areas, and dividing by delineated subwatershed area. GIS shapefiles for units logged within five years, roads, and stream crossings were obtained from Freedom of Information Act requests to the US Forest Service.

Significance tests were performed in R; all indices scores were determined in R except for abundance, EPT, and modified Family Biotic Index (MFBI) scores which were determined using Excel. R scripts are available in the appendix. 


\section{Chapter 3: Results}

\section{Environmental Conditions}

Sediment-related water quality parameters of turbidity, TDS, and SSC had higher values in non-reference streams. Average turbidity was 0.97 NTU in non-reference streams, approximately $1.8 \mathrm{X}$ higher than average turbidity in reference stream; average turbidity in reference streams was 0.54 NTU (Figures 5 and 6; Table 2). Average turbidity in non-reference streams was significantly higher than in reference streams $(p=0.01$ and $n=24)$. Average TDS was higher in non-reference sites $(0.04 \mathrm{mg} / \mathrm{L})$ as compared to reference sites $(0.03 \mathrm{mg} / \mathrm{L})(n=24 ; p=0.10)$ (Figure 6). Suspended sediment concentrations (SSC) were different in reference vs. non-reference streams $(p=0.04)$, and were approximately 2.6 times greater in non-reference streams. Average SSC values were 1.42 and $0.54 \mathrm{mg} / \mathrm{L}$ in non-reference and reference streams, respectively. Correlation between SSC and turbidity was strong, and had an R squared value of $0.92(n=6)$. 
Table 2: Significance test summaries for water quality and environmental parameters: sample size, whether data were logged (yes or no), significance test used, and p-values of water quality parameters and environmental variables.

\begin{tabular}{|l|c|c|c|c|c|}
\hline \multicolumn{1}{|c|}{ Variable } & $n$ & $\begin{array}{c}\text { Logged } \\
\text { data? }\end{array}$ & Test used & $\begin{array}{c}\text { Significant } \\
\text { difference? }\end{array}$ & p-value \\
\hline Turbidity & 24 & No & Welch's & Yes & $\mathbf{0 . 0 1}$ \\
\hline Flow & 24 & Yes & t-test & Yes & $\mathbf{0 . 0 3}$ \\
\hline SSC & 6 & Yes & t-test & Yes & $\mathbf{0 . 0 4}$ \\
\hline TDS & 24 & No & t-test & No (marginal) & $\mathbf{0 . 1 0}$ \\
\hline DO & 24 & Yes & t-test & No & 0.14 \\
\hline EPA score & 6 & No & Wilcoxon & No & 0.16 \\
\hline Conductivity & 24 & Yes & Welch's & No & 0.23 \\
\hline Canopy cover & 6 & No & Wilcoxon & No & 0.70 \\
\hline Temperature & 24 & No & t-test & No & 0.75 \\
\hline Embeddedness & 6 & No & Wilcoxon & No & 0.83 \\
\hline Pebble counts & 6 & No & Wilcoxon & No & 0.83 \\
\hline
\end{tabular}

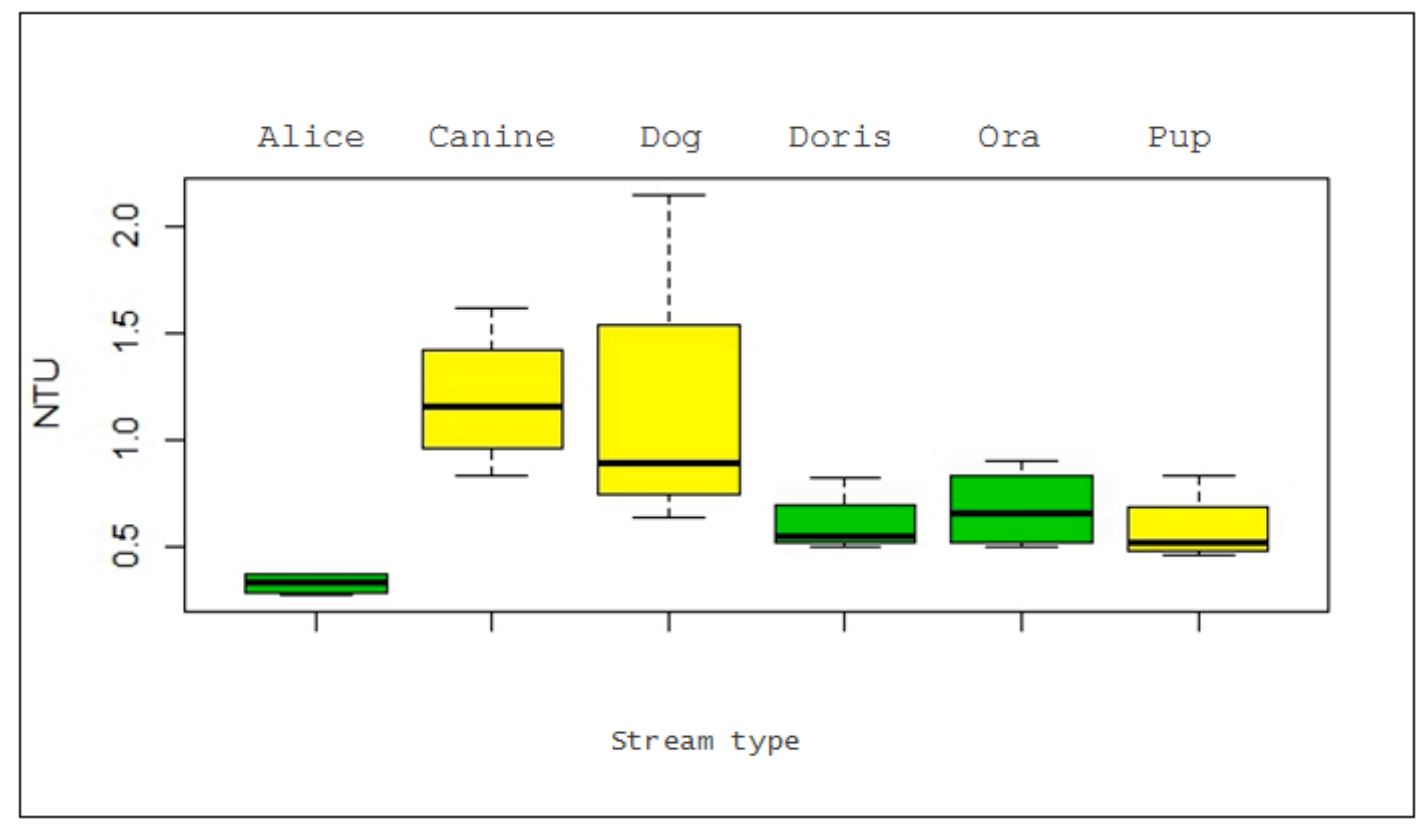

Figure 5: Average turbidity in reference (green) and non-reference (yellow) streams. These six streams were sampled on four sampling occassions, resulting in $n=24$. 


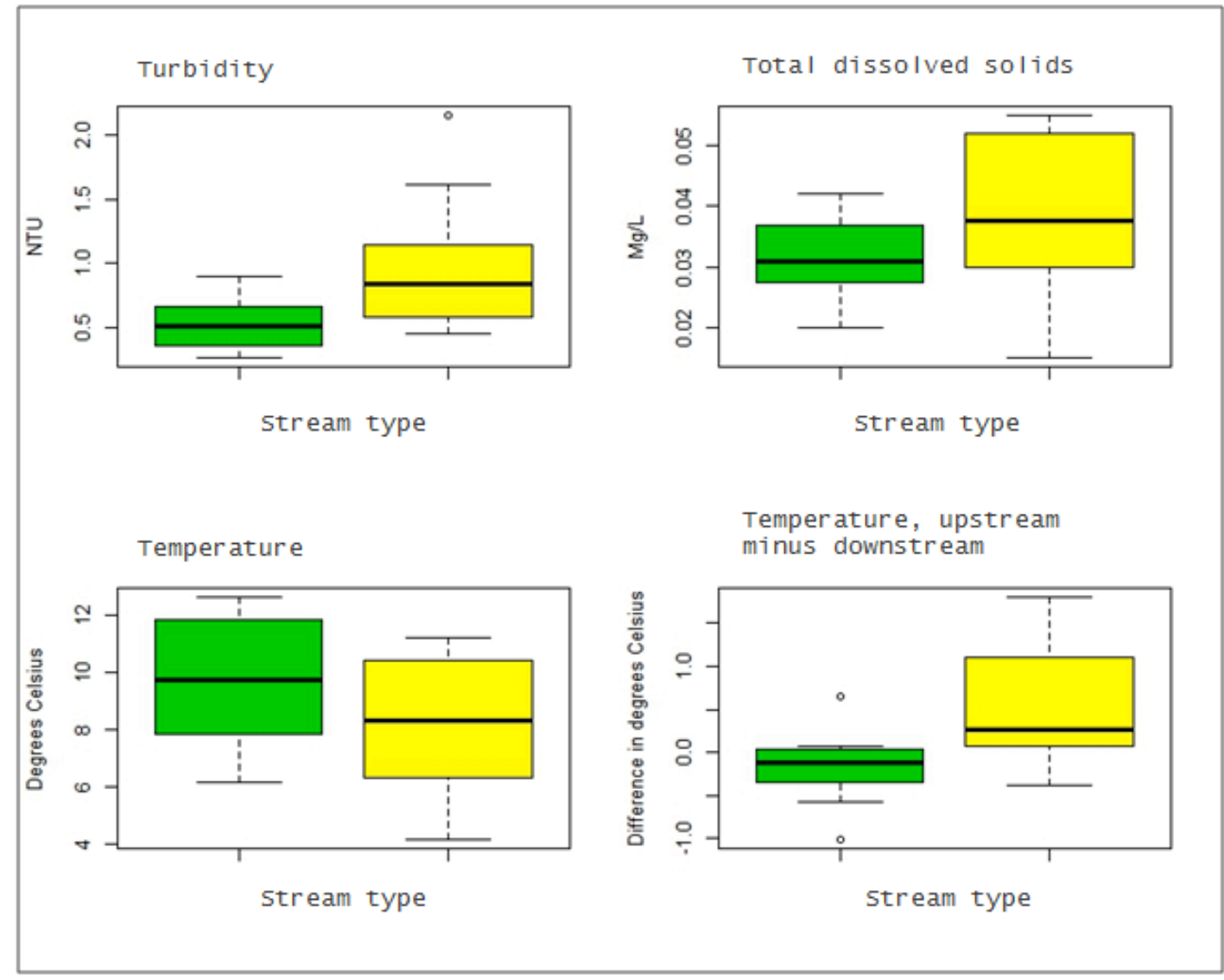

Figure 6: Turbidity is significantly different in reference vs. non-reference streams $(p=0.001 ; n=24)$, but not in upstream vs. downstream of selective harvest units. TDS was different in reference vs. $\operatorname{logged}$ sites $(p=0.10 ; n=24)$, but no significant difference was found in upstream vs. downstream sites. Note greater variability in non-reference turbidity and TDS. Temperature was not significantly different in reference vs. nonreference overall (on left) but was significantly different in downstream and upstream values $(p=0.01 ; n=24)$.

Average flow in reference and non-reference streams was 0.35 and $0.97 \mathrm{cfs}$, respectively, and were approximately $2.75 \mathrm{X}$ higher than flow in reference streams (the difference was significant: $p=0.03)$. Non-reference flows ranged from .24 cfs to $2.07 \mathrm{cfs}$, while reference streams ranged from 0.19 to $0.73 \mathrm{cfs}$. Watershed size upstream of study reaches was approximately $2 \mathrm{X}$ larger in non-reference streams, and averaged 1.52 and 
$0.75 \mathrm{~km}^{2}$. Watershed size upstream of study reaches ranged from 0.19 to 3.29 while reference sites ranged from 0.26 to $1.22 \mathrm{~km}^{2}$ (Table 3).

Reference streams had an average temperature of 9.71 degrees Celsius, while non-reference streams averaged 8.19 degrees Celsius. No significant difference was found in average temperature of reference and non-reference streams overall (Figure 6). No differences were found in reference vs. non-reference streams in conductivity, dissolved oxygen, canopy cover, EPA rapid assessment scores, embeddedness, or pebble counts (Figure 7).

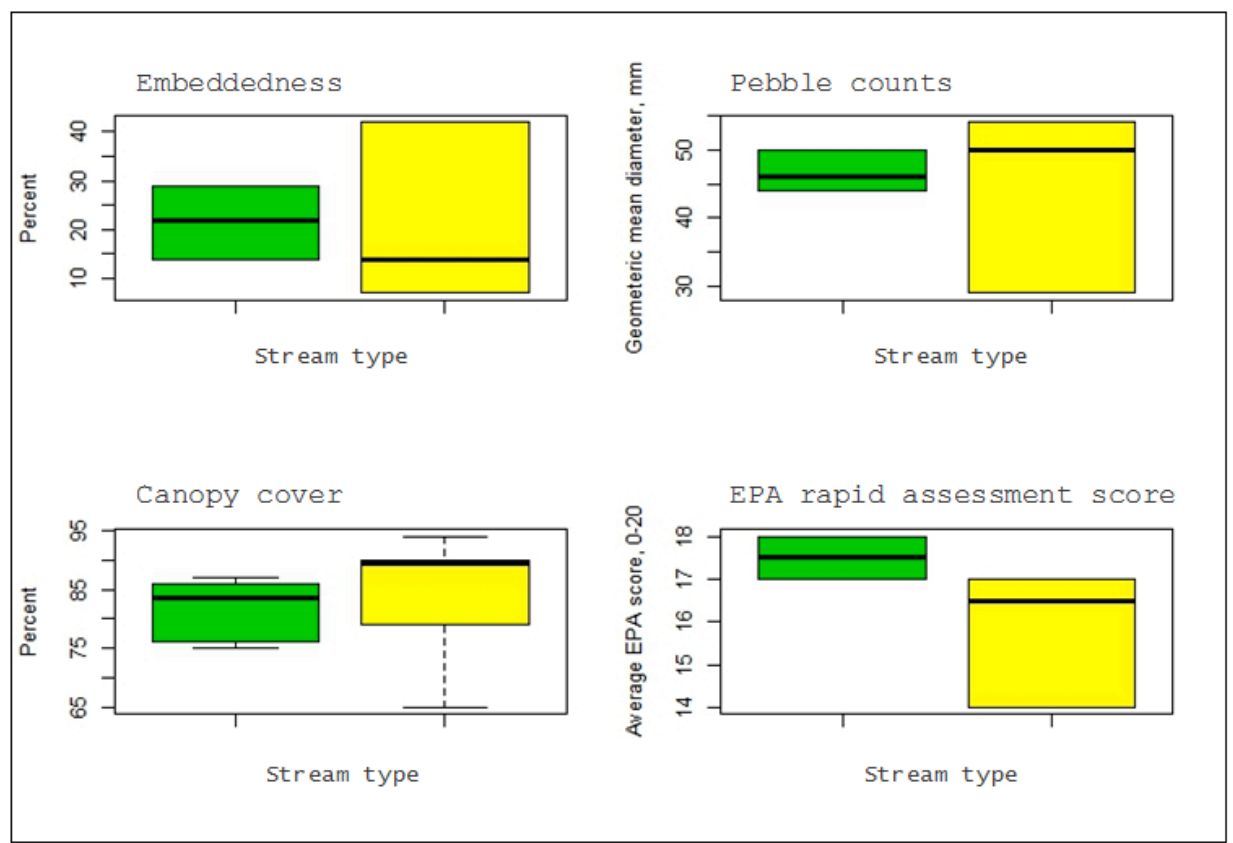

Figure 7: No difference was found in embeddedness, pebble counts, canopy cover, or EPA habitat scores in the reference (green) vs. non-reference (yellow) comparisons nor in upstream to downstream. Non-reference sites show trends of greater variability in these habitat parameters than reference sites. 
Table 3: Summary of all water quality and environmental parameters in reference and non-reference streams.

\begin{tabular}{|c|c|c|c|c|c|c|c|c|c|}
\hline \multirow{2}{*}{ Variable } & \multirow[t]{2}{*}{$n$} & \multicolumn{4}{|c|}{ Average non-reference values } & \multicolumn{4}{|c|}{ Average reference values } \\
\hline & & All & $\begin{array}{c}\text { Canin } \\
\mathrm{e}\end{array}$ & Dog & Pup & All & Alice & Doris & Ora \\
\hline $\begin{array}{l}\text { Turbidity } \\
\text { (NTU) }\end{array}$ & 24 & 0.97 & 1.19 & 1.14 & 0.58 & 0.54 & 0.33 & 0.60 & 0.68 \\
\hline $\begin{array}{c}\text { Conductivity } \\
(\mu \mathrm{S} / \\
\text { centimeters })\end{array}$ & 24 & 59.04 & 66.74 & 66.73 & 43.66 & $\begin{array}{c}48.0 \\
4\end{array}$ & 52.07 & 47.86 & 44.19 \\
\hline $\begin{array}{c}\text { Total } \\
\text { dissolved } \\
\text { solids } \\
\text { (milligrams/ } \\
\text { liter) }\end{array}$ & 24 & 0.04 & 0.04 & 0.04 & 0.03 & 0.03 & 0.04 & 0.03 & 0.03 \\
\hline $\begin{array}{l}\text { Dissolved } \\
\text { oxygen (\%) }\end{array}$ & 24 & 107.76 & 109.1 & 103.4 & 110.8 & 98.2 & 92.7 & 109.3 & 92.7 \\
\hline $\begin{array}{c}\text { Stream temp } \\
\left({ }^{\circ} \mathrm{C}\right)\end{array}$ & 24 & 8.19 & 7.71 & 9.02 & 7.86 & 9.71 & 9.63 & 9.59 & 9.91 \\
\hline $\begin{array}{l}\text { Flow (cubic } \\
\text { feet/second) }\end{array}$ & 24 & 0.97 & 0.24 & 0.86 & 1.81 & 0.35 & 0.58 & 0.28 & 0.20 \\
\hline $\begin{array}{c}\% \\
\text { embeddedness }\end{array}$ & 6 & 21 & 42 & 14 & 7 & 21 & 14 & 22 & 29 \\
\hline $\begin{array}{l}\text { Pebble count } \\
\text { geometric } \\
\text { mean diameter } \\
\text { (millimeters) }\end{array}$ & 6 & 44 & 29 & 50 & 54 & 47 & 44 & 50 & 47 \\
\hline $\begin{array}{l}\text { \% canopy } \\
\text { cover }\end{array}$ & 6 & 85 & 92 & 72 & 90 & 82 & 79 & 87 & 81 \\
\hline $\begin{array}{l}\text { Watershed } \\
\text { size upstream } \\
\text { of study } \\
\text { reaches } \\
\text { (square km) }\end{array}$ & 6 & 1.52 & 0.36 & 1.10 & 3.10 & 0.75 & 1.22 & 0.78 & 0.26 \\
\hline $\begin{array}{l}\text { Elevation at } \\
\text { site (meters) }\end{array}$ & 6 & 814 & 852 & 742 & 847 & 813 & 846 & 776 & 818 \\
\hline $\begin{array}{l}\text { Slope at site } \\
\text { (degrees) }\end{array}$ & 6 & 10 & 12 & 10 & 10 & 14 & 18 & 10 & 13 \\
\hline
\end{tabular}




\begin{tabular}{|c|c|c|c|c|c|c|c|c|c|}
\hline $\begin{array}{c}\text { Relief of } \\
\text { watershed } \\
\text { upstream of } \\
\text { study reaches } \\
\text { (meters) }\end{array}$ & 6 & 407 & 256 & 369 & 594 & 470 & 511 & 471 & 430 \\
\hline $\begin{array}{c}\text { \% forest cover } \\
1992\end{array}$ & 6 & 85 & 89.6 & 83.7 & 81.0 & $\begin{array}{c}100 . \\
0\end{array}$ & 99.9 & 100.0 & 100.0 \\
\hline $\begin{array}{l}\text { \% logged in } \\
\text { watershed } \\
\text { upstream of } \\
\text { study reaches } \\
\text { within } 5 \text { years }\end{array}$ & 6 & 7.42 & 18.14 & 3.92 & 0.21 & 0 & 0 & 0 & 0 \\
\hline $\begin{array}{c}\text { road density } \\
\text { (kilometers/ } \\
\text { square } \\
\text { kilometers) }\end{array}$ & 6 & 4.03 & 3.18 & 5.26 & 3.66 & 0 & 0 & 0 & 0 \\
\hline $\begin{array}{l}\text { Number of } \\
\text { stream } \\
\text { crossings } \\
\text { upstream of } \\
\text { study reaches }\end{array}$ & 6 & 3 & 3 & 3 & 5 & 0 & 0 & 0 & 0 \\
\hline EPA score & 6 & 16 & 14 & 17 & 17 & 18 & 18 & 17 & 18 \\
\hline $\begin{array}{l}\text { Large woody } \\
\text { debris per } \\
\text { reach (square } \\
\text { meters) }\end{array}$ & 6 & 24 & 32 & 12 & 29 & 12 & 16 & 6 & 14 \\
\hline $\begin{array}{c}\text { \% bedrock } \\
\text { boulders } \\
\text { cobble }\end{array}$ & 6 & 64 & 60 & 53 & 80 & 53 & 60 & 50 & 50 \\
\hline$\%$ gravel $/$ sand & 6 & 30 & 30 & 43 & 18 & 37 & 37 & 35 & 40 \\
\hline$\%$ silt/clay & 6 & 6 & 10 & 5 & 3 & 10 & 4 & 15 & 10 \\
\hline$\% \mathrm{mud} / \mathrm{muck}$ & 6 & 10 & 25 & 1 & 3 & 3 & 1 & 4 & 3 \\
\hline $\begin{array}{c}\text { annual } \\
\text { precipitation } \\
\text { (centimeters) }\end{array}$ & 6 & 203 & 203 & 198 & 208 & 226 & 229 & 224 & 226 \\
\hline $\begin{array}{c}\text { Average } \\
\text { maximum air } \\
\text { temperature } \\
\left({ }^{\circ} \mathrm{C}\right)\end{array}$ & 6 & 55.0 & 55.1 & 56.0 & 53.9 & 55.9 & 55.3 & 56.2 & 56.1 \\
\hline
\end{tabular}




\begin{tabular}{|c|c|c|c|c|c|c|c|c|c|}
$\begin{array}{c}\text { Average } \\
\text { minimum air } \\
\text { temperature } \\
\left({ }^{\circ} \mathrm{C}\right)\end{array}$ & 6 & 36.5 & 36.3 & 37.0 & 36.4 & 36.1 & 35.6 & 36.4 & 36.4 \\
\hline $\begin{array}{c}\text { Average soil } \\
\text { permeability } \\
\text { centimeters/ } \\
\text { hour }\end{array}$ & 6 & 6.9 & 7.1 & 6.5 & 7.2 & 7.1 & 7.9 & 6.6 & 7.1 \\
\hline
\end{tabular}

Non-reference streams had greater variability in water quality parameters of turbidity, TDS, SSC, and conductivity, and stream habitat conditions of canopy cover, embeddedness, and pebble counts (Table 4, Figure 7). Streamflow and conductivity were also more variable in non-reference streams, though streamflow and size of watershed upstream of study reaches were strongly correlated, as were conductivity and TDS. EPA rapid habitat assesment scores were slightly more variable in non-reference streams. While water quality and habitat parameters in non-reference streams showed more variability than in reference streams, macroinverterbrate assemblages showed patterns on NMDS ordination suggesting less variability in macroinvertebrate assemblages in nonreference streams- i.e., more tightly grouped and homogenous community structures in non-reference streams compared to those of reference streams. 
Table 4: Mean, median, and range of values for water quality and environmental parameters in non-reference and reference streams. Greater variability is displayed in non-reference streams in turbidity, total dissolved solids (TDS), conductivity, suspended sediment concentrations (SSC), flow, canopy cover, embeddedness, pebble counts, and EPA rapid habitat assessment scores.

\begin{tabular}{|c|c|c|c|c|c|c|}
\hline Parameter & $\begin{array}{l}\text { Mean } \\
\text { values: } \\
\text { non- } \\
\text { reference } \\
\end{array}$ & $\begin{array}{l}\text { Median } \\
\text { values: } \\
\text { non- } \\
\text { reference } \\
\end{array}$ & $\begin{array}{l}\text { Mean } \\
\text { values: } \\
\text { referenc } \\
\text { e } \\
\end{array}$ & $\begin{array}{l}\text { Median } \\
\text { values: } \\
\text { reference }\end{array}$ & $\begin{array}{c}\text { Variability: } \\
\text { Range of } \\
\text { values } \\
\text { non-reference } \\
\text { streams } \\
\end{array}$ & $\begin{array}{l}\text { Variability: } \\
\text { Range of } \\
\text { values in } \\
\text { reference } \\
\text { streams } \\
\end{array}$ \\
\hline $\begin{array}{l}\text { Turbidity } \\
\text { (NTU) }\end{array}$ & 0.97 & 0.97 & 0.54 & 0.55 & $0.5-2.15$ & $0.27-0.82$ \\
\hline $\begin{array}{c}\text { TDS } \\
\text { (milligrams/ } \\
\text { liter) }\end{array}$ & 0.04 & 0.04 & 0.03 & 0.03 & $0.02-0.06$ & $0.02-0.04$ \\
\hline $\begin{array}{l}\text { Conductivity } \\
(\mu \mathrm{S} / \\
\text { centimeter })\end{array}$ & 59.04 & 65.57 & 48.04 & 47.86 & $27.25-84.5$ & $31-58.5$ \\
\hline $\begin{array}{c}\mathrm{SSC} \\
\text { (milligrams/ } \\
\text { liter) } \\
\end{array}$ & 1.42 & 1.13 & 0.54 & .48 & $0.48-3.16$ & $0.24-1.04$ \\
\hline $\begin{array}{l}\text { Flow (cubic } \\
\text { feet/second) }\end{array}$ & 0.97 & 0.86 & 0.35 & 0.28 & $0.17-2.8$ & $0.04-0.95$ \\
\hline $\begin{array}{l}\text { Temperature } \\
\text { (Celsius) }\end{array}$ & 8.19 & 8.06 & 9.71 & 9.74 & $7.38-8.73$ & $9.4-9.96$ \\
\hline $\begin{array}{c}\text { Dissolved } \\
\text { Oxygen }(\%)\end{array}$ & 107.8 & 109.03 & 98.2 & 94.04 & $\begin{array}{c}101.63- \\
111.28 \\
\end{array}$ & $90.65-109.42$ \\
\hline $\begin{array}{c}\text { Canopy cover } \\
(\%) \\
\end{array}$ & 85 & 89.5 & 82 & 83.5 & $65-94$ & $75-87$ \\
\hline $\begin{array}{c}\text { Embeddedness } \\
(\%)\end{array}$ & 21.2 & 13.5 & 20.7 & 22 & $7-42$ & $14-29$ \\
\hline $\begin{array}{l}\text { Pebble counts } \\
\text { (geometric } \\
\text { mean } \\
\text { diameter, } \\
\text { millimeters) }\end{array}$ & 44 & 45 & 47 & 46.5 & $29-42$ & $44-50$ \\
\hline $\begin{array}{c}\text { EPA rapid } \\
\text { habitat scores } \\
\text { (out of } \\
\text { possible } 20 \\
\text { points) }\end{array}$ & 15.8 & 16.5 & 17.5 & 17.5 & $14-17$ & $16-18$ \\
\hline
\end{tabular}

Highest average turbidities occurred in the non-reference streams of Canine and Dog creeks, with a combined average turbidity of 1.16 NTU $(n=8)$. Pup Creek (also nonreference) had an average turbidity of $0.58(n=4)$, the lowest average turbidity of the non- 
reference streams and closer in similarity to reference streams. Alice Creek had the lowest average turbidity of the reference streams: $0.32 \mathrm{NTU}(n=4)$; Doris and Ora creeks (also reference streams) had similar range of average turbidity values, and had a combined average turbidity of $0.64 \mathrm{NTU}(n=8)$. In sediment-related parameters, Pup Creek had average values more similar to those of reference streams for turbidity, TDS, EPT and MFBI. Alice Creek had average values similar to those of non-reference creeks in percentages of both gatherer-collectors and shredders. Pup Creek had the largest average flow values of all streams (1.8 cfs); non-reference streams Canine and Dog creeks had similar average flows to those of reference streams Alice and Doris creeks ( 0.54 and $0.43 \mathrm{cfs}$ average flows, respectively). Ora Creek had lowest average flows $(0.24 \mathrm{cfs})$.

Average precipitation for the seven days prior to spring sampling events was 3.3 $\mathrm{cm}$ for non-reference areas and $1.5 \mathrm{~cm}$ in reference areas. For the two days prior to spring sampling events, precipitation accumulation was $0.5 \mathrm{~cm}$ in non-reference areas and zero $\mathrm{cm}$ in reference areas. There was no average precipitation accumulation for the week prior to early summer sampling events in non-reference and reference areas. Average precipitation accumlation seven days prior to late summer sampling was $1.8 \mathrm{~cm}$ in nonreference streams and $1.3 \mathrm{~cm}$ in reference streams; there was no accumlation two days prior to sampling. Average precipitation accumulation for the seven days prior to fall sampling events was $5.3 \mathrm{~cm}$ in non-reference areas and $4.1 \mathrm{~cm}$ in reference areas. Average precipitation accumulation for two days prior to fall sampling events was $1.1 \mathrm{~cm}$ in non-reference areas and $1.5 \mathrm{~cm}$ in reference areas. 


\section{Upstream vs. downstream}

Non-reference sites had a greater increase in stream temperature from downstream to upstream than did reference sites $(p=0.01)$, and increased an average of 0.6 degrees Celsius while reference streams were 0.2 degrees cooler on average. Canine Creek had the largest average temperature increases from upstream to downstream (an average increase of 0.65 degrees Celsius). Pup Creek had the smallest increase of 0.45 degrees Celsius.

My hypothesis that sediment-related water quality parameters, stream habitat measurements, and macroinvertebrate index scores would indicate increased levels of fine sediments from upstream to downstream in non-reference sites was not supported. No differences were found in magnitude of change from upstream to downstream in reference vs. non-reference streams in: turbidity, conductivity, TDS, DO, flow, EPA rapid assessment scores, embeddedness, or pebble counts. No significant differences were found in magnitude of change from upstream to downstream in non-reference vs. reference streams for any macroinvertebrate functional feeding groups, EPT or MFBI indices, habitat preferences, abundance, diversity or species richness. No differences were found in predators, filterer/collectors, or scraper functional feeding groups in magnitude of change from upstream to downstream in non-reference vs. reference streams. No differences were found between downstream and upstream for Shannon's or Simpsons diversity indices, nor in Shannon entropy or Pielou evenness.

All water quality parameters tested for significant differences between reference and non-reference streams and between magnitude of change in reference vs. non- 
reference streams had an $n=24$ except for SSC, embeddedness, pebble counts, and canopy cover, which were $n=6$.

\section{Macroinvertebrate Assemblages}

Macroinvertebrate Metrics

Macroinvertebrate assemblages in non-reference streams were more abundant in density and taxa number. Average abundance was approximately 3.9 times higher in nonreference streams than in reference streams, a marginally significant difference $(p=0.05$; Table 5). Average total abundance was 1079 individuals in non-reference streams, almost four times as great as abundance in reference streams (Figure 8). Average macroinvertebrate densities were approximately 5994 individuals per square meter in non-reference streams and 1533 individuals per square meter in reference streams. Pup Creek (non-reference) had the highest abundance of all streams, approximately one and a half to two times as great as average abundances of Canine and Dog creeks (nonreference creeks). Alice Creek had the highest abundance of reference creeks, 1.2 times larger than Ora Creek and four times larger than Doris Creek. Total number of individual macroinvertebrates counted was 8100 (7941 keyed to family or most appropriate taxonomic level). 


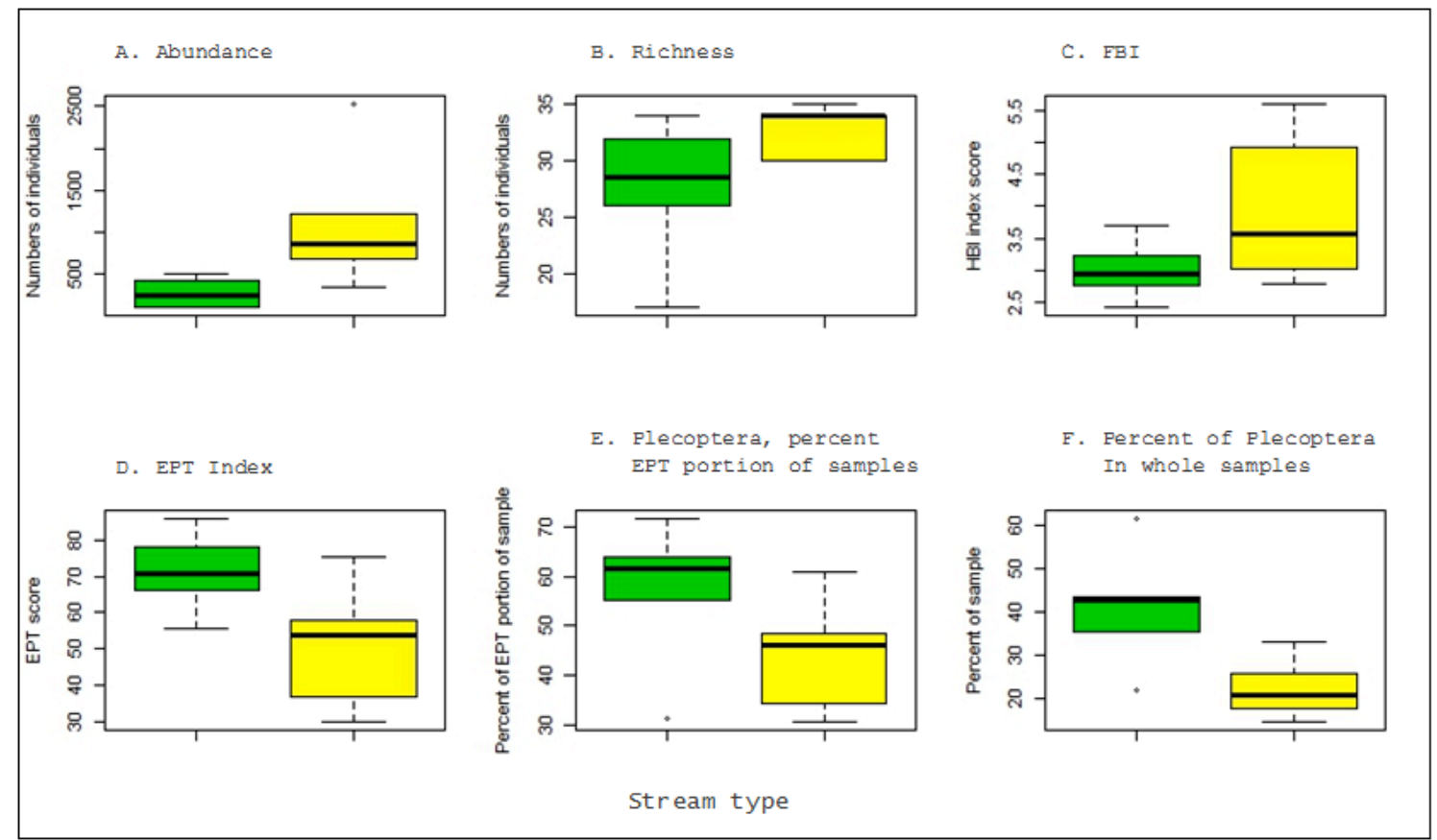

Figure 8: Boxplots depicting abundance, richness, MFBI scores, EPT scores, Plecotpera as a percent of EPT portion of sample, and Plecoptera as a percent of whole samples. Lower MFBI scores suggest better water quality. Green boxplots represent reference streams, yellow represent non-reference streams.

Taxa richness was higher in non-reference streams; this difference was marginally significant $(p=0.05)$. A total of 43 taxa were found across all sites, with an average of 33 taxa in non-reference streams and 28 taxa in reference streams (Figure 8). Average taxa richness in non-reference streams ranged from 32 to 35 families; taxa richness in reference streams ranged from 23 to 31 families. 
Table 5: Selected macroinvertebrate metrics in non-reference and reference streams.

\begin{tabular}{|c|c|c|c|c|c|c|}
\hline 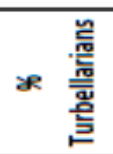 & $\stackrel{2}{\sim}$ & $\stackrel{m}{\sim}$ & $\stackrel{\leftrightarrow}{\forall}$ & 9 & 웅 & $\vec{m}$ \\
\hline × 总 & $\vec{\sim}$ & $\ddot{\sim}$ & 뭉 & $\underset{\infty}{\infty}$ & $\stackrel{\sim}{\sim}$ & $\stackrel{\vec{i}}{ }$ \\
\hline 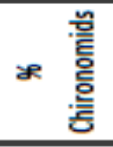 & $\mathscr{\omega}$ & 导 & $\vec{g}$ & 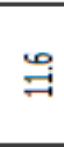 & $\tilde{b}$ & $\stackrel{\sim}{m}$ \\
\hline × & 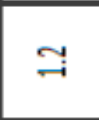 & $\widetilde{ح}$ & $\stackrel{\infty}{\sim}$ & $\stackrel{\infty}{-}$ & 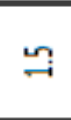 & $\stackrel{\infty}{0}$ \\
\hline 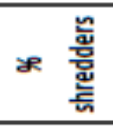 & $\stackrel{\overbrace{}}{\leftrightarrows}$ & $\exists$ & 름 & 글 & $\begin{array}{l}\mathscr{\sigma} \\
\text { 宇 }\end{array}$ & 㐫 \\
\hline 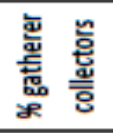 & 동 & 그 & శี & 음 & 光 & 을 \\
\hline 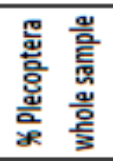 & $\ddot{\sim}$ & $\stackrel{\text { }}{\leftrightarrows}$ & $\stackrel{\infty}{\sim}$ & ల్ల & นี & $\begin{array}{l}\infty \\
\infty \\
\infty\end{array}$ \\
\hline 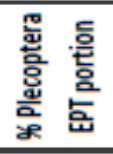 & 芦 & gి & ตై & $\stackrel{m}{g}$ & ํํㅇ & $\ddot{B}$ \\
\hline 氮 & $\stackrel{9}{\overrightarrow{7}}$ & $\stackrel{\sim}{\approx}$ & 守 & $\stackrel{\sim}{\sim}$ & 䓃 & $\stackrel{\infty}{8}$ \\
\hline$\overline{\frac{B}{\Sigma}}$ & $\vec{y}$ & $\underset{\forall}{\dddot{Z}}$ & ભి & 욤 & $\stackrel{2}{2}$ & ฉి \\
\hline 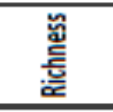 & లి & $\stackrel{m}{m}$ & లี & D & $\approx$ & $\vec{m}$ \\
\hline 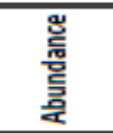 & $\mathscr{8}$ & స్ & ఫ్తి & 票 & ஜㅁㅇ & లి \\
\hline 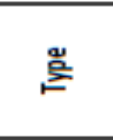 & 畜 营 & 言 总 & 言 & 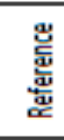 & 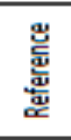 & 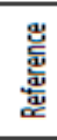 \\
\hline $\begin{array}{l}\text { E్ } \\
\text { 总 }\end{array}$ & 总 & 응 & 을 & 总 & 䜌 & 쫑 \\
\hline
\end{tabular}

The top two dominant taxa in all sites combined were Chironomidae and

Nemouridae, and comprised $18.4 \%$ of samples (Table 6 ). The top two dominant taxa in non-reference streams were Chironomidae and Ostracoda, which comprised 24 percent of 
macroinvertebrate taxa. In reference streams, the top two most dominant taxa were Nemouridae and "slenderflies" (Capniidae and Leuctridae combined). These two taxa comprised 24.1 percent of macroinvertebrate samples in reference streams. Dominant taxa calculations included two taxa which were not common to all streams, i.e., Ostracoda and Gastropoda were present in five of six streams, but had high NMDS values and were significant in the ordination plot. Taxa that occurred in non-reference sites only were: Veronida, Psephenidae, Pelecorhynchidae, and Limnephilidae; taxa that occurred in reference sites only were: Ptilodactylidae, Hydroptilidae, and Corydalidae.

Table 6: Dominant taxa in all study streams, reference streams, and non-reference streams. The Plecoptera families of Capniidae and Leuctridae were combined into the single category of "slenderflies".

\begin{tabular}{|c|c|c|c|c|c|}
\hline $\begin{array}{l}\text { Dominant taxa- } \\
\text { all streams }\end{array}$ & $\%$ & $\begin{array}{l}\text { Reference sites- } \\
\text { dominant taxa }\end{array}$ & $\%$ & $\begin{array}{l}\text { Non-reference- } \\
\text { dominant taxa }\end{array}$ & $\%$ \\
\hline Chironomidae & 10.4 & Peltoperlidae & 12.1 & Chironomidae & 13.6 \\
\hline Nemouridae & 8 & Nemouridae & 12.0 & Ostracoda & 11.4 \\
\hline Peltoperlidae & 7.3 & "slenderflies" & 7.6 & Heptageniidae & 7.2 \\
\hline "slenderflies" & 7.2 & Gastropoda & 7.3 & "slenderflies" & 6.7 \\
\hline Ostracoda & 6.9 & Chironomidae & 7.2 & Rhyacophilidae & 6.7 \\
\hline Gastropoda & 6.4 & Chloroperlidae & 6.5 & Elmidae & 5.6 \\
\hline Heptageniidae & 5.9 & Baetidae & 4.6 & Gastropoda & 5.5 \\
\hline Chloroperlidae & 5.7 & Leptophlebiidae & 4.5 & Chloroperlidae & 4.8 \\
\hline Rhyacophilidae & 5.5 & Heptageniidae & 4.5 & Baetidae & 4.0 \\
\hline Baetidae & 4.3 & Rhyacophilidae & 4.3 & Nemouridae & 4.0 \\
\hline
\end{tabular}

Macroinvertebrate assemblages were dominated by pollution sensitive taxa. Average EPT index scores were 71.2 in reference streams, and approximately $28 \%$ higher than those of non-reference streams. The difference was statistically significant $(p=0.03)$. Plecoptera averaged 22 percent of macroinvertebrates in non-reference samples and 41 
percent of reference samples as a percentage of the entire sample, and was higher in reference samples $(p=0.01)$. Percent plecotera of the EPT portion of reference samples was 44 percent in non-reference stream samples and 58 percent of reference samples, though the difference was statistically marginal $(p=0.10$; Figure 8$)$. Average MFBI index scores were 3.00 and 3.91 in reference and non-reference streams, respectively. However, the difference in MFBI scores was not significant $(p=0.09)$ (Table 5).

Macroinvertebrate groups classified on their functional feeding modes were significantly different between non-reference and reference sites. Collector-gatherers comprised 44 percent of non-reference macroinvertebrate samples, approximately 1.9 times higher than those of reference sites. The difference was statistically significant $(p=0.02)$. Thirty five percent of macroinvertebrates in reference streams were shredders, approximately 2.3 times higher than non-reference streams. The difference was marginally significant ( $p=0.05$; Table 5; Figure 9). Chironomids comprised an average of 13.6 percent of non-reference samples and 7.2 percent of reference samples. Chironomids in Pup Creek comprised $70.5 \%$ of all chironomids in non-reference streams. Chironomids in Alice Creek comprised $71.0 \%$ of all chironomids in reference streams. Dipterans comprised an average of 2.0 percent of non-reference samples and 1.4 percent of reference samples. 


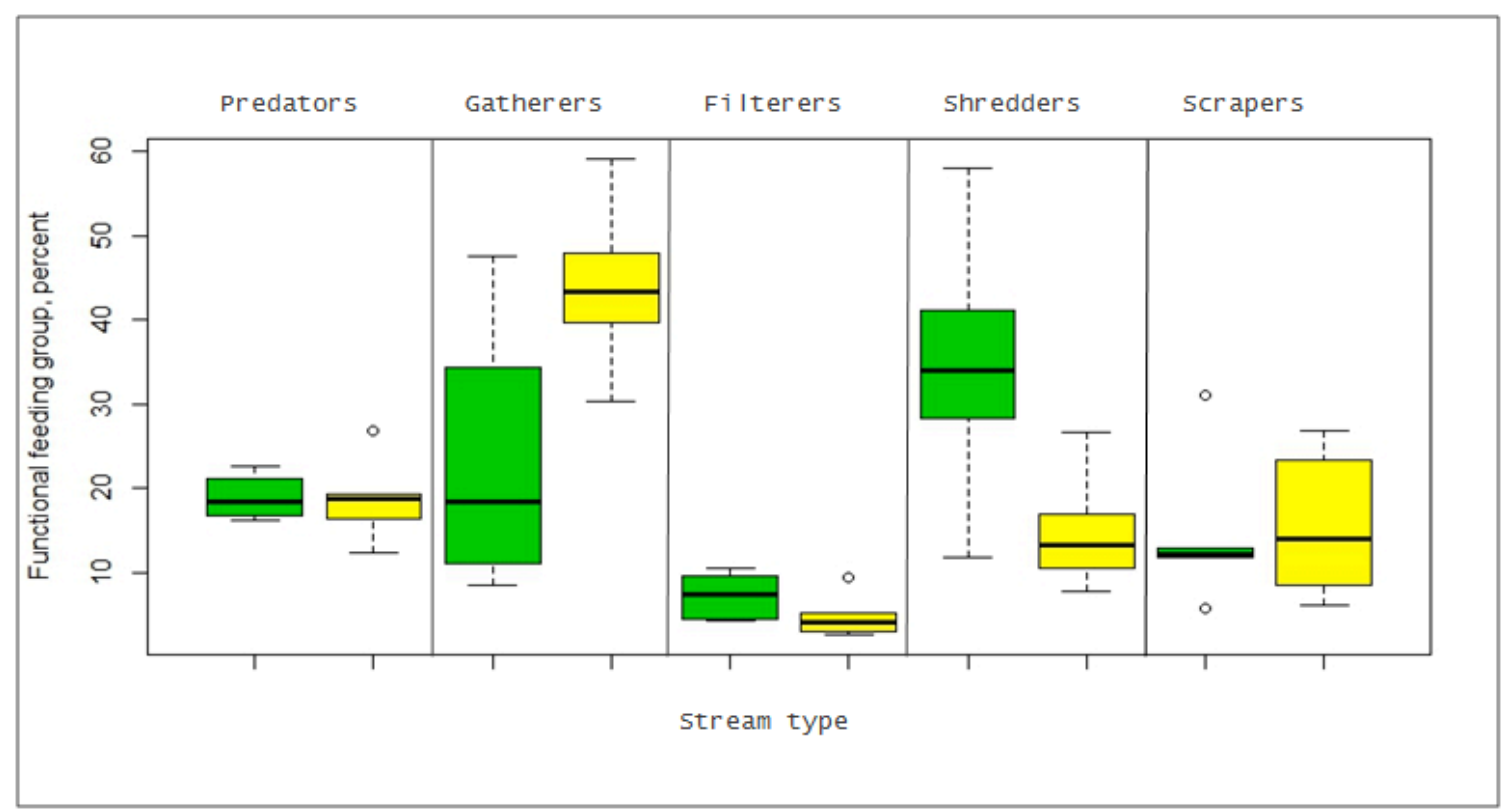

Figure 9: Macroinvertebrate functional feeding groups in reference (green box plots) vs. non-reference (yellow box plots) sites. Percent of gatherer-collectors and shredders were different in reference vs. non-reference streams ( $p$-values $=0.02$ and 0.05 , respectively).

Average values were similar in diversity and evenness indices in non-reference vs. reference sites. No differences were found in reference vs. non reference streams for Shannon's or Simpsons diversity indices, Shannon's entropy, Pielou evenness, predators, filterer/collectors, or scraper functional feeding groups. Average Shannon's diversity scores were 16.07 and 15.45 for non-reference and reference streams, respectively. Simpsons diversity scores were 10.92 and 10.63 for non-reference and reference streams, respectively.

Pup Creek had the lowest average MFBI score (3.26) and highest average EPT score (64) of the non-reference streams, with values closer to those of reference streams than other non-reference streams. Canine Creek, which had the lowest streamflow of the non-reference streams, had the highest MFBI (4.31) and lowest average EPT (42) scores 
of non-reference creeks. Ora Creek had the highest average MFBI score (3.26) and the lowest average EPT score (61) of the reference creeks. Alice and Doris creeks had similar MFBI and EPT scores, with overall averages of $\mathrm{MFBI}=2.9$ and and $\mathrm{EPT}=76$.

Average percentages of gatherer-collectors and shredders in Alice Creek (reference) were more similar to non-reference streams. Gatherer-collectors and shredders had similar average percentages across non-reference streams; Doris and Ora creeks (reference streams) also had similar average percentages to each other. Of the nonreference streams, Canine Creek had the highest percentage of gatherer-collectors (51 percent); Dog and Pup creeks had similar percentages of gatherer-collectors (42 and 39 percent, respectively). Ora Creek had the lowest percent of gatherer-collectors (13 percent), while Alice Creek had the highest (41 percent). Alice Creek had the lowest percentage of shredders (22 percent), and Doris Creek had the highest percentage of shredders (48 percent). Chironomids comprised 42 percent of the gatherer-collector guild in non-reference streams, and 32 percent in reference streams. Gatherer-collectors in Pup Creek comprised 48 percent of gatherer-collectors in all non-reference streams. Gatherercollectors in Alice Creek comprised $72 \%$ of all gatherer-collectors in reference streams.

\section{Macroinvertebrate Assemblage Distributional Patterns}

Reference and non-reference streams had significantly different macroinvertebrate assemblages. NMDS analysis showed that reference sites generally fall along the left half of the NMDS plot, and non-reference sites on the right (Figure 10). ANOSIM tests indicated that the difference was significant $(p=0.007)$. 
Non-reference sites are more tightly grouped together on the ordination plot compared to reference streams, showing that macroinvertebrate assemblages in nonreference streams are more homogenous. Reference streams are further apart relative to each other, and have more dissimilar assemblages.

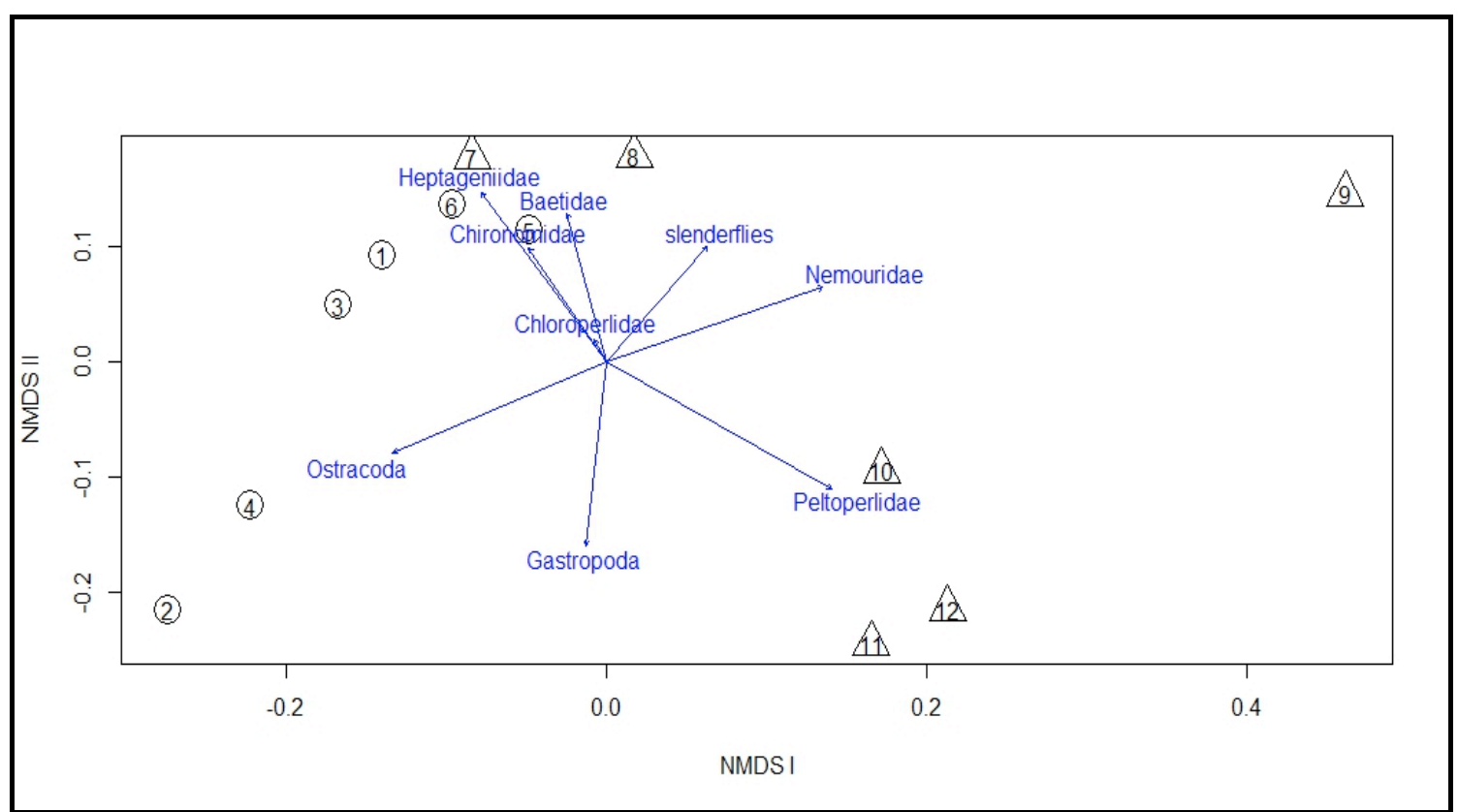

Figure 10: Dominant taxa on the NMDS ordination plot based on macroinvertebrate assemblages in all study sites. Sites 1-6 are non-reference sites and 7-12 are reference sites and are represented by circles and triangles, respectively; downstream locations are represented by odd numbers and upstream sites are represented by even numbers. ANOSIM test showed significant differences in reference vs. non-reference sites $(p=0.007)$.

Taxa strongly associated with macroinvertebrate distributional patterns on the NMDS I axis that were associated with non-reference sites were: Empididae, Philopotmidae, Ephemerellidae, Oligochaeta, Ostracoda, and Veronida (Table 7). Taxa strongly associated with distributional patterns on the NMDS I axis that were associated 
with reference sites were: Simulidae, Ceratopogonidae, Hydroptilidae, Nemouridae, Peltoperlidae, and Brachycentridae. Taxa strongly associated with NMDS II axis were: Dixidae, Gastropoda, Hydracarina, Apataniidae, Baetidae, Goeridae, Heptageniidae, and Psychodidae. Significant and marginally significant taxa largely overlapped with dominant taxa, but were not identical (Figure 11). Some taxa strongly associated with distributional patterns on the NMDS 1 and 2 axes also influenced macroinvertebrate metrics, and trends are clearly visible across study sites in reference and non-reference streams (Figures 12 and 13).

Table 7: NMDS 1 and 2 scores, $R^{2}$ values, and $p$-values for significant macroinvertebrates on NMDS ordination plot. Single asterisks indicate significance; two asterisks indicate lowest $\mathrm{p}$-values.

\begin{tabular}{|l|r|r|r|r|l|}
\hline Vectors & NMDS1 & \multicolumn{1}{|c|}{ NMDS2 } & \multicolumn{1}{|l|}{$\mathrm{R}^{2}$} & \multicolumn{1}{|c|}{$\operatorname{Pr}(>\mathrm{r})$} & \\
\hline Hydroptilidae & 0.928 & -0.373 & 0.863 & 0.004 & $* *$ \\
\hline Peltoperlidae & 0.787 & -0.617 & 0.788 & 0.004 & $* *$ \\
\hline Ephemerellidae & -0.903 & 0.430 & 0.736 & 0.005 & $* *$ \\
\hline Heptageniidae & -0.470 & 0.883 & 0.687 & 0.005 & $* *$ \\
\hline Ceratopogonidae & 0.989 & -0.151 & 0.638 & 0.015 & $*$ \\
\hline Gastropoda & -0.080 & -0.997 & 0.637 & 0.004 & $* *$ \\
\hline Ostracoda & -0.861 & -0.509 & 0.594 & 0.015 & $*$ \\
\hline Hydracarina & -0.116 & -0.993 & 0.594 & 0.015 & $*$ \\
\hline Dixidae & 0.116 & -0.993 & 0.565 & 0.028 & $*$ \\
\hline Oligochaeta & -0.899 & 0.4381 & 0.564 & 0.017 & $*$ \\
\hline Nemouridae & 0.900 & 0.435 & 0.554 & 0.026 & $*$ \\
\hline Simulidae & 0.999 & 0.038 & 0.546 & 0.041 & $*$ \\
\hline Psychodidae & -0.641 & 0.768 & 0.515 & 0.037 & $*$ \\
\hline Apataniidae & 0.176 & -0.984 & 0.500 & 0.050 & $*$ \\
\hline Brachycentriade & 0.717 & -0.698 & 0.496 & 0.047 & $*$ \\
\hline Empididae & -0.998 & 0.069 & 0.494 & 0.046 & $*$ \\
\hline
\end{tabular}



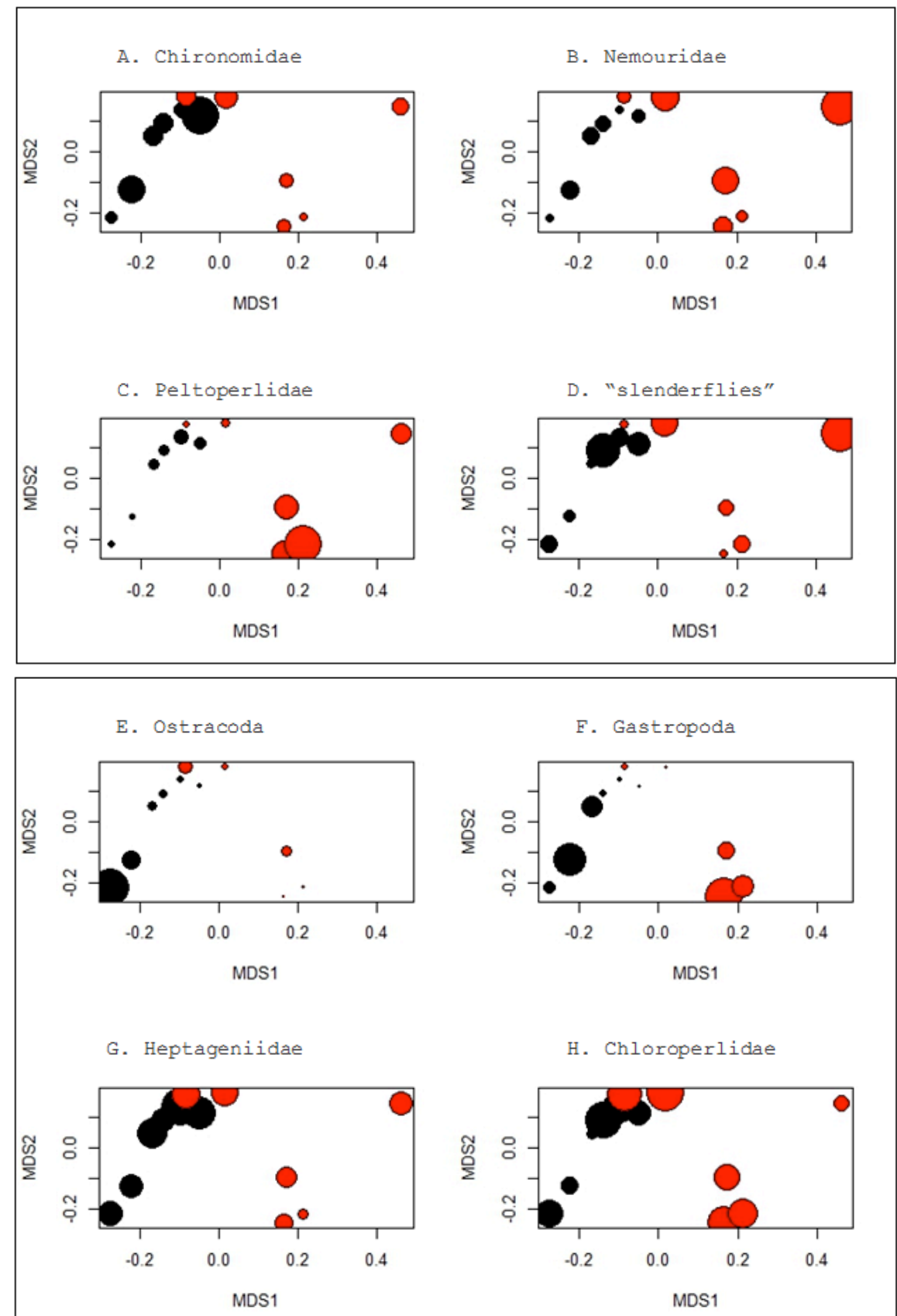

Figure $11(\mathrm{~A}-\mathrm{H})$ : Bubble plots of dominant taxa on NMDS ordination based on macroinvertebrate assemblages at all study sites. Taxa are shown in order of most dominant for the first eight most dominant taxa. Reference streams are depicted in red; non-reference in black. 


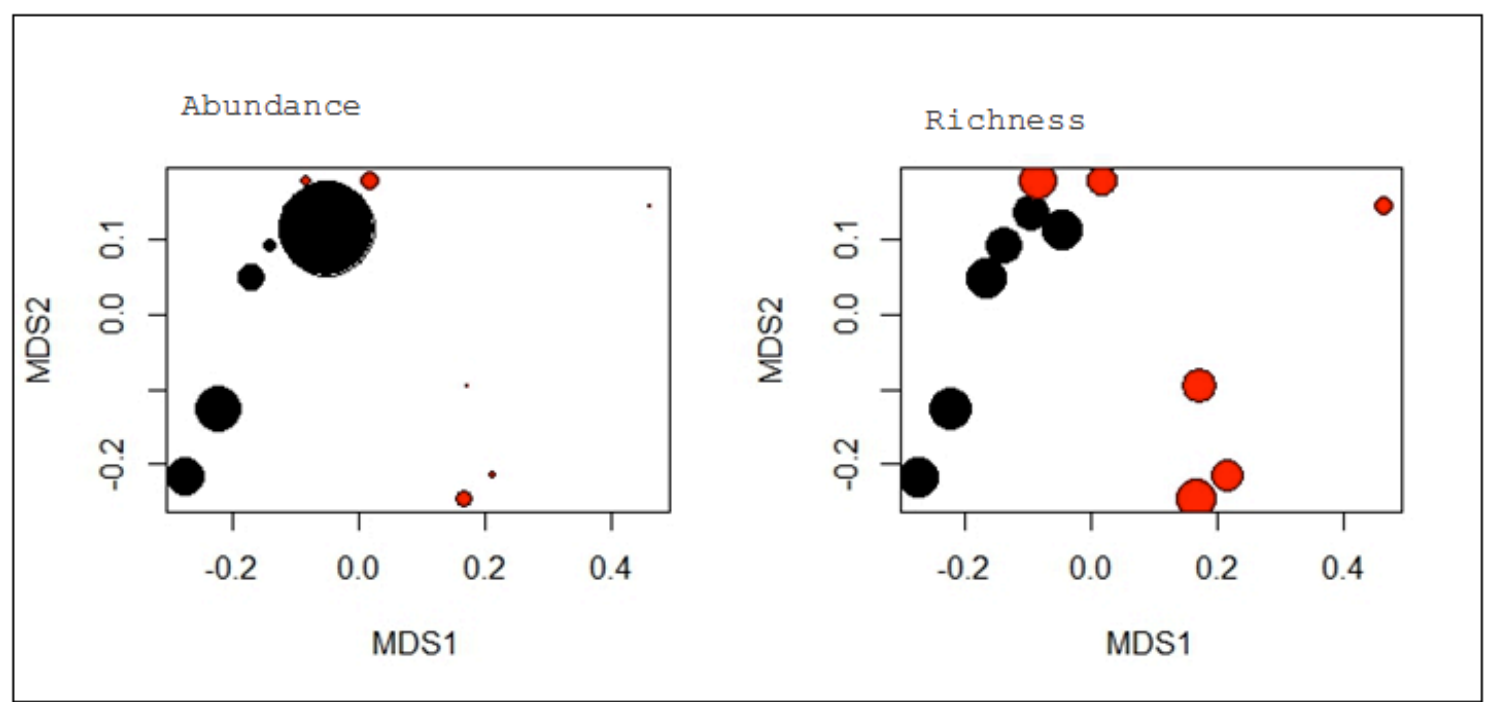

Figure 12: Bubble plots showing abundance on the left and richness on the right. Both are based on NMDS ordination plot of macroinvertebrate community assemblages at each study site. Reference streams are depicted in red circles, non-reference streams in black.

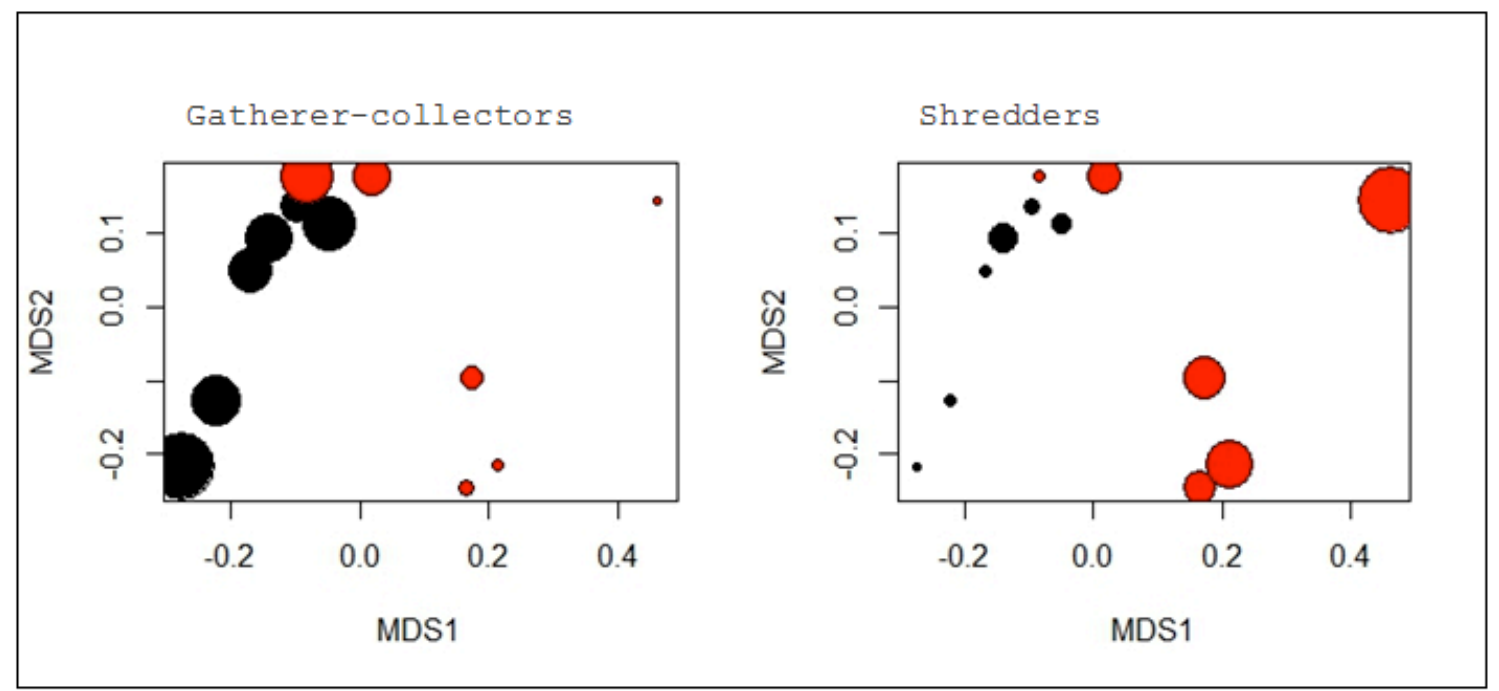

Figure 13: Bubble plots showing functional feeding groups of gatherer/collectors and shredders on NMDS ordination of macroinvertebrate community assemblages at each study site. Reference streams are depicted in red circles, non-reference in black. The percentage of gatherer-collectors was higher in non-reference streams $(p=0.02)$, while the percentage of shredders was higher in reference streams $(p=0.05)$. 


\section{Macroinvertebrate Assemblage Distributional Patterns and Environmental Variables}

Both anthropogenic variables and environmental conditions were associated with overall macroinvertebrate distributional patterns (Table 8). Linear vector fitting analysis indicated that watershed land use and land cover (road density and percent forest cover (from 1992 dataset)), water quality (TDS, conductivity, stream temperature, and percent silt/clay), annual precipitation, and relief of delineated watershed were associated with changes in macroinvertebrate assemblages (Figures 14 and 15). These associations were significant or marginally significant (Table 8). Turbidity, percent of mud/muck, size of watershed upstream of study sites, number of stream crossings, and the presence of adjacent logging within five years ( $\mathrm{Y}$ or $\mathrm{N}$ ) had a very weakly association with macroinvertebrate assemblages. 


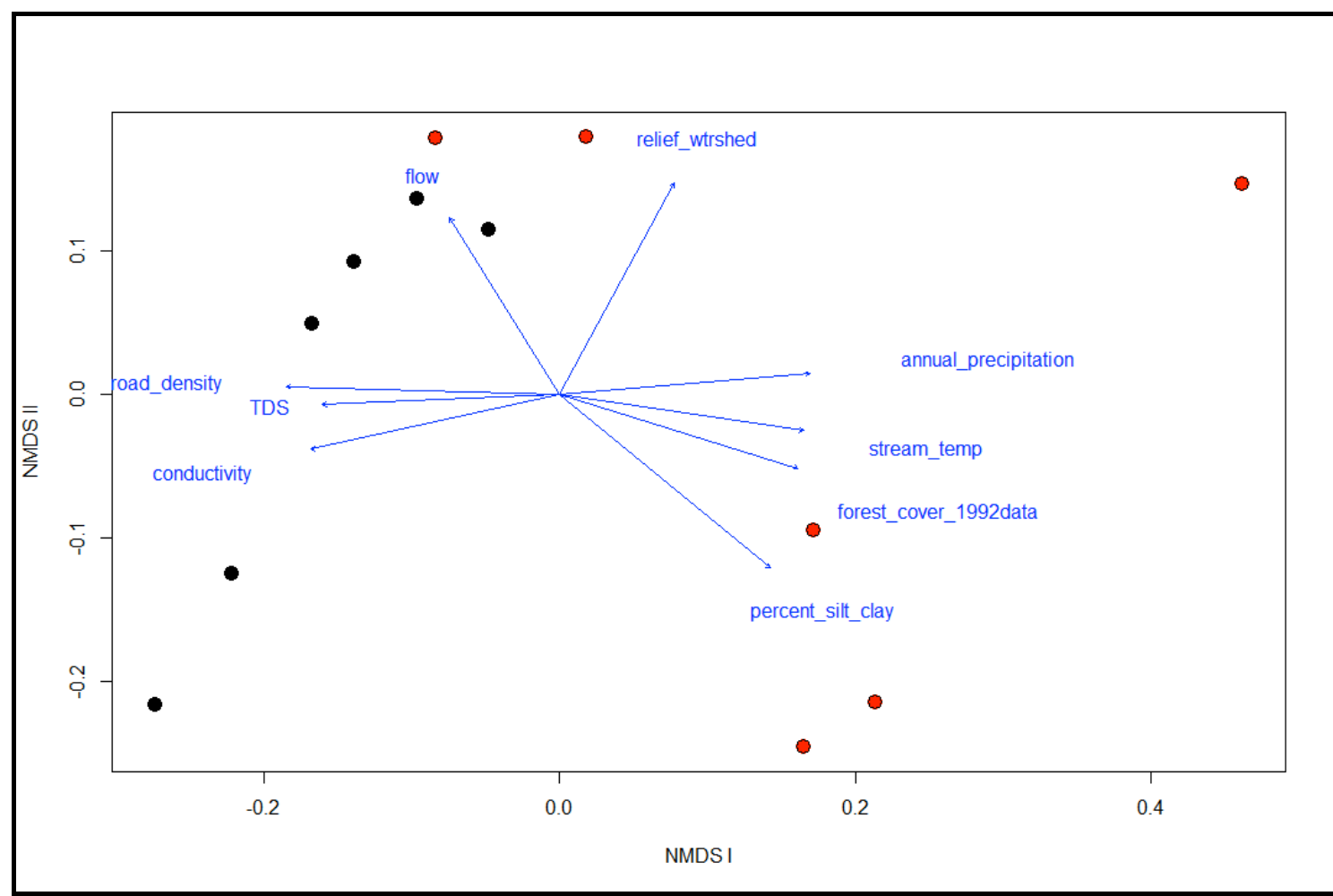

Figure 14: Envfit of environmental variables on the NMDS plot based on dissimilarities of macroinvertebrate community assemblages across all study sites. Environmental variables displayed are significant or marginally significantly associated with macroinverterbate assemblages on NMDS ordination. Black circles represent nonreference sites; red circles represent reference sites. 


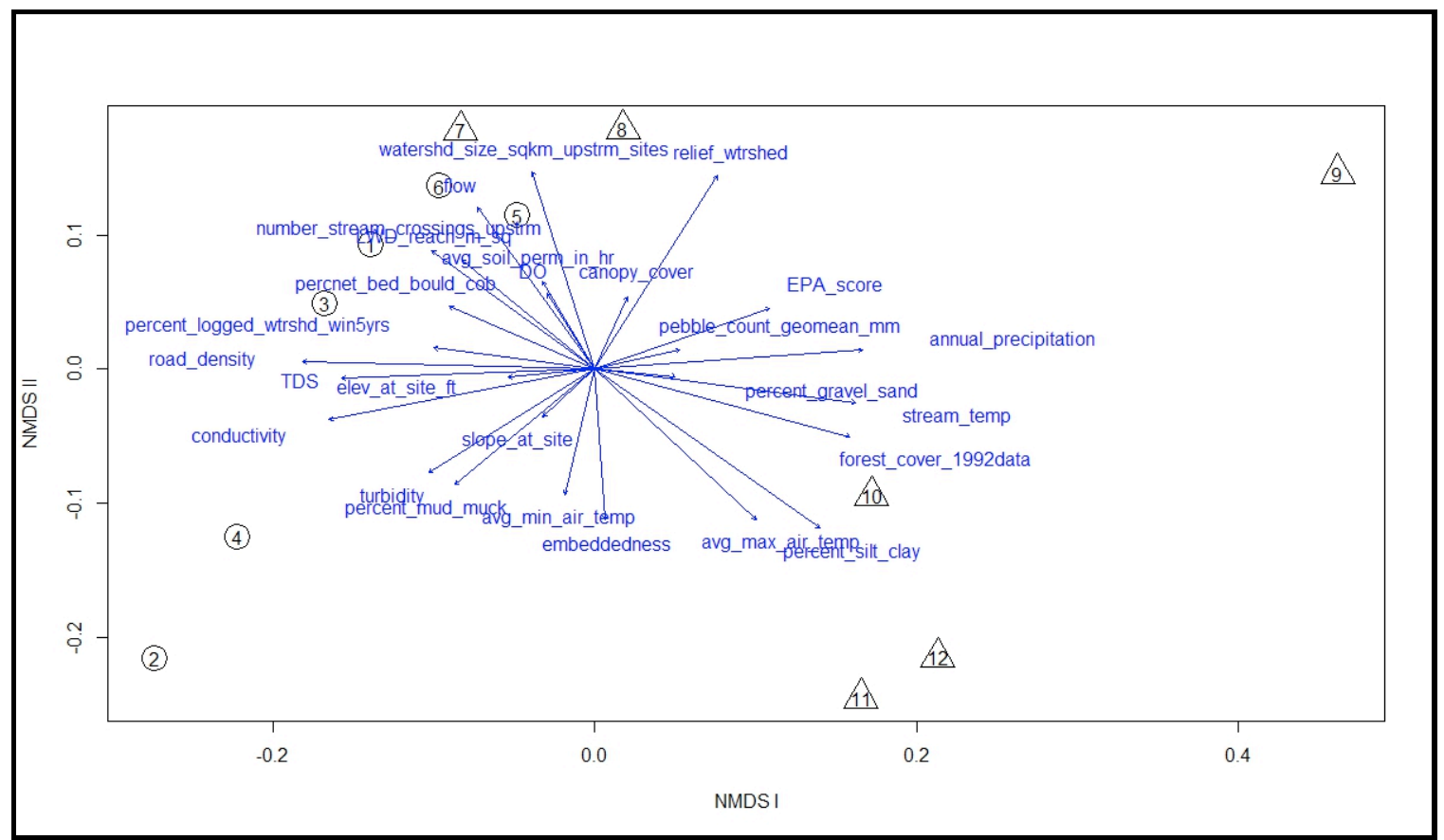

Figure 15: NMDS plot with all environmental variables, regardless of strength of association or signfiicance.

Increased road density was strongly associated with non-reference macroinvertebrate assemblage patterns. Road density had the highest absolute value of all NMDS I scores $(-0.9995)$ as well as a low p-value $(p=0.029)$. Envfit overlay shows a strong association between increased percentage of historic forest cover (1992 dataset) and macroinvertebrate community structure patterns (NMDS I $=0.95$ and $p=0.068)$. The number of stream crossings was moderately associated with macroinvertebrate assemblage patterns $(p=0.21)$, and had NMDS I and II scores of -0.76 and 0.65 , respectively, but also had moderate to strong Pearson's correlation coefficient values with road density (0.71), and was omitted as it nearly overlapped with road density on the ordination plot. Envfit shows a weak association $(p=0.12)$ with the presence of recent 
logging within five years adjacent to study sites (Yes vs. No). No significant difference was found in the ANOSIM test based on the difference between the two groups (Yes or No for presence of adjacent logging within five years).

Environmental conditions which had a strong or moderately strong association with macroinvertebrate community assemblages using envfit on the NMDS plot included: TDS, annual precipitation, conductivity, stream temperature, percent silt/clay, flow, and relief. Increased TDS was strongly associated with reference macroinvertebrate community structure patterns, and had the second-highest NMDS I value of both natural and anthropogenic envfit variables. TDS and conductivity had a Pearson's correlation coefficient of 0.90, as TDS is based on conductivity. Increasing stream temperature was strongly associated with assemblages patterns in reference stream along the NMDS I axis. Silt/clay as a percent of streambed composition had moderate influence on both the NMDS I and II axes, and was approximately opposite to increasing flow, though flow was more influential along the NMDS II axis than on the NMDS I axis. Relief was strongly influential on the NMDS II axis, and was associated with assemblage patterns in both reference and non-reference streams. Turbidity, percent mud/muck, and watershed size upstream of study reach showed moderate associations with macroinvertebrate assemblage patterns, but had relatively high p-values (turbidity and percent mud/muck) or were correlated with other variables (watershed size upstream and flow had a Pearson's correlation coefficient of 0.93 and nearly overlapped; flow had a larger NMDS I value and so watershed size was omitted on NMDS plots). ANOSIM tests did not find 
macroinvertebrate structure patterns to be significantly different based on aspect $(p=0.28)$.

Table 8: NMDS I and 2 scores, $\mathrm{R}^{2}$ values, and $\mathrm{p}$-values for environmental conditions associated with macroinvertebrate assemblage patterns on the NMDS ordination plot. Vectors that were significant are denoted with asterisks $\left(^{*}\right)$; marginally significant vectors are denoted with periods (.).

\begin{tabular}{|l|c|c|c|c|l|}
\hline Vectors & NMDS1 & NMDS2 & $\mathrm{R}^{2}$ & $\operatorname{Pr}(>\mathrm{r})$ & \\
\hline Percent silt and clay & 0.762 & -0.647 & 0.564 & 0.0280 & $*$ \\
\hline Road density & -0.999 & 0.0307 & 0.554 & 0.0310 & $*$ \\
\hline Conductivity & -0.975 & -0.221 & 0.482 & 0.039 & $*$ \\
\hline Annual precipitation & 0.997 & 0.0837 & 0.467 & 0.058 &. \\
\hline Percent forest cover (1992 data) & 0.953 & -0.303 & 0.464 & 0.065 &. \\
\hline Stream temperature & 0.988 & -0.153 & 0.450 & 0.074 &. \\
\hline Relief & 0.466 & 0.885 & 0.448 & 0.069 &. \\
\hline Total dissolved solids & -0.999 & -0.0422 & 0.417 & 0.065 &. \\
\hline
\end{tabular}

Pearson's correlation coefficients were moderate for associations between the percent of the watershed logged upstream of study sites within the past five years, and sediment-related water quality parameters including conductivity, TDS, turbidity, embeddedness, and pebble counts; the correlations were $0.75,0.72,0.76,0.75$, and -0.89 , respectively ( $n=6$; Figure 16). 


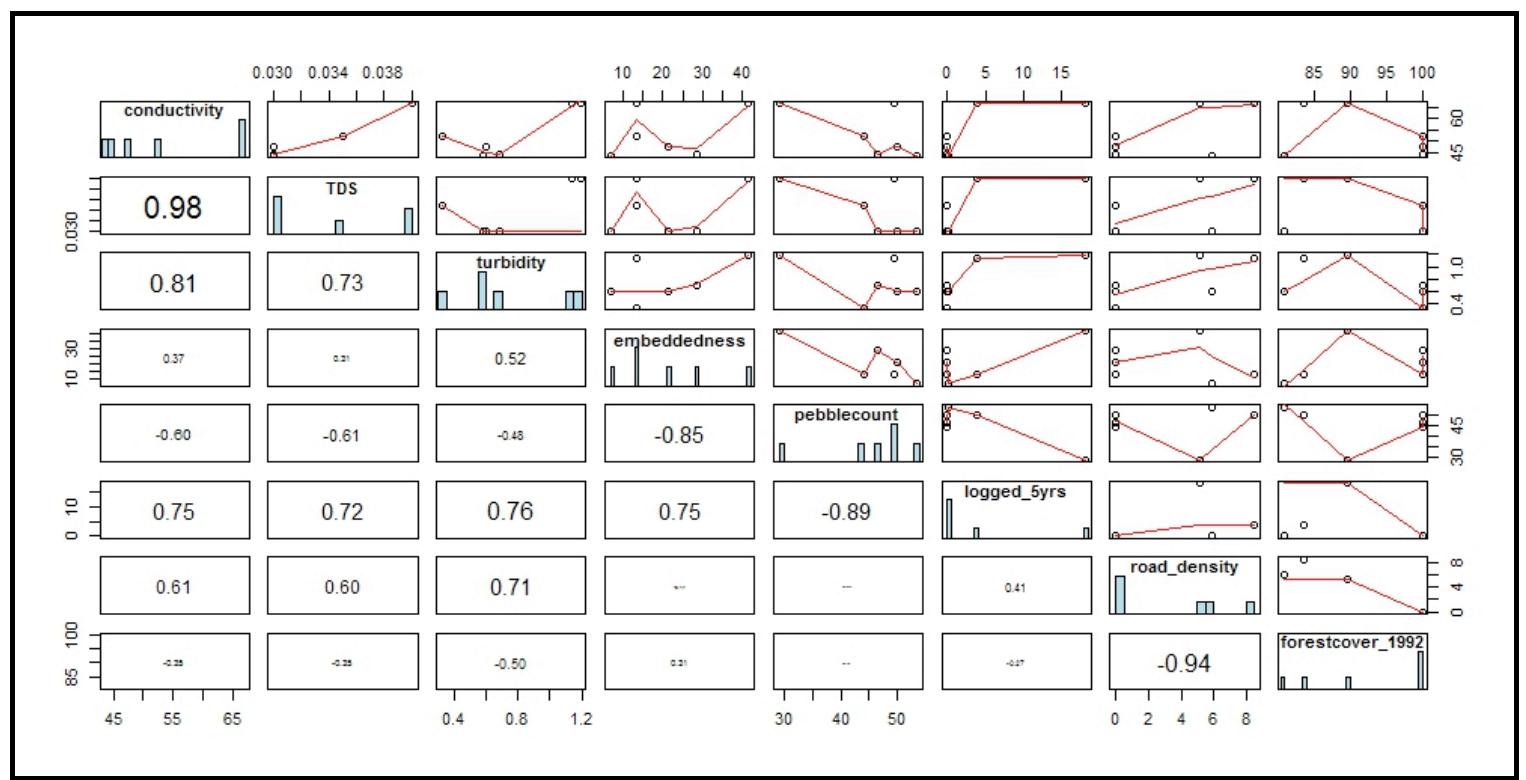

Figure 16: Correlation matrix showing Pearson's correlation coefficients for selected environmental conditions, from top right to bottom left: conductivity, total dissolved solids (TDS), turbidity, embeddedness, pebble count (geometeric mean diameter in millimeters), percent of watershed logged within the last five years (upstream of study reaches), road density, and percent of forest cover (1992 data). The larger the correlation, the larger the phont of the Pearson's correlation value $(n=6)$. 


\section{Chapter 4: Discussion}

\section{Responses of Macroinvertebrate Assemblages to Forest Management}

Associations between land use, fine sediments, and changes in macroinvertebrate metrics and community assemblages were apparent at the reference vs. non-reference scale. It is likely that macroinvertebrates are responding, at least in part, to past logging and high road densities in non-reference streams. Fewer indications were found that recent logging may be affecting water quality and macroinvertebrates. Pearson's correlation coefficients show that the percent of recent logging upstream of study sites was correlated with several measures of fine sediments, suggesting that recent land use may be affecting water quality. However, Pearson's correlation coefficients were based on $n=6$, and so these results should be interpreted with caution due to the small sample size. Macroinvertebrates in downstream non-reference sites clustered together in tow of three non-reference streams, as did those upstream, suggesting possible responses to similar recent environmental stressors. Stream temperatures increased from upstream to downstream in non-reference sites, possibly in response to recent selective logging. Even though temperatures were collected only during sampling events and no continual data were collected in this study, the history of widespread and continuing temperature standard exceedances in the area indicates that further research investigating how selective logging may affect temperature in the Clackamas is warranted. Temperature increases in non-reference streams may be the result of time of day of sampling. However, reference and non-reference streams were sampled in the same standardized fashion at very similar times of day. No other differences in water quality parameters 
were found from upstream to downstream, possibly because water quality was

sufficiently protected, or because signals from land use impacts may be obscured by a several factors, including upstream confounding factors such as past logging and roads, and natural variability.

\section{Macroinvertebrate Metrics: Abundance, Density, and Richness at Reference vs. Non-reference Sites}

Increased macroinvertebrate abundance and density in non-reference streams in this study was likely driven by increased nutrient availability in relation to land use impacts. Increases in secondary production in relation to logging have generally been attributed to greater algal growth in streams in response to increased available light related to larger canopy openings, with some streams experiencing shifts from allochthonous to autochthonous primary production (Richardson and Danehy 2007, Sponseller et al. 2001, Stone and Wallace 1998, Webster et al. 1992). However, silvicultural prescriptions in non-reference sites in my thesis research included upland selective logging and riparian buffers with limited cutting, with non-reference sites having denser average canopy cover compared to reference sites. Thus, it is unlikely that increased algal production in response to increased light is the sole or dominant driver of the greater macroinvertebrate density found in non-reference areas. While most research has focused on macroinvertebrate response to clearcut logging with small or no riparian buffers, some studies have investigated selective logging. For example, Miserendino and Masi (2010) investigated macroinvertebrate response to selective logging with riparian buffers and also found increased total macroinvertebrate density, though the authors did 
not speculate about the possible mechanisms for this increase they noted that at least one of these streams also had increased sediment levels. Additionally, not all research on clearcut logging found increases in macroinvertebrate abundance and density to be linked solely to increased light resources stimulating autochthonous energy production. Some studies found secondary production increases to be at least partly associated with higher stream temperatures, increased nitrogen and phosphorus availability (Sponseller et al. 2001, Webster et al. 1992), and shifts from conifer to deciduous tree species composition (Piccolo and Wipfli 2002, Progar and Moldenke 2009). In deciduous forests at Coweeta, Stone and Wallace (1998) found higher secondary production as well as more rapid processing of leaf litter in streams in logged deciduous forests compared to undisturbed streams. They postulated that this rapid processing of leaves might limit microbial colonization opportunities, thereby increasing nutrient availability and, in turn, the greater secondary production found in disturbed streams. In research on adult aquatic emergent insects, Progar and Moldenke (2009) found that headwater streams in young, previously clearcut conifer forests produced a 1.5 fold higher density and biomass of insects than did streams in mature forests. They attributed this increase to either: labile nutrient availability in deciduous leaf letter, increased insolation providing for increased periphyton production, or a combination of these factors. In the Fish Creek Watershed Analysis, the USFS (1994) suggests that increased summertime stream temperatures in Fish Creek may be affecting nutrient enrichment in Fish Creek, the stream that one of my non-reference creeks (Dog Creek) drains into. Stone and Wallace (1998) found that macroinvertebrate abundance was still elevated 16 years after logging, which supports the 
theory that the increased abundance in non-reference streams in this study may be related to past logging as well as current land use impacts including road density, other roadrelated activities, and recent logging. Sponseller et al. (2001) emphasized the importance of scale in analysis, and noted that macroinvertebrate density was related at the 2000 meter sub-corridor scale to non-forested land. Contrary to results in this study, other studies have found macroinvertebrate abundance, density, and richness to decrease in relation to increasing fine sediments associated with logging (Angradi 1999, Zweig and Rabeni 2001, Waters 1995). It is not clear why increased sediments are associated with decreased secondary production in some studies and not in others. Possibly, increased availability of nutrients and warmer stream temperatures may stimulate secondary productivity, but only up to a threshold, after which detrimental impacts may exceed benefits and sufficient portions of taxa experience negative impacts, resulting in declines in total abundance, density, and richness. If such a threshold exists, it is likely that it would interact with fine sediments, gradient, streamflow, streambed substrates, and other environmental conditions in complex interactions producing great variability and making predictions concerning macroinvertebrate abundance and density challenging.

Natural variability among stream sites, including differences in canopy species and size of stream, may also be related to increased secondary production in this study. For example, greater presence of deciduous vegetation (based on qualitative observations) and larger streamflows in Pup Creek (non-reference) and in Alice Creek (reference) seem to be linked to the particularly heightened macroinvertebrate abundance in those streams. In particular, Pup Creek contained the largest average macroinvertebrate 
abundance and density, and had the highest deciduous tree species presence and largest streamflows. Herlihy et al. (2005) noted increased abundance of Ephemeroptera, particularly Baetis, in association with increasing streamflows. While this study did not identify macroinvertebrate taxa to genera, the increase in Baetis in Herlihy et al. (2005) may be reflected in the increase in Baetidae and other Ephemeroptera families found in this study in relation to faster moving waters. In addition, Piccolo and Wipfli (2002) found that young-growth red alder stands exported far higher densities of macroinvertebrates than did young-growth conifers. Willacker et al. (2009) also found that deciduous streams had greater abundance, taxa richness, diversity, and unique taxa compared to conifer (hemlock) dominated streams. However, the trend of increased abundance and density in non-reference sites continues to be present even if Pup Creek is excluded, suggesting that increased deciduous cover and streamflow are not related to increased macroinvertebrate abundance in other non-reference streams.

Contrary to results in this study, Zhang et al. (2009) and Waters (1995) found decreasing taxa richness in relation to logging, though their studies examined clearcut logging. Zweig and Rabeni (2001) found that taxa richness declined with increasing stream sediment deposits. However, Progar and Moldenke (2009) did not find differences in taxa richness between mature forests and young stands that had been clearcut 10 years before. Taxa richness in non-reference sites in this study may have been related to increased nutrient availability, with instream conditions retaining sufficiently high water quality to maintain the presence of most sensitive species. 


\section{Macroinvertebrate Metrics: EPT and MFBI at Reference vs. Non-reference Sites}

Lower EPT abundance and higher MFBI scores may indicate poorer water quality in relation to anthropogenic impacts in non-reference streams compared to reference streams, though the increase in MFBI scores was only marginally statistically significant. Zweig and Rabeni (2001) and Waters (1995) found EPT abundance and density to be negatively correlated with increased fine sediments. Increased fine sediment levels in non-reference streams may be partly responsible for the lower EPT and higher MFBI scores in non-reference streams, as these streams also contained greater turbidity, TDS, and SSC than reference streams. In research focusing on selective logging, Flaspohler et al. (2002) found a negative correlation with year of logging and EPT abundance, contrary to their original expectations that selective harvest would not produce significant responses. However, decreased EPT abundance was not correlated with fine sediments in their study. Brook char (Salvelinus fontinalis) were negatively correlated with year of selective harvest, and they noted that streams with high EPT scores also had intermediate total macroinvertebrate densities, possibly suggesting a relationship between secondary productivity potential and habitat quality which may exert distinct influences on macroinvertebrate composition and density (Flaspohler et al. 2002). Contrary to the results in this study, Progar and Moldenke (2009) did not find changes in EPT density, richness, or biomass in insects from streams in areas clearcut 10 years before compared to those in mature forests. Gravelle et al. (2009) also found that logging and roads did not seem to affect EPT indices, and that any statistical differences present in their study were small and attributable to natural variability. Barbour et al. (1999) reported that MFBI 
scores increased and EPT density decreased with increasing perturbation. Differences in EPT and MFBI sensitivity to perturbation may vary in relation to a wide range of factors, including natural variation among sites, intensity of logging, and other influences. It may also be possible that the differences found in macroinvertebrate metrics in this study may be related to natural variability or other unknown factors, and that apparent associations with logging and roads are coincidental and partly an artifact of small sample size. Additionally, Hilsenhoff (1988) cautioned that the family-level identification of macroinvertebrates, while useful for rapid assessments, may not provide sufficient precision and may produce erroneous conclusions regarding water quality, and is not meant to replace MFBI indices. Zweig and Rabini (2001) found that identification to the genus level was necessary for accurate determination of MFBI scores, and that family level identification may not be sufficient, especially with Chironomid identification and associated tolerance levels because some Chironomidae genera are sensitive to sediments and other disturbances, while others are very tolerant. However, other studies have found little difference in effectiveness between family and genus level identification for determining stream impairment, including distinctions between non-impaired, moderately impaired, and severely impaired waters (Hewlett 2000). Lenat and Resh (2001) noted that while family and genus/species biotic indices were highly correlated in North Carolina studies, family-level identification can result in erroneous conclusions. Genera tolerance scores may vary widely within a single family, producing intermediate family tolerance scores that may not accurately represent genera or conditions present. Bailey et al. (2001) found that family level identification produced very similar results to genus level 
identification in multivariate analyses, and for areas with relatively low diversity. However, they found that genus/species identification was beneficial for specific indicators of particular pollutants (Bailey et al. 2001). It is possible that MFBI scores may have yielded erroneous conclusions regarding water quality in this study. However, given that EPT indices also suggest poorer water quality, and that Plecoptera and shredders decreased in reference sites while gatherer-collectors increased, it seems likely that the multiple metrics suggesting impaired water quality have accurately detected an actual deviation in conditions compared to reference streams.

Significant and nearly-significant smaller percentages of Plectoptera in both overall sample and in the EPT portion of samples in non-reference streams may also suggest possibly poorer water compared to reference streams. Percent plecoptera has been found to decrease in relation to increasing perturbation (Barbour et al. 1999, Herlihy et al. 2005), including logging (Wood and Armitage 1997). Progar and Moldenke (2009) also found greater Plecoptera biomass in emergent aquatic insects in mature forests vs. those in forests clearcut 10 years previous.

\section{Macroinvertebrate Metrics: Gatherer-collectors at Reference vs. Non-reference Sites}

Higher average percent of gatherer-collectors in non-reference streams in this study may be related to increased sediment levels in non-reference streams. Greater turbidity, TDS, and SSC indicate greater levels of sediment in non-reference streams, though TDS and SSC were only marginally significant, and all sediment-related parameters had relatively low values. Kreutzweiser et al. (2005) found that selective 
logging with $42 \%$ basal area removal produced shifts in macroinvertebrate structure, including increases in several gatherer taxa, which appeared to be linked to an increase in fine organic sediment deposition. It is difficult to compare the intensity of the project Kreutzweiser studied to the logging in this study due to the different metrics provided (i.e., basal area vs. canopy cover and relative density), though both were classified as "moderate" thins. Silvicultural prescriptions in this study included logging in riparian areas, as well as areas of "gaps" and "heavy thins" with as low as $20 \%$ relative density interspersed across the landscape (USFS 2006), which seem to suggest logging prescriptions approximately equal to those found in Kreutzweiser's research. Research at Coweeta regarding clearcut logging, as summarized by Webster et al. (1992), also found that annual instream sediment transport clearly exceeded reference levels after logging, even in catchments where no roads or skid trails were built and no logs were removed. In other catchments containing roads, the majority of instream sediment transport was attributed to road-related activities, with some affected streams continuing to export excess sediments eight years later. In addition, instream sediments were shown to have a higher fraction of organic material compared to undisturbed streams, which may have been associated with increased collector abundance (Webster et al. 1992). Stone and Wallace (1998), also studying streams at Coweeta Experimental Forest, found collectors to have three times greater abundance than undisturbed streams, though this included filterer-collectors as well as gatherer-collectors. The Fish Creek Watershed Analysis (USFS 1994) suggested that decreased retention of coarse organic matter in Fish Creek 
may be shifting macroinvertebrate functional feeding groups from shredders to collectorgatherers.

Chrinomids are part of the gatherer-collector functional feeding group, tend to be associated with higher sediment environments (Wood and Armitage 1997), and are generally considered to be tolerant (Herlihy et al. 2005). Overall, non-reference sites in this study have a larger average percentage of Chironomids, as well as greater turbidity, TDS, and SSC. Canine and Dog creeks had high sediment-related water quality values compared to reference streams and to Pup Creek. However, deciduous canopy composition in some sites and larger stream flow may also have produced increases at certain sites in some taxa classified as gatherer-collectors. For example, it is possible that increased presence of deciduous trees, in addition to being partly responsible for overall abundance in Pup Creek, was partly responsible for the larger percentages of Chironomids and hence of gatherer-collectors in Pup Creek. Pup Creek contained the largest percentages of Chironomids, yet had the lowest average values for turbidity, TDS, SSC, and embeddedness compared to other non-reference streams (differences in turbidity, TDS, and SSC were significant or marginally significant; differences in embeddedness were not significant). When Pup Creek is excluded, the non-reference streams Canine and Dog creeks still contain greater percentages of Chironomids compared to reference streams, though the difference is not as large. Qualitative observations of species compositions in Canine and Dog creeks indicate that conifers dominate riparian areas, with a low abundance of deciduous trees or shrubs. Qualitative observations during laboratory processing of macroinvertebrates suggest that the majority 
of Chironomids collected from the downstream portion of Pup Creek were attached to alder leaves collected in Surber nets during field sampling process. The large increases in Chironomids in Pup Creek may be related to the much larger deciduous tree (alder) presence in the downstream study reach of Pup Creek, while increases in Chironomids in Canine and Dog Creeks may be related to their higher average values of sediment-related water quality parameters. This might also explain the increased presence of Chironomids in Alice Creek (reference stream) compared to other reference creeks, as this creek may have had more deciduous vegetation along study reaches compared to other reference creeks. While riparian vegetation and tree species compositions were not quantitatively measured as part of this study, field observations and pictures indicate a large alder stand is dominant in the riparian area in portions of the downstream study reach of Pup Creek. Similarly, observations of Alice Creek indicate higher presence of deciduous vegetation, and downstream portions of Alice Creek were uniquely challenging to access due to the abundance of low deciduous shrubs. Increased presence of deciduous vegetation may be due to a number of ecosystem processes and disturbances such as larger stream width allowing more light onto forest floor, slope instability, increased canopy complexity and heterogeneity related to old growth structure in reference stands, and past logging in nonreference stands.

In addition to increased vegetation in riparian areas, larger stream size and faster flows in Pup and Alice creeks may be partly responsible for the distinct macroinvertebrate assemblage distributions patterns in these two creeks. Faster stream flow may be associated with increases in overall abundance of certain families of 
Ephemeroptera, and particularly the genus Baetis (Herlihy et al. 2005). Increases in Baetidae were partly responsible for driving overall increases in abundance in this study, as well as the increases in gatherer-collectors. While this study did not identify macroinvertebrates to genus level, it is possible that the increases in Baetis as discussed in Herlihy et al. (2005) may be similarly reflected in this study at the family level. Pup and Alice creeks had the largest streamflows as well as the highest percentages of Baetids and the largest overall macroinvertebrate abundances compared to all other creeks. Part of this increase in abundance was driven by taxa in the Ephemeroptera order, including Baetidae, Ephmerellidae, and Heptageniidae. Herlihy et al. (2005) also found certain Ephemeroptera to increase with increasing streamflow, particularly Baetis and two genera in the Heptageniidae family: Epeorus, and Rithrogena. Angradi (1999) found Baetidae to increase with increasing percentage of fine sediments. Abundances of Baetidae, Ephmerellidae, and Heptageniidae increased in non-reference streams in this study, particularly in Pup Creek, the stream with the largest streamflow. Relative abundances of Ephmerellidae and Heptageniidae also increased in reference vs. nonreference streams. All Ephemeroptera families increased in the reference stream with the largest flow (Alice Creek) compared to other reference streams, also supporting the assertion that certain taxa of Ephemeroptera increase with increasing streamflow. Overall relative abundance of Baetidae in this study was slightly greater in reference than nonreference streams overall, hence, my original hypothesis that Baetids would increase with increasing sediments and in non-reference sites was not supported. 
Chironomids and Baetids partly comprise the gatherer-collector functional feeding group which increased in Pup and Alice creeks, despite the low levels of sediment present in these creeks. Thus, part of the increase in gatherer-collectors in nonreference streams may be due to increased deciduous vegetation and larger streamflow, rather than demonstrating an across-the-board association with increased sediments. Willacker et al. (2009) found that conifer streams had larger percentages of gatherercollectors and lower percentages of shredders and predators compared to deciduous streams, indicating that influences of deciduous vegetation on gatherer-collectors may be variable and complex. Even so, the association between increased fine sediment levels and Chironomids, and collector-gatherers is likely present in the remainder of nonreference streams, i.e., Canine and Dog creeks. Those streams had increased abundance and relative abundance of Chironomids as well as higher turbidity, TDS, and SSC, and EPT and MFBI scores that suggested poorer water quality.

Fine sediments may have complex dynamics not captured in this study due to infrequent, non-continuous sampling, and by the absence of measurements of streambed permeability and percent of sediments at depth in the stream bed. Cover et al. (2008) found that fine sediments may accumulate in the subsurface portions of the stream bed, even if they don't accumulate on the surface, particularly in steeper areas. The authors found that in the steep areas of the Klamath Mountains, accumulation of sediments on stream surfaces was prevented by the large transport capacity of streams, though gravel permeability was nevertheless reduced and abundant silt and sand can still accumulate in these circumstances. It is possible that fine sediments may be accumulating below the 
surface in interstitial spaces and thus impacting macroinvertebrate assemblage compositions and abundance, even though low levels of fine sediments were detected in the water column and on stream bed surfaces. The Fish Creek Watershed Analysis (USFS 1994) noted that stream channels in the Fish Creek Watershed have been altered by debris flow and often been scoured to bedrock, which has led to channel simplification, loss of roughness, loss of habitat, and loss of storage capacity for sediment and nutrients. The Watershed Analysis also notes that water clarity is extremely high, with not a lot of fine sediment accumulation, except apparently during early winter storms because the sediments due to land management and erosion flushed out. Surveys suggest that degradation in the form of downcutting may be occurring in some areas (USFS 1994). Pup Creek and other non-reference streams may be experiencing sediment dynamics that include both scour and as deposition in different areas and in complex patterns. One of the non-reference streams (Dog Creek) drains into Fish Creek. Other non-reference sites in this study do not drain into Fish Creek, but are just over the ridge on the other side of the Fish Creek divide, and are connected to the same road system used above Fish Creek, and likely had similar intensity of past management. It is also possible that gatherercollectors, including Chironomids and Baetids, may also be reacting to other unknown stressors not addressed or measured in this study.

As expected, the percent of shredder functional feeding group taxa was smaller in non-reference sites, and may be related to changes in allochthonous input dynamic in non-reference streams. Shredder assemblages may change in relation to the quality, quantity, timing, and decomposition rates of these inputs (Lecerf and Richardson 2010). 
Overall average and median canopy cover is slightly higher in non-reference streams in this study (the difference is insignificant), which would seem to suggest that nonreference sites might be more likely to have higher shredder abundance than reference sites, the opposite of what was found. The mechanism for decreased shredder abundance in non-reference streams in this study is not entirely clear, though it may be a combination of factors. For example, taxa within the shredder functional feeding group are typically sensitive, and therefore may respond negatively to land use impacts (Barbour et al. 1999). Even though canopy cover in non-reference sites was slightly greater, changes to the amount, timing, or quality of allochthonous inputs could be affecting shredder abundance. Additionally, increased algal growth due to increased nutrient availability related to increases in organic fine sediments and more light availability may be taking place in some areas, particularly in one non-reference stream. Dog Creek (non-reference) had the lowest canopy cover of all sites, and some of the lowest shredder abundances. In their summary of research at Coweeta Experimental Forest, Webster et al. (1992) noted that shredder abundance decreased in relation to increasing autochthonous primary production in streams, as did other research (Barbour et al. 1999, Progar and Moldenke 2009, and Zhang et al. 2009). However, Lecerf and Richardson (2010) found that shredder abundance and richness decreased in streams with upland clearcutting regardless of riparian buffer size or treatment, but no changes were found in shredder abundance or richness in selectively logged reaches. The authors found increased total dissolved nitrogen in selectively logged reaches (which they believed to be related to possible increased sediment inputs), and decreased leaf decomposition rates 
in streams with both clearcut and selectively logged upland areas, regardless of riparian buffer widths or treatments. Lower decomposition rates in thinned reaches may have been influenced by increased fine sediments smothering leaf packs and retarding breakdown processes. Decay rates of organic inputs are complex and depend on type of leaf/needle litter, fungal presence and interactions, and fine sediment levels (which may encase/coat leaves and slow decomposition) (Lecerf and Richardson 2010). Haggarty et al. (2003) also speculated that changes in shredder abundance from logging may be responses to alteration of detritus supplies. Part of their rationale was that no changes were found in scraper abundances, which would be expected if algal growth was increased. No difference was found in this study in the percent of scrapers in nonreference vs. reference sites, further supporting my speculation that algal growth is not the sole or primary driver of shifts in macroinvertebrate community structure in nonreference streams. However, these processes are not well understood, and much of the research has focused on deciduous rather than coniferous forests. It is not clear if or how disruption to decomposition processes might affect shredder assemblages in some streams, though it would seem that possible alterations to processes associated with their base food resources might also affect them.

\section{Macroinvertebrate Metrics: Dipterans, Oligochaetes, and Turbellarians at Reference vs. Non-reference sites}

As expected, Dipteran and Oligochaete relative abundances increased in nonreference streams. Turbellarians also had greater relative abundance in non-reference streams. Greater relative abundance of these taxa in non-reference streams is likely a 
response to land use impacts, including increased fine sediments. Cover et al. (2008) found increases in Turbellaria and Oligochaetes to be associated with increased fine sediments, though the relationships were not always significant depending on the method of analysis and scale. Reid et al. (2010), Waters (1995), and Wood and Armitage (1997) found Oligochaetes to increase in association with increases in fine sediments, and Zweig and Rabeni (2001) found Oligochaetes to be tolerant of sediments. Cover et al. (2008) noted that most Oligochaetes are obligate burrowers in fine sediment. Progar and Moldenke (2009) found dipterans were the primary constituent driving the increased macroinvertebrate abundance found in streams flowing through forests that were clearcut 10 years prior, and that Dipteran density and biomass were higher in previously clearcut forests. Many Dipteran families were noted to be indicators of open canopies (Progar and Moldenke 2009). Barbour et al. (1999) also found Dipteran to increase with increasing perturbation, and Reid et al. (2010) found Dipteran density to increase with increasing riparian harvest. In this study, while overall average abundance of Dipterans was greater in non-reference streams, some Dipteran families had higher abundances in reference sites, including Ceratopogonidae, Dixidae, and Simulidae, possibly due to increased sensitivity to disturbance and/or fine sediments. Other Dipteran taxa were more abundant in non-reference streams, including Empididae, Pelecorhynchidae, and Psychodidae.

\section{Macroinvertebrate Assemblage Distributional Patterns and Environmental Variables:}

As expected, macroinvertebrate assemblage distributional patterns showed dissimilarity between reference and non-reference sites on NMDS ordination plots, with 
significant associations including both anthropogenic activities and environmental conditions. Strong associations found in this study between macroinvertebrate community assemablages in envfit with roads and past harvest suggest that these land use activities may be related to macroinvertebrate assemblage dissimilarities between reference and non-reference sites. In addition, higher variability in water quality data and stream habitat conditions as well as greater similarity among macroinvertebrate assemblages in non-reference streams compared to reference streams suggest possible chronic and long-term impacts in relation to land management activities, and aligns with literature findings regarding ecosystem responses to anthropogenic stressors. Several studies have found ongoing indications of effects from past logging, even many years later (Lecerf and Richardson 2010, Flaspohler et al. 2002, Stone and Wallace 1998, Zhang et al. 2009). Angrandi (1999) noted that even in watersheds that have not experienced recent timber harvest, chronic issues with elevated levels of increased fine sediments may exist from roads and past land use activities. Differences in sedimentrelated water quality parameters such as turbidity, SSC, and TDS, as well as differences in macroinvertebrate trends suggest higher levels of in-stream fine sediments in nonreference streams, possibly in relation to land management activities.

Road density is the primary significant parameter associated with macroinvertebrate assemblage distribution patterns along the NMDS I axis in nonreference streams, suggesting that road-related impacts may have a stronger influence on macroinvertebrate assemblages than other environmental variables, including past logging. While it is beyond the scope of this study to disentangle road-related water 
quality impacts from logging impacts, these results are supported by numerous studies which have documented that roads may be the primary factor affecting certain water quality parameters in managed watersheds (Croke and Hairsine 2006, Wemple et al. 1996, Wemple et al. 2000). Road densities in all non-reference subwatersheds in this study exceed the NOAA threshold of 1.24 kilometers/square kilometers road density for "properly functioning" watersheds ( i.e., watersheds with greater than 1.24 kilometers/square kilometers are not considered to be properly functioning) (NOAA 1996). Existing road densities in non-reference subwatersheds in this study ranged from 1.7 kilometers/square kilometers to 3.57 kilometers/square kilometers, and existing road densities in drainages delineated upstream of study reaches ranged from 3.06 to 5.76 kilometers/square kilometers (this includes temporary roads used in this logging project, as well as a small percentage of skid trails). In addition, road densities in most of the subwatersheds, as well as in all delineated drainages upstream of study sites, exceed the 2.5 kilometers/square kilometers densities above which Cederholm et al. (1980) found that road densities generated sediments at 2.6 to 4.3 times the natural rate. Given the high road densities found in non-reference streams and the findings provided in the literature concerning road-related contributions to instream fine sediment inputs, it is likely that road-related impacts may be at least partly responsible for the dissimilarities in macroinvertebrate patterns and water quality parameters of turbidity, TDS, and SSC in reference vs. non-reference streams, though differences in TDS and SSC was only marginally significant. In addition, TDS and conductivity were also associated with macroinvertebrate assemblage distribution patterns, showing longitudinal patterns similar 
to those of road density and associated with influence on non-reference sites and further suggesting that increased levels of sediments in non-reference sites may be most strongly associated with road density and/or road/related activities.

Envfit overlay showed a strong association between increased percentage of historic forest cover (1992 dataset) and macroinvertebrate community structure patterns in this study, indicating that extensive logging that has taken place historically throughout the non-reference watersheds continues to impact stream biota (Figure 17). Similarly, one study found that the single strongest predictor of biodiversity in streams was land cover patterns from 1950 at the catchment scale (Sponseller et al. 2001). Land cover patterns from 1950 were stronger predictors of current biodiversity than land cover patterns from 1970 to 1990 . Zhang et al (2009) found at the catchment scale that macroinvertebrate assemblages continued to be affected by logging up to 40 years later. The authors also noted that "surface runoff, water quality, flow regime, channel morphologic habitat and fluvial ecosystem processes" may all be affected by previous logging disturbance. Responses to logging may show complex temporal patterns, and may take several years to manifest (Flaspohler et al. 2002, Zhang et al. 2009). Flaspohler et al. (2002) noted that effects from selective logging in riparian areas persisted for approximately 30 years. Streams may experience long-term and chronic fine sediment impacts related to past logging (Angradi 1999) which may be occurring in non-reference watersheds in this study. Zhang et al. (2009) found courser substrates in streams flowing through mature forests as compared to young forests. Past logging has been extensive in non-reference areas, and may also be contributing to elevated stream sediments in this study. For 
example, the Fish Creek Watershed, which one of the non-reference creeks drains into, has been severely negatively impacted by past logging. The Fish Creek Watershed Analysis (USFS 1994) noted that "[t]imber harvest and road construction have increased rates of mass wasting in areas selected for survey in the watershed. Measured as the number of events over a 43 year period, rates of landslides originating from harvested areas and road locations are approximately three times natural levels". They also noted that debris slides were approximately two times more common than debris flows in managed areas, whereas in unmanaged areas debris flows were three times more common than debris slides.

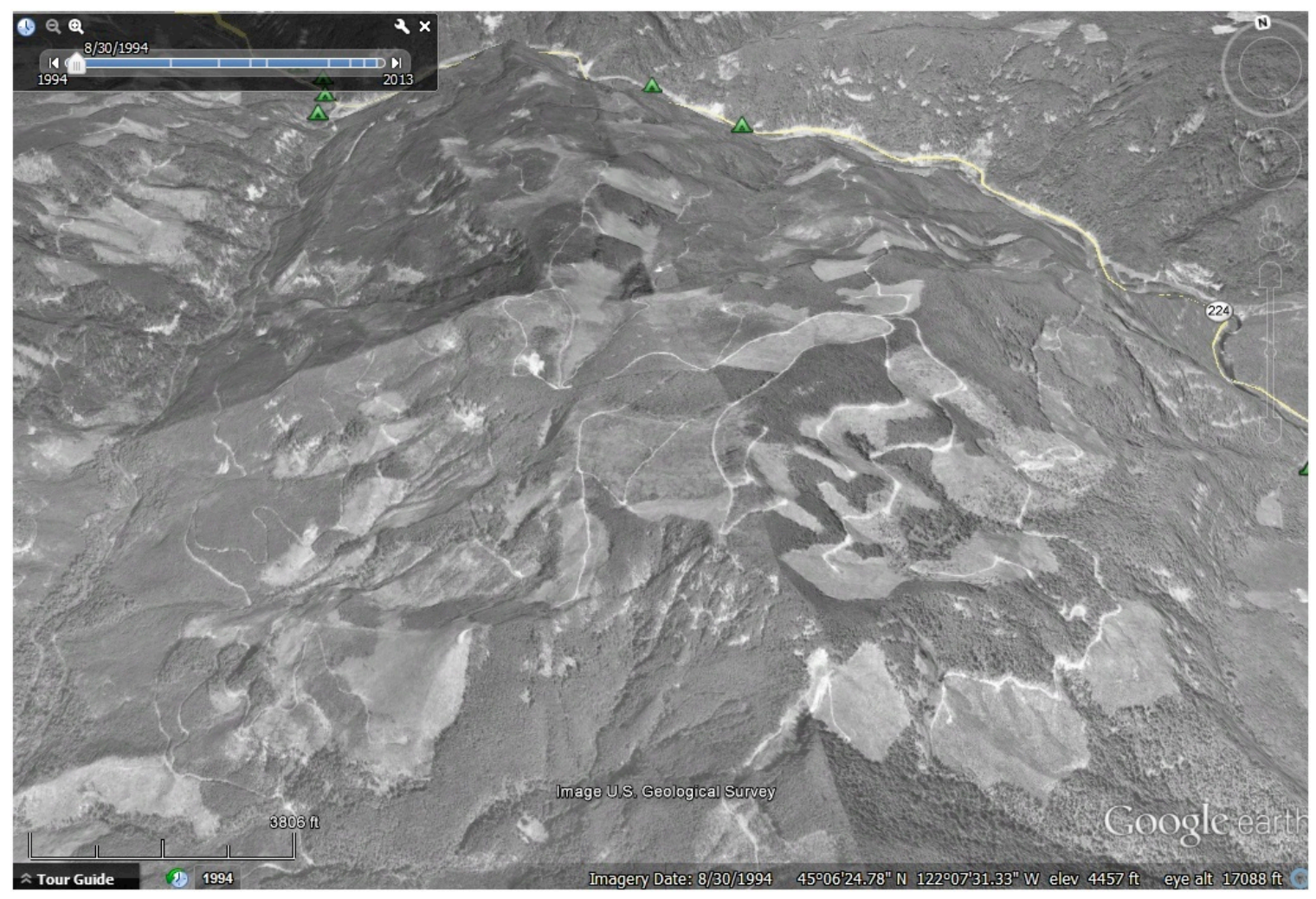

Figure 17: Roads and past logging in the Fish Creek Divide, circa 1994. 
Non-reference streams showed an increase in sediment-related water quality parameters as well as in macroinvertebrates that have been associated with high sediment conditions in other studies (gatherer-collectors, Chironomids, Oligochaetes, Dipterans, and Turbellarians), suggesting that increased stream sediment levels are likely to be a primary stressor in non-reference streams. It is worth noting, however, that reference streams with high sediment levels continued to support macroinvertebrate assemblages that were very dissimilar to non-reference streams, even those with very similar size and streamflow, possibly suggesting that natural and anthropogenic sources of sediment production may cause different responses in macroinvertebrate community compositions. For example, Ora Creek had adjacent past burn and landslide activity, as well as the highest turbidity and embeddedness of the reference creeks, and the lowest flows of reference and non-reference creeks. Ora Creek also showed the closest association with increasing percentage of silt/clay on the envfit overlay. Nevertheless, macroinvertebrate assemblages in Ora Creek were more similar to other reference streams than to nonreference streams in the NMDS ordination plot, possibly suggesting that adjacent disturbance in this reference stream may have impacted stream biota differently compared to anthropogenic disturbances in non-reference streams.

Greater annual precipitation in reference sites was associated with macroinvertebrate assemblage distributional patterns, suggesting that climate as well as natural and spatial variability between reference and non-reference sites may have been influential. The three non-reference sites are spatially clustered together, and are approximately 26 kilometers away from the three reference sites which are also spatially 
clustered together (i.e., located adjacent to each other). While both reference and nonreference sites are in the Clackamas Basin, have similar and resistant geologies, and are at very similar elevations, they are nevertheless spatially separate groupings of subwatersheds which may exhibit natural variation in climactic patterns and other environmental conditions such as instream fine sediment levels. Also, precipitation events may have influenced turbidity, TDS, and conductivity in streams. However, with the exception of a large precipitation event prior to fall sampling in Dog Creek, other precipitation accumulation prior to sampling appeared relatively comparable between non-reference and reference creeks. In addition, possible macroinvertebrates responses to logging may be obscured by natural environmental gradients, particularly at large spatial scales (Herlihy 2005, Sponseller et al. 2001). While this study examined a relatively small spatial scale, Sponseller et al. (2001) found significant differences in macroinvertebrate assemblages at the reach scale that were not evident at larger scales such as the catchment scale.

The pattern of more similarity among macroinvertebrate assemblages in nonreference streams shown on the NMDS ordination plot may be related to the land use impacts in those watersheds. Literature suggests that homogenization of ecology and biota may occur in response to anthropogenic stressors (Zhang et al. 2009). Water quality parameters and environmental conditions in non-reference streams showed more variability than in reference streams, possibly in response to anthropogenic disturbances. While this study did not measure canopy structure or species composition, qualitative observations suggest that these parameters were more complex and diverse at reference 
sites, including more herbaceous shrubs and plant and tree species diversity, which may be partly responsible for the dissimilarity among macroinvertebrate assemblages in reference sites. Homogenization of instream habitats due to past land use may also be occurring in non-reference sites. For example, the Fish Creek Watershed Analysis (USFS 1994) states that by 1985 , pools formed from large woody debris were at $11 \%$ of their historic levels. Restoration efforts have concentrated on restoring large wood debris and pool habitats, with these habitat features restored to approximately $25 \%$ of historic levels at the time of the analysis. Recruitment for future large woody debris in riparian areas was considered to be low, and at approximately half of historic levels (USFS 1994). It is not clear what current levels are for large woody debris and pool habitats.

\section{Recent Logging: NMDS Ordination and Correlations with Stream Sediment}

\section{Measures}

The presence of recent logging within five years did not show any clear associations with macroinvertebrate assemblage distributional patterns, suggesting that if recent logging influenced stream biota, this influence was largely overshadowed by past logging, roads, and other environmental conditions. Indications of increased fine sediments have been found in relation to selective logging in certain sites in other studies (Kreutzweiser et al. 2005, Miserendino and Masi 2010). In this study, limited evidence exists to suggest that recent logging may be influencing water quality. In Canine and Dog non-reference creeks, the upstream sites grouped together, as did downstream sites on the NMDS ordination. Also, the percent of forest logged in the last five years in nonreference catchments showed a moderate positive Pearson's correlation coefficient with 
turbidity and embeddedness, as well as a moderate negative correlation with size of streambed particles based on pebble counts, which may suggest a possible association between recent management and water quality impacts. Canine and Dog Creeks (nonreference) contained both high road densities and high percent of recent logging in their watersheds, as well as similar significantly greater turbidity values compared to the reference streams with most similar streamflows, and index scores suggesting the worst water quality. Water quality responses to timber harvest may have complex temporal patterns in these watersheds (Zhang et al. 2009). Possible impacts on streams associated with current logging, if they exist, may manifest in different temporal and spatial scales than were accounted for in this study, and would likely require long-term study and more in-depth stream sampling to detect. Lecerf and Richardson (2010) noted that after logging "the importance of abiotic and biotic changes in stream ecosystems varies nonlinearly with the time elapsed since logging operations".

\section{Water Quality and Macroinvertebrates: Upstream vs. Downstream sites}

Stream temperature was the only parameter for which a significant difference was found in the magnitude of change from upstream to downstream of logging units in reference vs. non-reference stream. Temperature increases may be related to adjacent logging, though temperature data in this study this should be interpreted with caution given that no continual probe equipment was used and temperature readings were only collected during sample sessions. Selective logging has been shown to increase temperature in other studies. Guenther et al. (2012) found increases in stream temperature in relation to selective logging, and Johnson and Jones (2000) found increases in relation 
to patch cutting. Guenther et al. (2012) found increases in bed temperatures and in stream daily maximum temperatures in relation to $50 \%$ removal of basal area in both upland and riparian areas. Increases in daily maximum temperatures varied within the harvest area from 1.6 to 3 degrees Celsius. Effects on stream temperature can vary depending on the degree of logging within riparian buffers in both selective logging and in clearcuts. Kiffney et al. (2003), when investigating varying buffer widths adjacent to clearcuts, found that stream temperatures increased along a gradient of decreasing stream buffers compared to controls, with a $3{ }^{\circ} \mathrm{C}$ increase in the 10 meter treatment and a $1.6^{\circ} \mathrm{C}$ increase in the 30 meter treatment. Decreasing buffer widths in their study corresponded to increasing water mean temperatures in winter, spring, and summer, and maximum temperatures in spring and summer. Increases in temperatures and alteration of temperature regimes can directly affect macroinvertebrates, especially those that need cold water for survival, as well as indirectly affect them through increased algal growth and contributions to shifts towards autochthonous primary production. Other studies, such as Lecerf and Richardson (2010), did not find any change in stream temperatures in relation to selective logging.

Existing stream temperature data from the USFS for the Fish Creek watershed creates a relevant context for viewing stream temperature data in non-reference sites in this study. Multiple streams in the Fish Creek watershed have not meet water temperature standards for core cold water habitat (USFS 1994, ODEQ accessed 2015) or for designated spawning and rearing use (USFS accessed 2011) since at least 1999. In addition, Fish Creek had higher average daily summer temperatures than any other 
stream surveyed within the Clackamas River subbasin, including temperatures repeatedly reaching 75 degrees Fahrenheit (23.9 degrees Celsius), and the greatest diurnal temperature fluctuations (USFS 1994). Seven day maximum temperatures continue to exceed temperature standards in the most recent monitoring data available. For example, 2010 is the most recent year in which data is available (USFS accessed 2011), and temperatures at the mouth of Fish Creek continue to exceed core cold water standards by at least 3.5 degrees Celsius. Considering these observations of temperature data from the USFS, stream temperature may be important to monitor in relation to selective logging projects, particularly those that include logging within riparian buffers and in areas that are already water quality limited or drain into water quality limited streams. The small but significant increase in temperature found from upstream to downstream in nonreference sites in this study should be interpreted with extreme caution because temperature data were not continuous, and because the increase could be an artifact of sampling time of day combined with small sample size. However, given the widespread and continued exceedances of water temperature standards in the area, combined with increases in temperature associated with selective logging in other studies possible increases in temperature in relation to selective logging in the Clackamas at least merit further investigation.

Contrary to my original hypotheses, no other significant difference in water quality parameters or macroinvertebrate indices were detected in the magnitude of change from upstream to downstream of logging units in reference vs. non-reference sites. Several possible explanations exist for why impacts were not detected from 
upstream to downstream of recent selective harvest units: 1) Riparian buffers as well as remaining trees left on the landscape in upland areas may have been sufficient to protect water quality. 2) The "upstream" sites selected in this study failed to provide adequate control points due to past and current land use activities that took place upstream of both "upstream" and "downstream" study reaches. Land use activities and parameters which may have impacted water quality above my upstream study reaches included the building and use of temporary roads, high road densities, log haul, quarries, and (in one case) current logging. Noise from these activities may have confounded or obscured impacts on water quality due to the selective logging units. This study may have been unable to detect impacts related to present logging due to difficulties in separating past logging and chronic road impacts from current logging, especially since extensive current and past impacts exist throughout the all non-reference watersheds. 3) Natural variability obscured/confounded potential impacts on water quality. 4) Temporal responses to logging, as discussed earlier in the discussion section, may complicate detection of potential impacts. 5) The methodologies used in this study may have been insufficient to detect changes in water quality from upstream to downstream. A larger sample size, in a more spatially diverse set of subwatersheds, and with a gradient of logging intensity, may have detected impacts.

\section{Conclusion}

The complex dynamics in stream ecosystems suggest that perhaps a more precautionary approach to forest management may be necessary to protect listed and atrisk species. For example, the recent study by Steele et al. (2014) found that subtle 
dynamics which may not have initially been recognized as harmful, such as diurnal fluctuations in stream temperature- even stream temperatures that do not exceed 7-day average maximum standards- may have negative impacts on salmonid survival (Steele et al. 2014). In order to implement adaptive management, adhere to water quality standards, and protect aquatic resources, it is important to determine what effects selective logging in upland and riparian areas might have on stream temperature in particular and water quality in general, and whether or not selective logging is achieving the desired outcomes. However, a lack of sufficient data upon which to base land management decisions and adaptive management strategies continues to be problematic. Monitoring for in the Fish Creek watershed, for example, has not been implemented as extensively as outlined in restoration plans, despite a long history of past impacts and a recognized paucity of data. This study provides evidence that roads and past logging are influencing water quality and macroinvertebrate assemblages and metrics. Recent logging was correlated with sediment-related water quality parameters, and stream temperature may have increased in relation to selective harvest units. These findings suggest that further monitoring and research to determine possible effects of selective logging on water quality and stream health should be prioritized, especially in watersheds with sensitive and unique aquatic and riparian species. 


\section{References}

Adams, J. and Vaughan, M. (2007). Stream Bugs as Biomotiors: A Guide to Pacific Northwest Macroinvertebrate Monitoring. The Xerces Society.

Allan, J. (2004). Landscapes and riverscapes: the influence of land use on stream ecosystems. Annual Review of Ecology, Evolution, and Systematics, (35): 257-284.

Anderson, C. (2005). United States Geological Survey TWRI Book 9. Retrieved 2014 from <http://water.usgs.gov/owq/FieldManual/Chapter6/Section6.7_v2.1.pdf $>$.

Angradi, T. (1999). Fine sediment and macroinvertebrate assemblages in Appalachian streams: a field experiment with biomonitoring applications. Journal of North American Benthological Society, 18(1):49-66.

Bailey, R., Norris, R., Reynoldson, T. (2001). Taxonomic resolution of benthic macroinvertebrate communities in bioassessments. Journal of the North American Benthological Society, 20(2): 280-286.

Bain, M., and Stevenson, N. (1999). Aquatic habitat assessment: common methods. American Fisheries Society, Bethesda, MD. Retrieved 2014 from $<$ http://imasd.fcien.edu.uy/difusion/educamb/docs/pdfs/aquaticmethods.pdf $>$.

Banks, J., Li, J., Herlihy, A. (2007). Influence of clearcut logging, flow duration, and season on emergent aquatic insects in headwater streams of the Central Oregon Coast Range. Journal of North American Benthological Society, 26(4): 620-632.

Bark (2012). In the forest: timber sale database and list of Clackamas Basin timber sales. Retrieved 2013 from < http://jbatch.geos.odin.pdx.edu/timbersales.html $>$ and $<\mathrm{http}$ ://www.bark-out.org/forest.php>.

Barbour, M., Gerritsen, J., Snyder, B., and Stribling, J. (1999). Rapid bioassessment protocols for use in streams and wadeable rivers: periphyton, benthic macroinvertebrates, and fish. Second edition. EPA-841-B-99-002. U.S. EPA, Office of Water, Washington, DC. Retrieved 2013 from $<\mathrm{http}$ ://water.epa.gov/scitech/monitoring/rsl/bioassessment/index.cfm $>$.

Bauer, S. and Ralph, S. (2001). Strengthening the use of aquatic habitat indicators in clean water act programs. Fisheries, 26(6):14-25.

Bolstad, P. and Swank, W. (2007). Cumulative impacts of landuse on water quality in a southern Appalachian watershed. Journal of American Waters Association, 33(3): 519-533. 
Bryce, S., Lomnicky, G., and Kaufmann, P. (2010), Protecting sediment-sensitive aquatic species in mountain streams through the application of biologically based streambed sediment criteria. Journal of the North American Benthological Society, 29(2):657-672.

Cederholm C., Reid L., Salo E. (1980). Cumulative effects of logging road sediment on salmonid populations in Clearwater River, Jefferson County, Washington. College of Fisheries, University of Seattle, Washington. Retrieved 2014 from $<$ http://www.fs.fed.us/psw/publications/reid/Cederholm.pdf $>$.

Cover, M., May, C., Dietrich, W., Resh, V. (2008). Quantitative linkages among sediment supply, streambed fine sediment, and benthic macroinvertebrates in northern California streams. Journal of the North American Benthological Society, 27(1):135-149.

Croke, J. and Hairsine, P. (2006). Sediment delivery in managed forests: a review. Environmental Review, (14): 59-87.

Daniels, J. (2001). Timber processing capacity in Oregon: why mills still matter. Lecture and Powerpoint at Portland State University. United States Department of Agriculture and the Bureau of Business and Economic Research.

Decker v. Northwest Environmental Defense Center (2013), 568 U.S. Retrieved 2015 from <http://www.supremecourt.gov/opinions/12pdf/11-338_kifl.pdf>.

Dyrness, C., (1967). Mass soil movements in the H.J. Andrews experimental forest. Retrieved 2014 from < http://hdl.handle.net/2027/umn.31951d02995036k>.

Edwards, T., and Glysson, G. (1999). Techniques for water resource investigations of the United States Geological Society, Book 3 Applications of Hydraulics, Chapter C2: Field methods for measurements of fluvial sediment. United States Geological Society. Retrieved 2014 from <http://pubs.usgs.gov/twri/twri3-c2/pdf/twri_3C2_c.pdf $>$.

Ellison, C., Kiesling, R., and Fallon, J. (2010). Correlating streamflow, turbidity, and suspended-sediment concentration in Minnesota's Wild Rice River. United States Geological Survey, Second Joint Federal Interagency Conference, Las Vegas, NV. Retrieved 2014 from $<\mathrm{http}$ //acwi.gov/sos/pubs/2ndJFIC/Contents/8B_Ellison_12_03_09_paper.pdf $>$.

Flaspohler, D., Fisher, C., Huckins, C., Bub, B., and Van Dusen, P. (2002). Temporal patterns in qquatic and avian communities following selective logging in the Upper Great Lakes Region. Forest Science, 48(2):339-349. 
Galloway, J., Evans, D., and Green, R. (2005). Comparability of suspended-sediment concentrations and total suspended-solids data for two sites on the L'Anguille River, Arkansas, 2001 to 2003. Scientific Investigations Report 2005-5193. United States Geological Survey. Retrieved 2014 from $<$ http://pubs.usgs.gov/sir/2005/5193/SIR2005-5193.pdf >.

Gravelle, J., Link, T., Broglio, J., and Braatne, J. (2009). Effects of timber harvest on aquatic macroinvertebrate community composition in a northern Idaho watershed. Society of American Foresters, 55(4): 352-366.

Gray, J., Glysson, G., Turcios, L., and Schwarz, G. (2000), Comparability of total suspended solids and suspended-sediment concentration data: U.S. Geological Survey Water-Resources Investigations Report 00-4191, 14. Retrieved 2014 from $<$ http://water.usgs.gov/osw/pubs/WRIR00-4191.pdf $>$.

Gray, J., Laronne, J., and Marr, J. (2010). Bedload-surrogate monitoring technologies. United States Geological Survey (USGS). Reston, Virginia. Retrieved 2012 from $<$ http://pubs.usgs.gov/sir/2010/5091/pdf/sir2010-5091.pdf $>$.

Guenther, S., Gomi, T., and Moore, R. (2012). Stream and bed temperature variability in a coastal headwater catchment: influences of surface-subsurface interactions and partial-retention forest harvesting. Hydrological Processes, 28: 1238-1249.

Guthrie, R. (2001). The effects of logging on frequency and distribution of landslides in three watersheds on Vancouver Island, British Columbia. Geomorphology 43(3-4): 273-292.

Guy, H. (1969). Techniques of water resources investigations for the United States Geological Survey: Chapter C1: Laboratory theory and methods for sediment analysis. United States Geological Survey. Retrieved 2014 from $<$ http://pubs.usgs.gov/twri/twri5c1/pdf/twri_5-C1_a.pdf $>$.

Hach Co. (1999). Portable Turbidimeter Model 2100P Instrument and Procedure Manual. Catalog number 46500-88.

Haggarty, S., Batzer, D., and Jackson, C. (2003). Macroinvertebrate response to logging in coastal headwater streams in Washington, USA. Canadian Journal of Fisheries and Aquatic Sciences, 61(4): 529-537.

Harr, D. and Coffin, B. (1992). Influence of timber harvest on rain-on-snow runoff: a mechanism for cumulative watershed effects. Interdisciplinary approaches in hydrology and hydrogeology. American Institute of Hydrology: 455-469. 
Henley, W., Patterson, M., Neves, R., and Lemly, D. (2000). Effects of sedimentation and turbidity on lotic food webs: a concise review for natural resource managers. Reviews in Fisheries Science, 8(2): 125-139.

Herlihy, A., Gerth, W., Li, J., and Banks, J. (2005). Macroinvertebrate community response to natural and forest harvest gradients in western Oregon headwater streams. Freshwater Biology, (50): 905-919.

Hewlett, R. (2000). Implications of taxonomic resolution and sample habitat for stream classification at a broad geographic scale. Journal of North American Benthological Society, 19(2): 352-361.

Hicks, B., Beschta, R., and Harr, D. (1991). Long-term changes in streamflow following logging in western Oregon and associated fisheries implications. Water Resources Bulletin, (27):2.

Hilsenhoff, W. (1988). Rapid field assessment of organic pollution with a family-level biotic index. Journal of the North American Benthological Society, (7): 65-68.

Hlass, L., Fisher, W., and Turton, D. (1998). Use of the index of Biotic Integrity to assess water quality in forested streams of the Ouachita Mountains ecoregion, Arkansas. Journal of Freshwater Ecology, 13(2): 181-192.

Idaho Department of Environmental Quality (IDEQ). (2003). Guide for selection of sediment targets for use in Idaho TMDLs. Retrieved from $<$ http://www.deq.state.id.us/WATER/ data_reports/surface water/monitoring/sediment_targets_guide.pdf $>$.

Jones, J. (2000). Hydrologic processes and peak discharge response to forest removal, regrowth, and roads in 10 small experimental basins, western Cascades, Oregon. Water Resources Research, 36(9): 2621-2642.

Jones, J. and Grant, G. (1996). Peak flow responses to clear-cutting and roads in small and large basins, western Cascades, Oregon. Water Resources Research, 32(4): 959974.

Johnson, S., and Jones, J. (2000). Stream temperature responses to forest harvest and debris flows in western Cascades, Oregon. Canadian Journal of Fisheries and Aquatic Sciences, 57(2): 30-39.

Johnson, L., Richards, C., Host, G., and Arthur, J. (2003). Landscape influences on water chemistry in Midwestern stream ecosystems. Freshwater Biology, 37 (1): 193208. 
Kiffney, P., Richardson, J., and Bull, J. (2003). Responses of periphyton and insects to experimental manipulation of riparian buffer width along forest streams. Journal of Applied Ecology, (40) 1060-1076.

Klemm, D., Lewis, P., Fulk, F., and Lazorchak, J. (1990). Macroinvertebrate field and laboratory methods for evaluating the biological integrity of surface waters. USEPA. Retrieved 2012 from $<$ http://www.epa.gov/bioiweb1/pdf/EPA600490030MacroinvertebrateFieldandLabor atoryMethodsforEvalutingtheBiologicalIntegrityofSurfaceWaters.pdf $>$.

Kreutzweiser, D., Capell, S., and Good, K. (2005). Macroinvertebrate community responses to selection logging in riparian and upland areas of headwater catchments in a northern hardwood forest. Journal of the North American Benthological Society, 24(1):208-222.

Kreutzweiser, D. and Capell, S. (2001). Fine sediment deposition in streams after selective forest harvesting without riparian buffers. Canadian Journal of Forest Research, v. 31 p. 2134-2142.

Lazorchak, J., Klemm, D., and Peck, D. (1998). Environmental monitoring and assessment program - surface waters: field operations and methods for measuring the ecological condition of wadeable streams. US Environmental Protection Agency. Retrieved 2012 from <http://www.epa.gov/bioiweb1/pdf/EPA-620-R-94004FFieldOperationsandMethodsforMeasuringtheEcologicalConditionofWadeableStr eams.pdf $>$.

Lecerf, A. and Richardson, J. (2010). Litter decomposition can detect effects of high and moderate levels of forest disturbance on stream condition. Forest Ecology and Management, 259 (2010) 2433-2443.

Lenat, D. and Resh, V. (2001). The benefits of genus- and species-level identifications. Journal of the North American Benthological Society, (20): 2, 287-298.

Lewis, J., Mori, S., Keppeler, E., and Ziemer, R. (2001). Impacts of logging on storm peak flows, flow volumes and suspended sediment loads in Casper Creek, California. Land use and watersheds: human influence on hydrology and geomorphology in urban and forest areas. American Geophysical Union: 85-126.

Lewis, J. (2003). Turbidity controlled sampling for suspended sediment load estimation. United States Department of Agriculture, Forest Service, Pacific Southwest Research Station, Ca, USA. Retrieved 2013 from $<$ http://www.fs.fed.us/psw/publications/4351/Lewis2003b.pdf $>$. 
Lewis, J. and Eads, R. (2009). Implementation guide for turbidity threshold sampling: principles, procedures, and analysis. USFS Pacific Southwest Research Station, General Technical Report PSW-GTR-212. Retrieved 2013 from $<$ http://www.fs.fed.us.proxy.lib.pdx.edu/psw/publications/4351/Lewis2009.pdf $>$.

Mandeville, S. (2002). Benthic macroinvertebrates in freshwaters- taxa tolerance values, metrics, and protocols. Soil \& Water Conservation Society of Metro Halifax. Retrieved 2014 from < http://lakes.chebucto.org/H-1/tolerance.pdf $>$.

Merritt, R. and Cummins, B. (2008). Introduction to the aquatic insects of North America. Fourth edition, Kendall/Hunt Publishing Co., Dubuque, Iowa.

Miserendino, L. and Masi, C. (2010). The effects of land use on environmental features and functional organization of macroinvertebrate communities in Patagonian low order streams. Ecological Indicators, 10(2): 311-319.

Montgomery, D., Schmidt, K., Greenberg, H., and Dietrich, W. (2000). Forest clearing and regional landsliding. Geological Society of America, (28): 311-314.

Moore, D. and Wondzell, S. (2005), Physical hydrology and the effects of forest harvesting in the Pacific Northwest: A review. Journal of the American Waters Association, 41(4): 763-784.

Nietch, C., Borst, M., and Schubauer-Berigan, J. (2005). Risk management of sediment stress: a framework for sediment risk management research. Environmental Management, (36):175-194.

National Oceanic and Atmospheric Administration (NOAA) 1996. Coastal salmon conservation: working guidance for comprehensive salmon restoration initiatives on the Pacific coast. Retrieved 2014 from

$<$ http://www.krisweb.com/biblio/gen_noaa_nmfs_1996_salmonconservation.pdf $>$.

Northwest Environmental Defense Center vs. Brown (2010). Ninth Circuit Court. Retrieved 2015 from <http://wflc.org/cases/docket/nedcvbrown>.

Olsen, D., Roper, B., Kershner, J., Henderson, R., and Archer, E. (2005). Sources of Variability in conducting pebble counts: their potential influence on the results of stream monitoring programs. Journal of American Water Resources Association, 41(5):1225-1236.

Oregon Department of Fish and Wildlife (ODFW). (2010). Willamette River Fish Recovery. Educational web resource. Retrieved 2014 from $<$ http://www.dfw.state.or.us/fish/CRP/docs/upper_willamette/FAQ.pdf $>$. 
Oregon Department of Water Quality (ODEQ). (2006). Willamette Basin TMDL: Clackamas Subbasin. Retrieved 2015 from $<$ http://www.deq.state.or.us/wq/tmdls/docs/willamettebasin/willamette/chpt6clackam as.pdf $>$.

Oregon Department of Water Quality (ODEQ). (Accessed 2013). Water quality standards- beneficial uses tables and figures. Retrieved 2014 from $<$ http://www.deq.state.or.us/wq/rules/div041tblsfigs.htm $>$.

Oregon Department of Water Quality (ODEQ). (Accessed 2015). Oregon Administrative Rules (OAR) 340-041, Retrieved 2015 from $<$ http://arcweb.sos.state.or.us/pages/rules/oars_300/oar_340/340_041.html>.

Oregon Department of Water Quality (ODEQ). (Accessed 2015). Water quality assessment database. Retrieved 2015 from $<$ http://www.deq.state.or.us/wq/assessment/rpt2010/results.asp $>$.

Packman, J., Comings K., and Booth, D. (2000). Using turbidity to determine total suspended solids in urbanizing streams in the Puget lowlands. The Center for Urban Water Resources Management at the University of Washington, Seattle, Washington.

Pacific Northwest Ecosystem Research Consortium. Accessed (2013). GIS geologic data. Retrieved 2012 from <http://oregonstate.edu/dept/pnw-erc/>.

Piccolo, J., and Wipfli, M. (2002). Does red alder (Alnus rubra) in upland riparian forests elevate macroinvertebrate and detritus export from headwater streams to downstream habitats in southeastern Alaska? Canadian Journal of Fisheries and Aquatic Sciences, (59): 2002.

Pollock, M., Beechie, T., and Imake, H. (2012). Using reference conditions in ecosystem restoration: an example for riparian conifer forests in the Pacific Northwest. ESA journal, 3(11): 98.

Pollock, M. and Beechie, T. (2014). Does riparian forest thinning enhance forest biodiversity? The ecological importance of downed wood. Journal of American Waters Resource Association (JAWRA), 50(3): 543-559.

Progar, R. and Moldenke, A. (2009). Aquatic insect emergence from headwater streams flowing through regeneration and mature forests in Western Oregon, Journal of Freshwater Ecology, (24):1, 53-66. 
Rasmussen, P., Gray, J., Glyyson, D., and Ziegler, A., (2011). Guidelines and procedures for computing time-series suspended-sediment concentrations and loads from instream turbidity-sensor and streamflow data. U.S. Geological Survey Techniques and Methods, book 3, chap. C4. Retrieved 2012 from $<$ http://pubs.usgs.gov/tm/tm3c4/pdf/TM3C4.pdf $>$.

Reid, D., Quinn, J., and Wright-Stow, A. (2010). Responses of stream macroinvertebrate communities to progressive forest harvesting: Influences of harvest intensity, stream size and riparian buffers. Forest Ecology and Management, 260(10): $<1804-1815$.

Relyea, C., Minshall G., and Danehy. R. (2000). Stream insects as bioindicators of fine sediment. Watershed Management 2000 Conference. Water Environment Federation, Alexandria, VA. Retrieved 2014 from $<$ https://www.deq.idaho.gov/media/525820Stream_Insects_Bioindicators_Fine_Sediment_Relyea_2000.pdf $>$.

Relyea, C., Minshall G., and Danehy, R. (2012). Development and validation of a fine sediment biotic index. Environmental Management, (49):242-252

Richardson, J. and Danehy, R. (2005). A synthesis of the ecology of headwater streams and their riparian zones in temperate forests. Forest Science, 53(2) 2007.

Salminen, E. (2005). Clackamas Basin Watershed summary overview. Watershed Professionals Network, prepared for Clackamas River Basin Council, Clackamas, Oregon.

Scott, M., Helfman, M., McTammany, M., Benfield, F., and Bolstad, P. (2007). Multiscale influences on physical and chemical stream conditions across blue ridge landscapes. Journal of American Water Resources Association. 38(5): 1379-1392.

Sigma-Adrich Supply Co. 2012. Whatman glass microfiber filters, binder free, grade GF/C 24 mm. Retrieved 2012 from $<$ http://www.sigmaaldrich.com/catalog/product/aldrich/Z242330?lang=en\&region=U $\mathrm{S}>$.

Smith, B., Davies, P., and Munks, S. (2009). Changes in macroinvertebrate communities in upper catchment streams across a gradient of catchment forest operation history. Forest Ecology and Management, (257): 2166-2174.

Sponseller, R., Benfield, E., and Valett, H. (2001). Relationship between land use, spatial scale, and stream macroinvertebrate communities. Freshwater Biology, (46): 1409-1424. 
Stark, J., Boothroyd, I.. Harding, J., Maxted, J., and Scarsbrook, M. (2001). Protocols for sampling macroinvertebrates in wadeable streams. New Zealand Macroinvertebrate Working Group Report No. 1. Prepared for the Ministry for the Environment. Sustainable Management Fund Project (5103): 57.

Steele, A., Beckman, B.; and Oliver, M. (2014). Stream temperature variability: why it matters to salmon. Science findings 163. Portland, OR: US Department of Agriculture, Forest Service, Pacific Northwest Research Station. Science findings (163): 6 .

Stone, M. and Wallace, B. (1998). Long-term recovery of a mountain stream from clearcut logging: the effects of forest succession on benthic invertebrate community structure. Freshwater Biology, (39):151-169.

Swanson, F. and Swanston, D. (1977). Complex mass movement terrains in the western Cascades Range, Oregon. Geological Society of America, (3).

Tague, C. and Grant, G. (2004). A geological framework for interpreting the low-flow regimes of Cascade streams, Willamette River Basin, Oregon. Water Resources Research, (40): W04303.

Taylor, B. (1999). Salmon and steelhead runs and related events of the Clackamas River Basin - a historical percpective. Prepared for Portland General Electric. Retrieved 2013 from $<$ https://www.portlandgeneral.com/community_environment/initiatives/protecting_fis h/clackamas_river/docs/clackamas_river_history_full.pdf $>$.

Troendle, C. and Olsen, W. (1993). Potential Effects of Timber Harvest and Water Management on Streamflow Dynamics and Sediment Transport. In: Sustainable Ecological Systems Proceedings. USDA Forest Service, Rocky Mountain Forest and Range Experiment Station GTR RM-247, Fort Collins, Colorado, pp. 34-41.

Ulrich, M. (2002). The advantage of continuous turbidity monitoring: a lesson from the North Santiam River Basin, Oregon; 1998-2000. Turbidity and other sediment surrogates workshop, April 30 - May 2, 2002, Reno, Nevada. US Geological Survey. Retrieved 2013 from <http://water.usgs.gov/osw/techniques/TSS/uhrich1.pdf>.

United States Environmental Protection Agency (USEPA). (2002). Using Biological Data as Indicators of Water Quality. Retrieved 2013 from $<$ http://www.epa.gov/owow/monitoring/calm/calm_ch5.pdf $>$. 
United States Environmental Protection Agency (USEPA). (2006). Framework for Developing Suspended and Bedded Sediments (SABS) Water Quality Criteria. Retrieved 2013 from $<$ http://cfpub.epa.gov/ncea/cfm/recordisplay.cfm?deid=164423\#Download $>$.

United States Environmental Protection Agency (USEPA). (2007). The wadeable streams assessment: a collaborative survey of the nation's streams. Fact sheet. Retrieved 2012 from $<\mathrm{http}: / /$ water.epa.gov/type/rsl/monitoring/upload/2007_10_25_monitoring_wsa_facts heet_10_25_06.pdf $>$.

United States Forest Service (USFS). (1979). Soil Resource Inventory, Mt. Hood National Forest. United States Department of Agriculture. Retrieved 2013 from $<$ http://www.fs.fed.us/r6/data-library/gis/mthood/>.

United States Forest Service (USFS). (1993). Clackamas National Wild and Scenic River and State Scenic Byway, Environmental Assessment and Management Plan. United States Department of Agriculture, Pacific Northwest Region. Retrieved 2014 from $<$ http://www.fs.usda.gov/Internet/FSE_DOCUMENTS/fsbdev3_036590.pdf>.

United States Forest Service (USFS). (1994). Fish Creek Watershed Analysis. United States Department of Agriculture. Retrieved 2014 from $<$ http://www.fs.usda.gov/Internet/FSE_DOCUMENTS/fsbdev3_036587.pdf > .

United States Forest Service (USFS) (2004). Forests of western Oregon, an overview. United States Department of Agriculture. Retrieved 2013 from $<$ http://www.fs.fed.us/pnw/publications/gtr525/gtr525a.pdf $>$.

United States Forest Service (USFS). (2006). 2007 Plantation Thin Biological Assessment. United States Department of Agriculture. Retrieved 2014 from $<$ http://www.bark-out.org/sites/default/files/barkdocs/2007_Thin_Final_Fish_BA.htm>.

United States Forest Service (USFS). (2006). Preliminary Assessment 2007 Plantation Thinning. United States Department of Agriculture. Retrieved 2014 from $<$ http://www.bark-out.org/sites/default/files/barkdocs/2007_preliminary_assessment.pdf

United States Forest Service (USFS). (2010). Mt. Hood National Forest annual monitoring report. United States Department of Agriculture. Retrieved 2013 from $<$ http://www.fs.usda.gov/main/mthood/landmanagement/planning $>$ 
United States Forest Service (USFS). (Accessed 2011). Unpublished GIS data for timber sales and roads, obtained by FOIA request.

United States Forest Service (USFS). (2012). National Best Management Practices for water quality management on national forest system lands. United States Department of Agriculture. Retrieved 2012 from

$<$ http://www.fs.fed.us/biology/resources/pubs/watershed/FS_National_Core_BMPs_ April2012.pdf $>$.

United States Forest Service (USFS). (2012). Forest Service schedule of proposed actions for Mt. Hood National Forest. United States Department of Agriculture. Retrieved 2012 from <http://www.fs.fed.us/sopa/forest-level.php?110606>.

United States Forest Service (USFS). (Accessed 2012). Mt. Hood National Forest data library, Geographic Information Services. Retrieved 2013 from $<$ http://www.fs.fed.us/r6/data-library/gis/mthood/index.shtml $>$.

US Fish and Wildlife Service. (2013). Bull trout reintroduction project. $<$ http://www.fws.gov/oregonfwo/Species/Data/BullTrout/ReintroductionProject.asp $>$.

United States Geological Survey (USGS). (1998). USGS WRD sediment laboratory chiefs workshop. Retrieved 2012 from $<$ http://water.usgs.gov/osw/techniques/USGSsedlab98.html>.

United States Geological Survey (USGS). (2000). Office of water quality technical memorandum no. 2001.03. Retrieved 2013 from $<\mathrm{http} / / /$ water.usgs.gov/admin/memo/SW/TSS.0103.html $>$.

United States Geological Survey (USGS). (Accessed 2012). Geologic units in Clackamas County. Retrieved 2012 from $<\mathrm{http}: / /$ mrdata.usgs.gov/geology/state/fipsunit.php? $\operatorname{code}=\mathrm{f} 41005>$.

United States Geological Survey (USGS). (Accessed 2012). Surface water information. Retrieved 2012 from $<$ http://water.usgs.gov/osw/data.html $>$.

United States Geological Survey (USGS). (Accessed 2013). Streamstats. Retrieved 2013 from $<$ http://streamstatsags.cr.usgs.gov/or_ss/default.aspx?stabbr=or\&dt=1365800898467 $>$.

Waters, T. (1995). Sediment in streams: sources, biological effects and control. American Fisheries Society, Bethesda, Maryland. 
Webster, J., Golladay, S., Benfield, E., Meyer, J., Swank, W., and Wallace, J. (1992). Catchment disturbance and stream response: an overview of stream research at Coweeta Hydrologic Laboratory. River Conservation and Management.

Wemple, B., Jones, J., and Grant, G. (1996). Channel network extension by logging roads in two basins, western Cascades, Oregon. Water Resources Bulletin, 32(6).

Wemple, B., Swanson, F., and Jones, J. (2000). Forest roads and geomorphic process interactions, Cascade Range, Oregon. Earth Surface Landforms and Processes, (26): 191-204.

Whitman, M., Moran, E., and Ourso, R. (2003). Photographic techniques for characterizing streambed particle sizes. American Fisheries Society, (132): 605-610.

Willacker, J., Sobczak, W., and Colburn, E. (2009). Stream macroinvertebrate communities in paired hemlock and deciduous watersheds. Northeastern naturalist, 16(1):101-112.

Wood, P. and Armitage P. (1997). Biological effects of fine sediment in the lotic environment. Environmental Management, 21(2): 203-217.

Zhang, Y., Richardson, J., and Pinto, X. (2009). Catchment-scale effects of forestry practices on benthic invertebrate communities in Pacific coastal streams. Journal of Applied Ecology, (46): 1292-1303.

Zweig, L. and Rabeni, C. (2001). Biomonitoring for deposited sediment using macroinverterbrate benthic invertebrates: a test on four Missouri streams. Journal of North American Benthological Society, (20)4:643-657. 